EDSON KIYOTAKA ISHIZUKA

MODULAÇÃO DA FUNÇÃO DE MACRÓFAGOS PELA NATTECTINA:

UMA LECTINA TIPO C DO VENENO DE Thalassophryne nattereri

Dissertação apresentada ao Programa de Pós-Graduação em Imunologia do Instituto de Ciências Biomédicas da Universidade de São Paulo, para obtenção do Título de Mestre em Ciências

São Paulo

2011 
EDSON KIYOTAKA ISHIZUKA

\title{
MODULAÇÃO DA FUNÇÃO DE MACRÓFAGOS PELA NATTECTINA: UMA LECTINA TIPO C DO VENENO DE Thalassophryne nattereri
}

Dissertação apresentada ao Programa de Pós-Graduação em Imunologia do Instituto de Ciências Biomédicas da Universidade de São Paulo, para obtenção do Título de Mestre em Ciências

Área de concentração: Imunologia

Orientadora: Dra. Carla Lima da Silva

\author{
Versão Original
}

São Paulo

2011 
DADOS DE CATALOGAÇÃO NA PUBLICAÇÃO (CIP)

Serviço de Biblioteca e Informação Biomédica do Instituto de Ciências Biomédicas da Universidade de São Paulo

reprodução não autorizada pelo autor

Ishizuka, Edson Kiyotaka.

Modulação da função de macrófagos pela Nattectina: uma lectina tipo C do veneno de Thalassophryne nattereri / Edson Kiyotaka Ishizuka. -São Paulo, 2011.

\section{Orientador: Carla Lima da Silva.}

Dissertação (Mestrado) - Universidade de São Paulo. Instituto de Ciências Biomédicas. Departamento de Imunologia. Área de concentração: Imunologia. Linha de pesquisa: Caracterização farmacológica, bioquímica e imunulógica de venenos e toxinas de peixes peçonhentos do Brasil.

Versão do título para o inglês: Modulation of macrophage function by Nattectin: a C-type lectin from Thalassophryne nattereri fish venom.

Descritores: 1. Nattectina 2. Lectina tipo C 3. Macrófagos 4. Thalassophryne nattereri I. Silva, Carla Lima da II. Universidade de São Paulo. Instituto de Ciências Biomédicas. Programa de PósGraduação em Imunologia III. Título. 
UNIVERSIDADE DE SÃO PAULO

INSTITUTO DE CIÊNCIAS BIOMÉDICAS

Candidato(a): $\quad$ Edson Kiyotaka Ishizuka.

Título da Dissertação: $\quad$ Modulação da função de macrófagos pela Nattectina: uma lectina tipo $\mathrm{C}$ do veneno de Thalassophryne nattereri.

Orientador(a): $\quad$ Carla Lima da Silva.

A Comissão Julgadora dos trabalhos de Defesa da Dissertação de Mestrado, em sessão pública realizada a I...
( ) Aprovado(a)
( ) Reprovado(a)

Examinador(a): Assinatura:

Nome:

Instituição:

Examinador(a): Assinatura:

Nome:

Instituição:

Presidente: Assinatura:

Nome:

Instituição: 


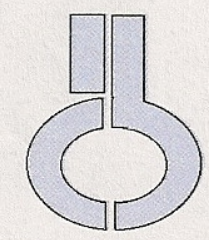

\section{UNIVERSIDADE DE SÃO PAULO INSTITUTO DE CIÊNCIAS BIOMÉDICAS}

Cidade Universitária "Armando de Salles Oliveira"

Av. Prof. Lineu Prestes, 2415 - CEP. 05508-000 São Paulo, SP - Brasil

Telefone :(55) (011) 3091.7733 - e-mail: cep@icb.usp.br

\section{Certificado}

Certificamos que o protocolo registrado sob $n^{\circ} 106$ nas fls. 91 do livro 02 para uso de animais em experimentação, sob a responsabilidade do Prof(a) $\operatorname{Dr}(a)$ Carla Lima, Coordenador(a) da Linha de pesquisa Modulação da função de macrófagos pela Nattectina: importância da sinalização via integrina do qual participam o(s) alunos Edson Kiyotaka Ishizuka e a pesquisadora Mônica Lopes Ferreira, está de acordo com os Princípios Éticos de Experimentação Animal adotado pela Sociedade Brasileira de Ciência de Animais de Laboratório (SBCAL) e foi aprovado pela COMISSÃO DE ÉTICA NO USO DE ANIMAIS (CEUA) em 06.10.2010, com validade de 3 anos.

São Paulo, 06 de outubro de 2010.

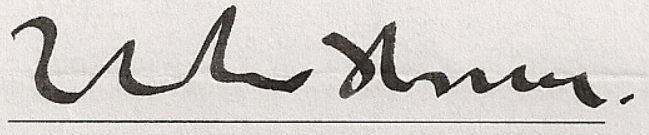

Prof.Dr.Wothan TAVARES DE LiMA

Coordenador CEUA - ICB/USP

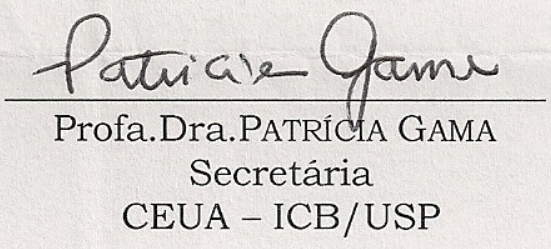




\section{CERTIFICADO}

Certificamos que o Projeto intitulado "Modulação da função de macrófagos pela galectina Nattectina: importância da sinalização via integrina" protocolo $\mathrm{n}^{\circ}$ 634/09, sob a responsabilidade de Dra. Carla Lima da Silva e Edson Kiyotaka Ishizuka, está de acordo com os Princípios Éticos na Experimentação Animal adotado pelo Colégio Brasileiro de Experimentação Animal (COBEA), e foi aprovado pela COMISSÃO DE ÉTICA NO USO DE ANIMAIS DO INSTITUTO BUTANTAN (CEUAIB) em reunião de 17/06/2009.

We certify that the research entitled "Modulation of macrophage functions induced by a galectin Nattectin: the importance of integrins signaling", protocol $n^{\circ} 634 / 09$, under the responsibility of Dra. Carla Lima da Silva and Edson Kiyotaka Ishizuka, is in agreement with the Ethical Principles in Animal Research, adopted by the Brazilian College of Animal Experimentation, and was approved by the ETHICAL COMMITTEE FOR ANIMAL RESEARCH of BUTANTAN INSTITUTE in the meeting of $\underline{06 / 17 / 2009}$

\begin{tabular}{|c|c|}
\hline $\begin{array}{c}\text { Vigência do Projeto: } \\
08 / 2009-09 / 2011\end{array}$ & $\mathbf{N}^{\circ}$ de animais/espécie \\
\hline $\begin{array}{c}\text { Laboratório Especial de } \\
\text { Toxinologia Aplicada }\end{array}$ & $92 /$ camundongo BALB/c Macho \\
\hline
\end{tabular}

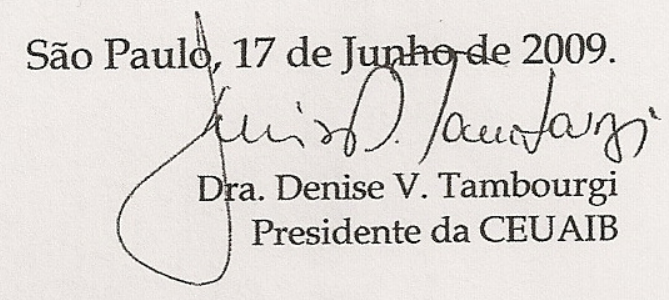

De acordo:

Dr. Otávio Azevedo Mercadante

Diretor do Instituto Butantan 
Aos meus pais e familiares pelo apoio constante e a Dra. Carla Lima e Dra. Mônica Lopes-Ferreira pela confiança e por terem acreditado no meu potencial 


\section{AGRADECIMENTOS}

A minha orientadora Dra. Carla Lima a quem tenho muito a agradecer pela força, confiança e dedicação com que se empenhou em me orientar e não mediu esforços para que eu pudesse alcançar os meus objetivos. Foi um prazer tê-la como a minha orientadora e serei eternamente grato por ter me orientado e pelos conhecimentos adquiridos.

A minha co-orientadora Dra. Mônica Lopes-Ferreira a quem também tenho muito a agradecer por ter prontamente me aceitado receber em seu laboratório de braços abertos, pelos momentos de alegria e descontração e pelas dicas valiosas transmitidas tanto no aspecto profissional como pessoal. Igualmente serei eternamente grato pelo apoio, incentivo e pela agradável convivência.

Aos meus pais Kiyokazu Ishizuka e Michiko Ishizuka, que sempre me apoiaram e me incentivaram mesmo nos momentos mais difíceis.

Ao meu irmão Elcio e a minha cunhada Aline, que nos momentos de aperto sempre se dispuseram a me ajudar. Obrigado pelo apoio, incentivo e pelas caronas.

A minha irmã Eliana pelo apoio e pelos momentos de alegria nas poucas vezes em que nos encontrávamos.

A toda minha família, em especial aos meus primos, pelas inúmeras festas organizadas e momentos de descontração.

A Fernanda Bruni, a quem acompanhei tão logo comecei a frequentar o laboratório. Obrigado pelo incentivo, conselhos e os momentos de alegria.

A Lidiane Grund e Evilin Komegae pela ajuda nos experimentos de cultura celular e análise dos resultados no FACS e pelas inúmeras dicas durante a elaboração dos relatórios.

A Fernanda Magalhães, pela amizade, pelas dicas e pela disposição em me ajudar. 
A Kátia Conceição, Anderson Ramos e Alessandra Cardoso, que me ajudaram no HPLC para a obtenção do meu objeto de estudo, a Nattectina.

Ao Márcio Ferreira, que me acompanhou nos experimentos in vivo e pela companhia nos congressos.

A Érica Coutinho, pela companhia na hora do almoço.

Ao Dr. Pedro Ismael e ao Dr. Robson Lopes pela utilização do HPLC e do liofilizador.

A todos do Laboratório Especial de Toxinologia Aplicada.

A Fundação de Amparo a Pesquisa do Estado de São Paulo (FAPESP) pelo auxílio financeiro.

Enfim, agradeço a todos que de alguma forma participaram na execução deste trabalho. 
"Há homens que lutam um dia e são bons. Há outros que lutam um ano e são melhores. Há os que lutam muitos anos e são muito bons. Porém, há os que lutam toda a vida. Esses são os imprescindiveis."

(Bertold Brecht) 


\section{RESUMO}

ISHIZUKA, E. K. Modulação da função de macrófagos pela Nattectina: uma lectina tipo $\mathrm{C}$ do veneno de Thalassophryne nattereri. 2011. 78 f. Dissertação (Mestrado em Imunologia) - Instituto de Ciências Biomédicas, Universidade de São Paulo, São Paulo, 2011.

A Nattectina é uma toxina isolada do veneno de Thalassophryne nattereri com massa molecular de $15 \mathrm{kDa}$ que possui homologia com lectinas do tipo $\mathrm{C}$. O objetivo deste trabalho foi avaliar a capacidade da Nattectina de ativar as funções de macrófagos e a influência de citocinas Th1/Th2 na ativação polarizada de macrófagos induzida por essa toxina. Nossos resultados mostram que a Nattectina foi capaz de induzir a ativação de macrófagos $\mathrm{F} 4 / 80^{\mathrm{pos}} \mathrm{CD} 11 \mathrm{~b}^{\mathrm{pos}} \mathrm{CD} 14^{\mathrm{pos}}$ Ly6C ${ }^{\text {low }}$ derivados da medula óssea mediante o aumento na expressão de moléculas co-estimuladoras (CD40, CD80, CD86) e MHC de classe II, na expressão de integrinas e da capacidade endocítica. Verificou-se uma dependência positiva da ligação da Nattectina a estruturas glicosiladas expressas nos macrófagos para a indução da expressão de MHC de classe II, da integrina CD49a e para o aumento da capacidade endocítica. A expressão de moléculas co-estimuladoras nos macrófagos foi dependente das vias de sinalização MAPK p38, e principalmente PI3K, enquanto a capacidade endocítica e a produção de MMP-9 foi positivamente regulada pela via ERK1/2. Verificamos ainda que alterações fenotípicas em macrófagos peritoneais e derivados da medula óssea induzida pela Nattectina em camundongos C57BL/6 são consistentes com a ativação clássica M1 dependente das citocinas IL-12 e IFN- $\gamma$, e regulada negativamente por IL-4, IL-10 e IL-13. Por fim, demonstramos uma ação coadjuvante da citocina IL-4 com IFN- $\gamma$ na mobilização de SPMs (Small Peritoneal Macrophages) na cavidade peritoneal e na ativação (expressão de MHC de classe II e CCR7) de macrófagos derivados de medula óssea. Dessa forma, a Nattectina pode ser considerada um importante agente imunomodulador, capaz de modular as funções de macrófagos, útil no desenvolvimento de vacinas e com aplicações terapêuticas.

Palavras-chave: Nattectina. Lectina tipo C. Macrófagos. Thalassophryne nattereri. 


\begin{abstract}
ISHIZUKA, E. K. Modulation of macrophage function by Nattectin: a C-type lectin from Thalassophryne nattereri fish venom. 2011. 78 p. Masters thesis (Immunology) - Instituto de Ciências Biomédicas, Universidade de São Paulo, São Paulo, 2011.

Nattectin is a $15 \mathrm{kDa}$ toxin isolated from Thalassophryne nattereri fish venom that has homology with C-type lectin. The aim of this study was to evaluate the Nattectin ability to activate macrophage functions and the influence of Th1/Th2 cytokines in polarized activation of macrophages induced by Nattectin. Our results show that Nattectin was able to induce $\mathrm{F} 4 / 80^{\mathrm{pos}} \mathrm{CD} 11 \mathrm{~b}^{\mathrm{pos}} \mathrm{CD} 14^{\mathrm{pos}}$ Ly6 $\mathrm{C}^{\text {low }}$ macrophage derived from bone marrow activation through CD40, CD80 and CD86 costimulatory molecules and MHC class II upregulation, and also an increase in integrins expression and endocytic capacity. It was found a positive dependence of Nattectin binding to glycosylated structures expressed in macrophages for induction of MHC class II, CD49a integrin expression and an increase in endocytic capacity. The expression of costimulatory molecules in macrophages was dependent the p38 MAPK signaling pathway and primarily PI3K signaling, while endocytic capacity and MMP-9 production was positively regulated through ERK1/2 signaling. We also demonstrated that phenotypic modifications in peritoneal and bone marrow-derived macropahges induced by Nattectin in C57BL/6 mice are consistent with classical (M1) activation of macrophages dependent on IL12 and IFN- $\gamma$ cytokines, and negatively regulated by IL-4, IL-10 and IL-13. Finally, it was demonstrated an adjuvant role of IL-4 with IFN- $\gamma$ in mobilization of SPMs (Small Peritoneal Macrophages) to peritoneal cavity and also in activation (expression of MHC class II and CCR7) of bone marrow-derived macrophages. Thus, Nattectin can be considered an important immunomodulatory agent able to modulate macrophage functions, useful in vaccines development and with therapeutic applications.
\end{abstract}

Key words: Nattectin. C-type lectin. Macrophages. Thalassophryne nattereri. 


\section{LISTA DE ILUSTRAÇÕES}

Figura 1- Modelo para a dicotomia funcional dos subtipos de macrófagos

Figura 2- Obtenção da Nattectina do veneno de $T$. nattereri

Figura 3- Obtenção de macrófagos de medula óssea femoral pelo uso de sobrenadante de células L929 produtoras de M-CSF. 36

Figura 4- Influência da ligação da Nattectina a açúcares na ativação de BMMo. 38

Figura 5- A ligação da Nattectina a açúcares não altera a expressão de CD44 em BMMo.

Figura 6- Nattectina induz a expressão de integrinas e a produção de MMPs pelas BMMo.

Figura 7- Avaliação do papel da ativação de MAPKs na modulação de BMMo induzida pela Nattectina

Figura 8- Avaliação da atividade das MMPs no sobrenadante de BMMo tratados com inibidores de vias de sinalização.

Figura 9- Influência da ligação da Nattectina a açúcares e da sinalização de MAPKs na capacidade endocítica de BMMo.

Figura 10- Neutrofilia induzida pela Nattectina é dependente de IL-4 e IFN- $\gamma$ e o subtipo de macrófagos por IFN- $\gamma$.

Figura 11- A produção de IL-6 induzida pela Nattectina é dependente de IFN$\gamma$.

Figura 12- Modulação por citocinas da expressão de CD40, MHC de classe II e CCR7 em BMMo ativados pela Nattectina.

Figura 13- Modulação por IL-10 e IL-13 da expressão de moléculas induzida pela Nattectina em BMMo. 


\section{LISTA DE ABREVIATURAS E SIGLAS}

ACN - acetonitrila

Akt - quinase serina/treonina

APC - célula apresentadora de antígeno

BMMo - macrófagos derivados da medula óssea

BSA - soro albumina bovina

C3b - fragmento da proteína C3 do complemento

CCR2 - receptor de quimiocina tipo 2

CCR7 - receptor de quimiocina tipo 7

$\mathrm{CD}$ - Cluster of differentiation

CD40L - CD40 ligante

CD62L - ligante da L-selectina

$\mathrm{CR}$ - receptor de complemento

CRD - domínio de reconhecimento de carboidratos

CSF-1 - Colony-Stimulating Factor-1

DC - célula dendrítica

DCreg - célula dendrítica reguladora

D-gal - D-galactose

DMEM - Dulbecco's Modified Eagle's Medium

DMSO - dimetilsulfóxido

ECM - matriz extracelular

EDTA - ácido etileno diamina tetra acético

ELISA - Enzyme Linked Immunosorbent Assay

ERK - quinase regulada por sinal extracelular

F4/80 - glicoproteína expressa por macrófagos

FACS - separação de célula ativada por fluorescência

FCS - soro fetal bovino

$\mathrm{Fc} \gamma \mathrm{R}$ - receptor para a porção $\mathrm{Fc}$ da imunoglobulina IgG

FITC - isotiocianato de fluoresceína

FSC - Forward scatter

GAGs - glicosaminoglicanos

Gal/GalNAc - lectina de superfície amebiana

GalNAc - N-acetilgalactosamina

Gr-1 - marcador de neutrófilo/monócito

HEK293 - células 293 de rim embrionário humano

HeLa S3 - células de carcinoma epitelial humano

HPA - hipotálamo-pituitária-adrenal

HPLC - cromatografia líquida de alta eficiência

ICAM-1 - molécula de adesão intercelular-1

ICAM-2 - molécula de adesão intercelular-2

IFN- $\gamma$ - interferon- $\gamma$

IgG - imunoglobulina $\mathrm{G}$

IL - interleucina

iNOS - óxido nítrico-sintase induzível

IPC - células produtoras de IFN tipo I

$\mathrm{KC}$ - quimiocina derivada de queratinócito

$\mathrm{KM}(+)$ - lectina isolada da planta Artocarpus integrifolia

$\mathrm{KO}$ - Knockout 
L929 - linhagem celular produtora de M-CSF proveniente de fibroblasto murino

LFA-1 - antígeno 1 associado a função leucocitária

LPM - Large Peritoneal Macrophage

LPS - lipopolissacarídeo

M1 - macrófago do tipo 1

M2 - macrófago do tipo 2

Mac-1 - antígeno de macrófago 1

MIF - média de intensidade de fluorescência

MALDI-TOF - Matrix-assisted laser desorption/ionization-time of flight

MAPK - proteína quinase ativada por mitógeno

MCP-1 - proteína quimiotática de monócitos-1

M-CSF - fator estimulador de colônia de macrófago

MDSC - células supressoras derivadas de precursores mielóides

MEK - quinase ativadora da MAPK

MHC- II - complexo principal de histocompatibilidade classe II

MMP - metaloproteinase

MT-MMP - metaloproteinase de matriz ligada a membrana

MyD88 - gene de resposta primária da diferenciação mielóide 88

NOD - receptores tipo NOD

NTC - Nattectina

PBS - tampão fosfato salina

PD98059 - inibidor da via ERK1/2

$\mathrm{PE}$ - ficoeritrina

PE-Cy5 - ficoeritrina cianina 5

PI3K - fosfatidil inositol 3-quinase

PKB - proteína quinase $\mathrm{B}$

Poly (I:C) - ácido poliinosínico:policitidílico

RAW264.7 - linhagem de macrófagos de camundongos leucêmicos

RLR - receptores tipo RIG

RNA - ácido ribonucléico

SB203580 - inibidor de p38 MAPK

SDS-PAGE - gel de poliacrilamida-dodecil sulfato de sódio

SPM - Small Peritoneal Macrophage

SSC - Side scatter

TCR - receptor de células T

TFA - ácido trifluoroacético

Th1 - linfócito $\mathrm{T}$ auxiliar 1

Th2 - linfócito T auxiliar 2

TLR - receptores do tipo Toll

TMB - tetrametilbenzidina

TmC4-47.2 - miotoxina isolada do veneno do peixe Thalassophryne maculosa

TNF- $\alpha$ - fator de necrose tumoral- $\alpha$

VCAM-1 - molécula de adesão celular vascular-1

Vero - linhagem celular derivado do rim do macaco verde Cercopithecus aethiops

WT - Wild type 


\section{SUMÁRIO}

1 INTRODUÇÃO

2 OBJETIVO

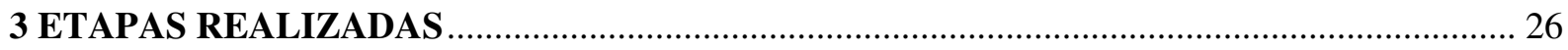

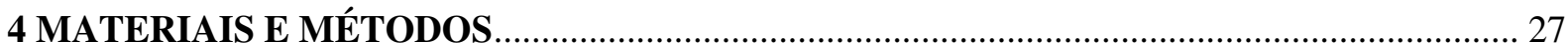

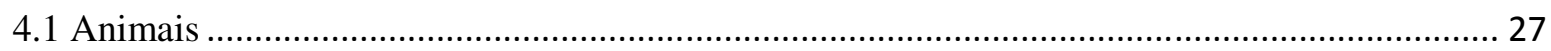

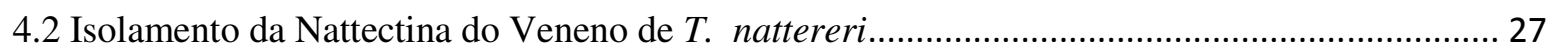

4.3 Obtenção de Macrófagos Derivados da Medula Óssea (BMMo) ……......................................... 28

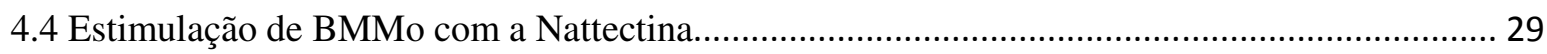

4.5 Avaliação da Ativação de Vias de Sinalização em BMMo Estimulados com Nattectina in vitro

4.6 Efeito da Nattectina na Capacidade Endocítica de BMMo in vitro ............................................. 30

4.7 Efeito da Nattectina na Expressão de Integrinas em BMMo in vitro .......................................... 30

4.8 Avaliação do Papel da Nattectina na Indução da Resposta Imune Inata....................................... 30

4.9 Determinação dos Níveis de Citocinas e MMPs por ELISA ………........................................... 31

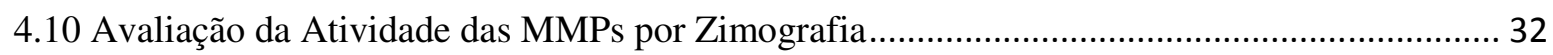

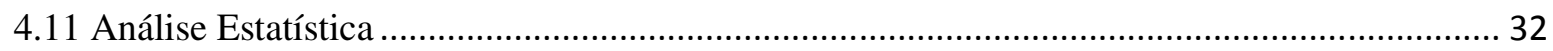

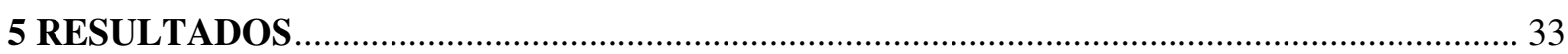

5.1 Obtenção da toxina Nattectina do veneno de T. nattereri ........................................................ 33

5.2 Caracterização Fenotípica de Macrófagos Derivados de Medula Óssea....................................... 35

5.3 Avaliação da Ação da Nattectina e a Influência da Ligação a Açúcares na Ativação de

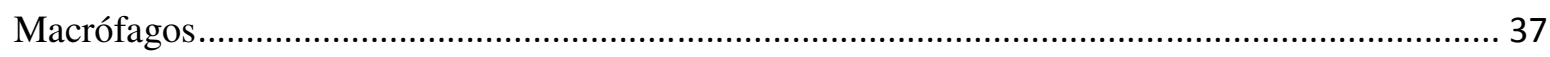

5.4 Nattectina Induz Aumento na Expressão de Integrinas em Macrófagos..................................... 40

5.5 A Ativação de Macrófagos Induzida pela Nattectina é Mediada por MAPK p38 e PI3K .......... 42

5.6 Nattectina Induz Síntese de Metaloproteinases Dependente de ERK1/2 ..................................... 44

5.7 Influência da Ligação da Nattectina a Açúcares e de Vias de Sinalização na Capacidade

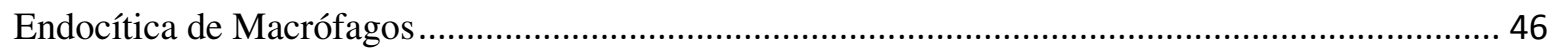

5.8 Indução da Resposta Imune Inata pela Nattectina........................................................................ 48

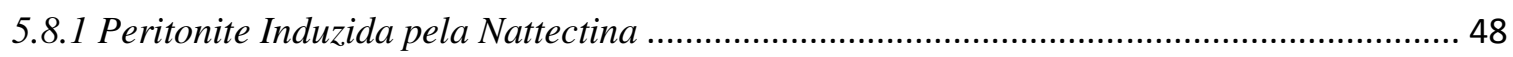

5.8.2 Síntese de Mediadores Inflamatórios Induzidos pela Nattectina ......................................... 49

5.9 Influência de Citocinas Th1/Th2 na Ativação Polarizada de Macrófagos Induzida pela

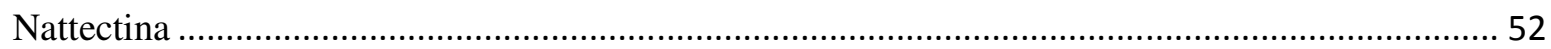

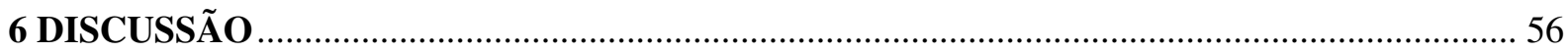

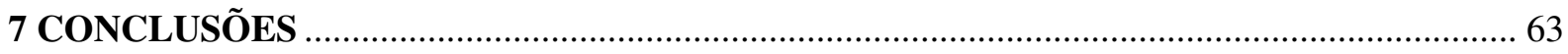

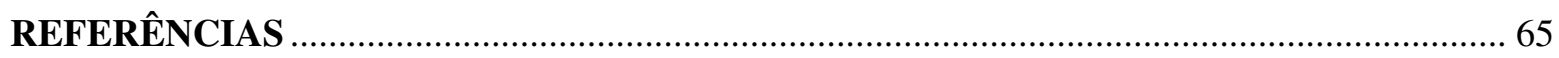




\section{INTRODUÇÃO}

A inflamação é uma resposta homeostática, dinâmica e protetora que o hospedeiro lança mão contra as diversas agressões a que é submetido. Dentre as diversas células atuantes neste processo, os macrófagos desempenham um importante papel, incluindo a eliminação de antígenos, a regulação da regeneração e a iniciação da resposta imune adaptativa (SIMON e GREEN, 2005; FUJIWARA e KOBAYASHI, 2005). Estas células iniciam o processo inflamatório pela secreção de citocinas pró-inflamatórias ou "de alerta” (IL-1, TNF- $\alpha$ e IL-6) que desencadeiam uma série de reações humorais e celulares, tanto no sítio da inflamação quanto a distância. A ativação das células do estroma (como fibroblastos e células endoteliais) pelas citocinas IL-1 e TNF- $\alpha$ provoca a secreção de quimiocinas, principalmente IL-8 (ou KC em camundongos) e MCP-1, que são quimiotáticas para neutrófilos e células mononucleares, respectivamente (CAMPBELL e BUTCHER, 2000; HANADA e YOSHIMURA, 2002).

Macrófagos pertencem ao sistema fagocítico mononuclear, que representa um subgrupo de leucócitos originalmente descrito como uma população de células mielóides derivadas da medula óssea, e são células da imunidade inata com funções bem estabelecidas na resposta primária a patógenos, mas também na homeostase do tecido, coordenação da resposta imune adaptativa, inflamação, resolução e reparo. Essas células reconhecem sinais de perigo através de receptores capazes de induzir programas de ativação especializados (GEISSMANN et al., 2010; MARTINEZ; HELMING; GORDON, 2009).

Os macrófagos têm sido considerados por muito tempo importantes células imunes efetoras, visto que Élie Metchnikoff, que ganhou o prêmio Nobel 100 anos atrás por sua descrição de fagocitose, propôs que a chave da imunidade era "estimular a fagocitose" (NATHAN, 2008). Desde esta descoberta, os imunologistas se ocuparam com o conceito dos macrófagos como células imunes efetoras e com a compreensão de como estas células participam na defesa do hospedeiro. Entretanto, por focar somente nas funções imunes dos macrófagos, ignoraram seu papel vital na homeostasia, que é independente de sua participação em respostas imunes.

Macrófagos detectam os sinais de perigo exógenos e endógenos que estão em restos de células necróticas através de receptores Toll-like (TLR); receptores Nod-like (NLR) e receptores RIG-I-like (RLR) (KONO e ROCK, 2008; PARK et al., 2004), os quais sinalizam muitas vezes através de MyD88 (CHEN et al., 2007). Esta função faz dos macrófagos 
sensores primários de perigo no hospedeiro. A fagocitose de componentes por macrófagos conduz a mudanças dramáticas na sua fisiologia, incluindo alterações na expressão das proteínas de superfície e na produção de citocinas e de mediadores pró-inflamatórios. As alterações na expressão de proteínas de superfície nos macrófagos em resposta a estes estímulos podem ser usadas como marcadores fisiológicos únicos destas células alteradas.

Uma característica importante dos macrófagos refere-se a sua notável plasticidade, o que permite que essas células respondam eficientemente aos sinais ambientais e mudem seu fenótipo; e sua fisiologia pode ser marcadamente alterada pelas respostas imunes inata e adaptativa. Em humanos, a distinta expressão de CD14 e CD16 permite a diferenciação de macrófagos em dois subtipos: um do tipo clássico $\mathrm{CD} 14^{\text {high }} \mathrm{CD} 16^{\text {neg }}$ e uma população minoritária, não-clássica CD14 ${ }^{\text {low }} \mathrm{CD} 16^{\text {pos }}$ (PASSLICK; FLIEGER; ZIEGLER-HEITBROCK, 1989; ZIEGLER-HEITBROCK et al., 1993). Em camundongos, duas populações de monócitos em processo final de maturação contínua foram identificadas e denominadas como inflamatórias ou residentes baseadas primeiramente na quantidade de tempo que gastam no sangue antes de migrar para os tecidos para se tornarem macrófagos (GEISSMANN; JUNG; LITTMAN, 2003). Estas populações de monócitos estão representadas aproximadamente igual no sangue dos camundongos (PASSLICK; FLIEGER; ZIEGLER-HEITBROCK, 1989) e podem ser diferenciadas baseadas na expressão de marcadores de superfície celular. Os monócitos inflamatórios são definidos como $\mathrm{CCR}^{\mathrm{pos}}$ (CC-chemokine receptor 2), CX3CR1 $1^{\text {low }}$ (CX3C-chemokine receptor 1) e GR1 $1^{\text {pos }}$ (também conhecido como Ly6), enquanto os monócitos residentes são definidos como $\mathrm{CCR} 2^{\text {neg }} \mathrm{CX} 3 \mathrm{CR} 1^{\text {high }} \mathrm{GR} 1^{\text {neg }}$ (GEISSMANN et al., 2003). 


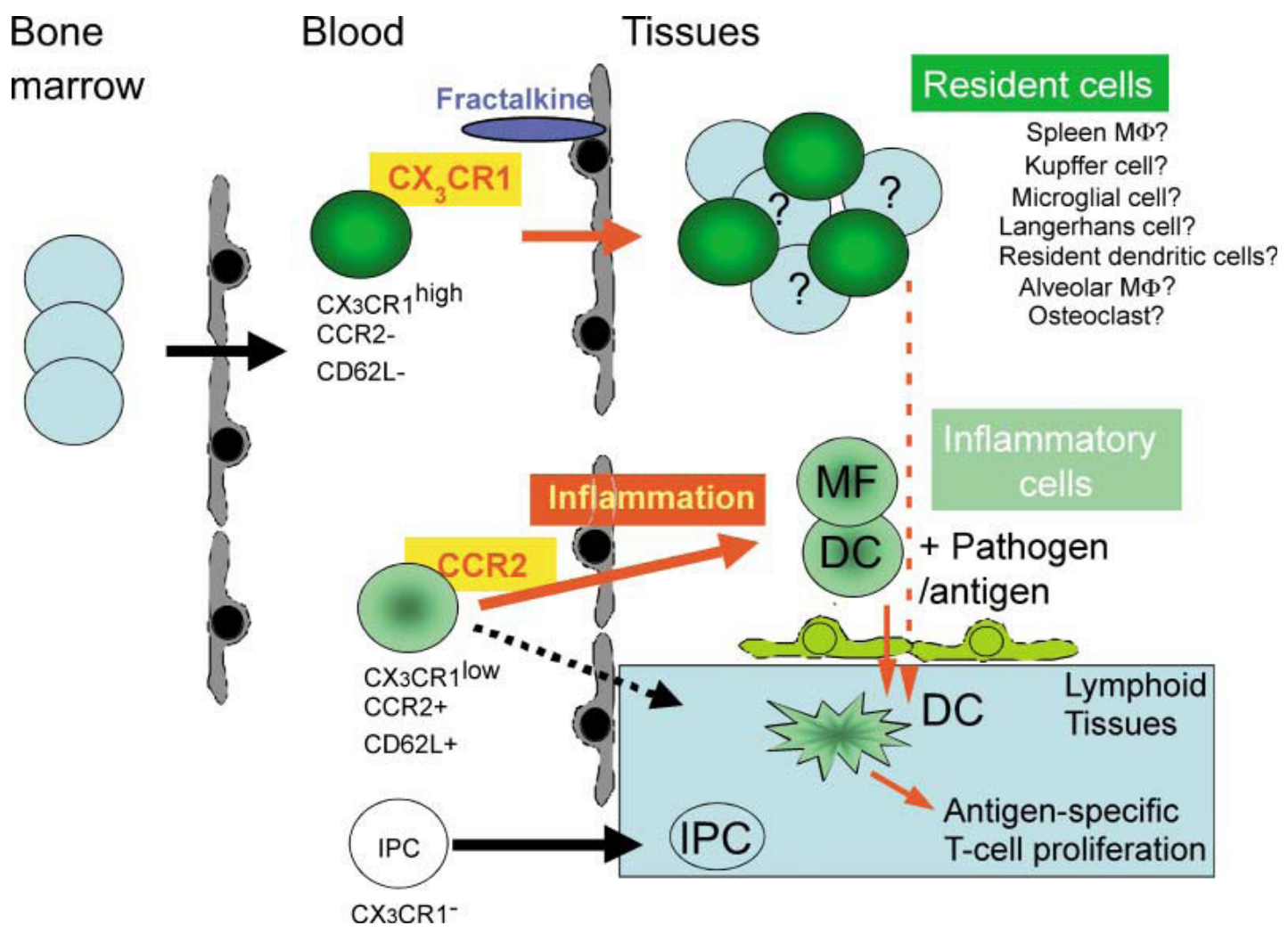

Figura 1- Modelo para a dicotomia funcional dos subtipos de macrófagos.

Fonte - Geissmann et al. (2003)

Em um esforço para equiparar-se à literatura dos linfócitos T, os macrófagos foram classificados, de maneira linear, como macrófagos M1 (classicamente ativados) em um extremo e macrófagos M2 (alternativamente ativados) em outro. Os macrófagos M1 sofrem ativação clássica induzida por IFN- $\gamma$, que desencadeia uma potente resposta pró-inflamatória necessária para matar patógenos intracelulares, enquanto os macrófagos M2 sofrem ativação alternativa induzida por IL-4 e IL-13, que desencadeiam um fenótipo importante para a resposta imune aos parasitas (MARTINEZ; HELMING; GORDON, 2009; MOSSER e EDWARDS, 2008). Mas de maneira mais global, envolvendo as funções na homeostasia e na inflamação, os macrófagos podem ser classificados como: macrófagos de defesa, de cicatrização e reguladores. Esta classificação ajuda também a ilustrar como os macrófagos podem evoluir para exibir as características que são compartilhadas por mais de uma população de macrófagos.

Os macrófagos de defesa são aqueles classicamente ativados que são produzidos durante respostas imunes mediadas por células. Na caracterização original de macrófagos classicamente ativados, a combinação de dois sinais, interferon- $\gamma($ IFN- $\gamma$ ) e o fator de necrose tumoral (TNF) gera uma população de macrófagos que tem aumentada capacidade 
microbicida ou tumoricida e secreta níveis elevados de citocinas e de mediadores próinflamatórios (MACKANESS, 1977; O’SHEA e MURRAY, 2008).

Os macrófagos da cicatrização podem se desenvolver em resposta aos sinais inatos ou adaptativos. Um dos primeiros sinais inatos a ser liberado durante a injúria do tecido é a citocina IL-4 (LOKE et al., 2007). Basófilos e mastócitos são fontes recentes importantes da produção inata de IL-4, embora outros granulócitos possam também contribuir (BRANDT et al., 2000). IL-4 estimula a atividade da arginase nos macrófagos, permitindo que convertam a arginina em ornitina, um precursor das poliaminas e do colágeno, contribuindo desse modo à produção de matriz extracelular (KREIDER et al., 2007). Os macrófagos da cicatrização podem também ser prejudiciais ao hospedeiro quando sua atividade de produção de matriz é desregulada, similarmente à desregulação da atividade de macrófagos classicamente ativados na auto-imunidade.

Similarmente às duas populações de macrófagos descritos acima, os macrófagos reguladores também estão presentes em ambas as respostas imunes. Embora as respostas de estresse não sejam consideradas tipicamente parte da imunidade inata, o eixo (HPA) hypothalamic-pituitary-adrenal pode exercer efeitos marcantes em macrófagos. Glucocorticóides são liberados por células adrenais em resposta ao estresse e podem inibir a defesa do hospedeiro dependente de macrófagos e suas funções inflamatórias inibindo a transcrição de genes de citocinas pró-inflamatórias e diminuindo a estabilidade do RNA mensageiro (STERNBERG, 2006), gerando uma população de macrófagos reguladores. Os macrófagos reguladores podem também aparecer durante os estágios mais tardios das respostas imunes adaptativas com papel de limitar a inflamação crônica (MOSSER, 2003). Há maneiras diferentes de gerar macrófagos reguladores, porém um único mecanismo molecular que medeia este processo de diferenciação fenotípica ainda não foi identificado, embora a sinalização via MAP quinases (extracellular-sinal-regulated kinase - ERK) apareça como um potencial candidato (LUCAS et al., 2005). Ao contrário dos macrófagos de cicatrização, estes macrófagos reguladores não contribuem para a produção de matriz extracelular, e muitas destas células reguladoras expressam níveis elevados de moléculas co-estimuladoras (CD80 e CD86) e podem consequentemente apresentar antígenos a linfócitos T (EDWARDS et al., 2006).

Em resumo, os sinais oriundos da resposta inata ou adaptativa podem influenciar a fisiologia de macrófagos, e estas alterações permitem que os macrófagos participem em processos homeostáticos, tais como remodelamento tecidual e fechamento de feridas e 
também na defesa do hospedeiro. A resposta dos macrófagos aos sinais de perigo endógenos é somente um exemplo de quantos estímulos diferentes provocam a ativação dos macrófagos nos tecidos e por isso pesquisas vêm sendo realizadas com imunoterápicos indutores ou supressores capazes de estimular macrófagos, modulando suas funções.

Para que o macrófago exerça suas atividades, é necessário que ele migre para outros sítios através da matriz extracelular, que é uma rede intricada de macromoléculas que ocupam o espaço extracelular nos tecidos. Além de estabilizar a estrutura física dos tecidos, a matriz influencia o desenvolvimento, a migração, a proliferação, as funções e a sobrevivência das células (VU e WERB, 2000). As moléculas que constituem a matriz extracelular são geradas localmente por diferentes tipos celulares, particularmente por uma família de células denominados fibroblastos. Três classes principais de macromoléculas constituem a matriz: cadeias polissacarídicas de glicosaminoglicanos (GAGs) unidas covalentemente a proteínas formando os PROTEOGLICANOS (agrim, perlecam, sindecam, glipicam, CD44 e betaglicam), as PROTEÍNAS FIBROSAS como a família dos colágenos e elastina, e as GLICOPROTEÍNAS como, por exemplo, a laminina e a fibronectina (ORLANDO e CHERESH, 1991; MEREDITH; FAZELI; SCHWARTZ, 1993).

Para a progressão celular pela matriz extracelular intersticial, é necessária uma série coordenada de etapas que incluem a adesão/liberação e a degradação focal da matriz (BIANCHI et al., 1997; LAUFFENBURGER e HORWITZ, 1996; BASBAUM et al., 1996). As integrinas de leucócitos têm um papel importante nas interações com as proteínas da matriz extracelular durante o processo de transmigração (SHIMIZU e SHAW, 1991; MOSTAFAVI-POUR et al., 2003; SCHWARTZ e GINSBERG, 2002). As integrinas são glicoproteínas transmembrana, compostas por dois heterodímeros não-covalentes designados subunidades $\alpha$ e $\beta$, cada uma com grande domínio extracelular e pequena, porém importante, extensão citoplasmática. Existem 15 cadeias $\alpha$ e 8 cadeias $\beta$ que já foram clonadas e sequienciadas. Os leucócitos expressam 13 diferentes integrinas as quais medeiam a ligação com as células endoteliais. As mais importantes para adesão endotelial são as integrinas $\beta 1$ (CD29), $\beta 2$ (CD18) e $\beta 7$. A subfamília $\beta 2$ é expressa em todos os leucócitos e consiste em uma subunidade $\beta 2$ ligada a uma das quatro subunidades $\alpha$ : CD11a (aL), CD11b (aM), CD11c (aX) ou CD11d (aD). Os linfócitos produzem primariamente CD11a/CD18 (LFA-1 ou lymphocyte function associated antigen-1), enquanto os eosinófilos, neutrófilos e monócitos produzem todas as quatro $\beta 2$ integrinas (IMHOF e AURRAND-LIONS, 2004). 
Após a marginação dos leucócitos ao longo do endotélio vascular, as integrinas são ativadas por pelo menos uma de uma variedade de quimiocinas e citocinas quimiotáticas associadas à superfície endotelial, e a firme adesão ao endotélio ocorre pela ligação de integrinas $\beta 1$ e $\beta 2$ expressas nos leucócitos com os vários membros da superfamília das imunoglobulinas expressas no endotélio (ICAM-1, ICAM-2 e VCAM-1).

Durante a adesão firme, a combinação da sinalização via integrinas e exposição a quimiocinas imobilizadas na porção apical das células endoteliais induz uma alteração marcante na morfologia dos leucócitos. Os leucócitos estendem de frente para trás uma extensão apical larga (lamellipodium) rica em filamentos F-actina, a qual constitui a extremidade principal de movimento celular. Algumas células do sistema imune como as células dendríticas (dendritic cells, DCs) e os macrófagos apresentam estruturas adesivas específicas conhecidas como podossomos. Estas células apresentam-se como um exemplo das poucas células do sistema imune que formam fibras de estresse ou adesão focal — uma característica que pode explicar a sua alta mobilidade dependente de integrina nos substratos, diferentemente das células aderentes como fibroblastos e células endoteliais. Enquanto a formação da extensão lamellipodium é regulada pelos processos de polimerização da actina e contração da actomiosina, a desadesão parece ser dependente da contração e da ação de metaloproteinases de matriz (DIAKONOVA; BOKOCH; SWANSON, 2002; VICENTEMANZANARES e SÁNCHEZ-MADRID, 2004).

Sabendo do papel das integrinas na adesão focal dos leucócitos, vários estudos têm sido realizados para o entendimento dos mecanismos envolvidos na degradação focal da matriz extracelular durante a transmigração dos leucócitos. Recentes trabalhos sugerem um importante papel para as metaloproteinases de matriz (matrix metalloproteinases, MMPs) na degradação da matriz extracelular (STERNLICHT et al., 2000; PARKS; WILSON; LÓPEZBOADO, 2004; VU e WERB, 2000). MMPs são uma família de endopeptidases dependentes de zinco capazes de degradar todos os componentes da matriz extracelular e que têm sido classificadas de acordo com a especificidade pelo substrato em gelatinases, estromelisinas, colagenases (BIRKEDAL-HANSEN, 1995) e metaloproteinase transmembrana (MT-MMP), expressa na superfície de células tumorais invasivas ou em células estromais (SATO et al., 1994). A degradação controlada da matriz extracelular é uma característica importante em uma variedade de processos biológicos, tais como o desenvolvimento do embrião e o remodelamento e reparo tecidual. O reparo de feridas inicia-se com a agregação de plaquetas, formação de coágulos de fibrina e liberação de fatores de crescimento a partir de vias de 
coagulação ativadas, células danificadas, plaquetas e componentes da matriz extracelular, seguido pela migração de células inflamatórias para o local da ferida (RAVANTI e KAHARI, 2000). Metaloproteinases são sintetizadas na forma inativa com um pró-peptídio aminoterminal que deve ser clivado para tornarem-se ativas (GOETZL; BANDA; LEPPERT, 1996; BIRKEDAL-HANSEN, 1995). Entre estas, MMP-2 e MMP-9 são consideradas responsáveis pela degradação de laminina, colágeno tipo IV, este último o maior constituinte da membrana basal (PARKS; WILSON; LÓPEZ-BOADO, 2004).

MMP-2 é expressa constitutivamente em várias células, enquanto MMP-9 é induzida principalmente por estímulos inflamatórios como TNF- $\alpha$, endotoxinas e IL-1, por várias células como também por macrófagos. Outros estudos sugerem que MMP-9 é um forte candidato para a indução/ativação das funções de macrófagos, estas relacionadas com a resposta inflamatória (PARKS; WILSON; LÓPEZ-BOADO, 2004). Além disso, MMP-9 está associada aos processos de re-epitelização e eventos reparadores agudos (VU e WERB, 1998), enquanto MMP-2 é importante durante a fase de remodelamento prolongado (AGREN, 1994; STRICKLIN; LI; NANNEY, 1994). As metaloproteinases afetam a sobrevivência e a proliferação ou a morte celular, efeitos regulados por sinais gerados em eventos adesivos específicos. Estas diferenças de efeitos das MMPs refletem diferenças nos substratos das enzimas envolvidos em cada resposta. Assim, a regulação das funções inflamatórias leucocitárias pela interação com os componentes da matriz extracelular pode fornecer informações importantes a respeito de como a resposta inflamatória será resolvida.

Considerando, portanto, que os macrófagos são células importantes no sistema imune tendo em vista a sua participação em diversos processos como inflamação, eliminação de antígenos e regeneração, é importante modular as suas funções através do uso de substâncias como citocinas, agonistas de receptores do tipo Toll, galectinas e lectinas derivadas de plantas e animais como, por exemplo, peixes.

No Brasil, o peixe Thalassophryne nattereri destaca-se entre os animais peçonhentos de importância médica pelo número de acidentes que provoca, principalmente nas regiões Norte e Nordeste (ALMEIDA et al., 1989; AUTO, 1992; FONSECA e LOPES-FERREIRA, 2000; HADDAD JR et al., 2003; FACÓ et al., 2005). T. nattereri é considerado um peixe peçonhento por apresentar glândulas cutâneas especializadas na produção de veneno conectadas a ductos excretores canaliculados (espinhos) localizados em cada um dos lados das regiões dorsal e lateral (FRÓES, 1933a, b, c). Os acidentes provocados pelo T. nattereri ocorrem principalmente nas regiões plantar ou palmar das vítimas após a introdução dos 
espinhos canaliculados na pele com conseqüente ruptura das glândulas. As principais características do quadro clínico em humanos são dor e edema intensos e duradouros desencadeados imediatamente após o acidente. Em conseqüência, pode haver o desenvolvimento de necrose, que em casos graves acomete todo o membro, levando a seqüelas irreversíveis como a hipertrofia muscular e a perda da função (FONSECA e LOPESFERREIRA, 2000).

$\mathrm{O}$ veneno de $T$. nattereri e suas toxinas vêm sendo amplamente estudados quanto a diferentes aspectos como: os efeitos tóxicos causados nas vítimas humanas (FONSECA e LOPES-FERREIRA, 2000) e em modelos experimentais (LOPES-FERREIRA et al., 1998, 2001, 2002; FACÓ et al., 2003), os aspectos bioquímicos e farmacológicos (LOPESFERREIRA et al., 2004; MAGALHÃES et al., 2005, 2006), e a capacidade de indução de anticorpos neutralizantes para os principais efeitos tóxicos em camundongos e os mecanismos imunológicos envolvidos nesta resposta (LOPES-FERREIRA et al., 2000; LIMA et al., 2003; GRUND et al., 2006; PIRAN-SOARES et al., 2007). O trabalho de Lima et al. (2003) demonstra que o veneno é capaz de induzir uma resposta inflamatória localizada na pata de camundongos, rica em citocinas de fase aguda, porém com raros leucócitos presentes na lesão. Assim, o estudo deste veneno tornou-se importante para o entendimento do processo de lesão e regeneração tecidual visto no envenenamento como também para o entendimento da relação entre a adesão de leucócitos e a matriz extracelular e os mecanismos de sobrevivência decorrentes desta relação.

Comprovadas as inúmeras atividades biológicas do veneno de T. nattereri, tornou-se fundamental o estudo de suas toxinas. Assim, Magalhães et al. (2006) identificaram grupos de toxinas no veneno: a família das proteases Natterinas, constituída por cinco toxinas, 1, 2, 3, 4 e P, com massa molecular em torno de $35 \mathrm{kDa}$ e com homologia entre si, mas não com proteínas existentes nos bancos de dados, e a Nattectina com massa molecular de $15 \mathrm{kDa}$ e com homologia com lectinas do tipo C. Através da análise do domínio CRD (QPD, Gln-ProAsp) e N-terminal da seqüência de aminoácidos, foi observado que a Nattectina apresenta afinidade por estruturas terminadas em galactose ou glicanas terminadas em $\mathrm{N}$ acetilgalactosamina (GalNAc), semelhante às galectinas (LOPES-FERREIRA et al., 2011). Além disso, a Nattectina também apresenta homologia com outras lectinas descritas como a echinoidina, uma lectina mitogênica e quimiotática isolada do veneno do ouriço-do-mar (Toxopneustes pileolus) e a miotoxina TmC4-47.2, isolada do veneno do peixe Thalassophryne maculosa (SOSA-ROSALES et al., 2005). 
Lectinas formam um grupo de proteínas ligantes de carboidrato estruturalmente heterogêneo que compreende distintas famílias de proteínas evolutivamente relacionadas. Sua principal característica consiste na capacidade de se ligar especificamente e de forma reversível a moléculas de carboidratos. $\mathrm{O}$ termo tipo $\mathrm{C}$ refere-se à dependência dessas lectinas pelo íon cálcio para exercer suas atividades e também por apresentarem homologia estrutural com o domínio de reconhecimento para carboidratos tipo C (DAY, 1994). As lectinas são particularmente interessantes por suas características biológicas, farmacológicas e bioquímicas. Embora sejam descritas principalmente por possuírem atividade hemaglutinante, vale ressaltar seu importante papel no sistema imune. Destacam-se como moléculas promotoras de comunicação entre células do sistema imune, como reguladoras da migração celular, na captação e apresentação de antígeno e na adesão celular (WILSON; CHEN; RATCLIFFE, 1999).

Muitas lectinas, especificamente aglutinadoras de bactérias ou parasitas têm sido identificadas em animais marinhos invertebrados, especialmente em espécies comercialmente importantes como mexilhão, molusco, camarão, caranguejo e ostra (COMINETTI et al., 2002; DENIS et al., 2003; LUO et al., 2006; NAGANUMA et al., 2006; UTARABHAND; RITTDACH; PAIJIT, 2007; WANG et al., 2007). Desde a identificação e caracterização da primeira lectina Electrolectin isolada da enguia Electrophorus electricus, um número substancial de lectinas têm sido também identificado em peixes elasmobrânquios e teleósteos, principalmente no plasma, na pele e no muco com função de defesa contra vírus e bactérias (VASTA et al., 2004). Entretanto, não existe nenhum trabalho identificando ou mostrando a relevância de uma lectina isolada do veneno de peixe na regulação do sistema imunológico. Sendo assim, a Nattectina foi recentemente estudada por nosso grupo e demonstramos sua capacidade de induzir resposta imune inata e específica do tipo Th1 em camundongos, mediante a diferenciação e ativação de células dendríticas derivadas de macrófagos (SARAIVA et al., 2011).

Sabendo da importância dos macrófagos em processos homeostáticos assim como na defesa do hospedeiro e contando com a possibilidade de obtenção de agentes terapêuticos de fontes naturais capazes de modular o sistema imune, especificamente macrófagos, o objetivo deste trabalho é a verificação da capacidade da Nattectina na ativação das funções de macrófagos, importantes para a resposta imune inata bem como na indução da resposta adaptativa. 


\section{OBJETIVO}

Verificação da capacidade da Nattectina de ativar as funções de macrófagos como fagocitose, produção de mediadores inflamatórios, expressão de moléculas co-estimuladoras e integrinas e da influência de citocinas Th1/Th2 na ativação polarizada de macrófagos induzida pela Nattectina. 


\section{ETAPAS REALIZADAS}

- Obtenção da Nattectina;

- Caracterização fenotípica de macrófagos derivados de medula óssea;

- Avaliação da influência da ligação da Nattectina a açúcares na ativação de macrófagos;

- Avaliação da capacidade da Nattectina de induzir aumento na expressão de integrinas em macrófagos;

- Avaliação do papel da ativação de MAPKs na modulação de macrófagos induzida pela Nattectina;

- Avaliação da capacidade da Nattectina de induzir a síntese de metaloproteinases;

- Verificação da influência da ligação da Nattectina a açúcares e das vias de sinalização na capacidade endocítica de macrófagos;

- Verificação da capacidade de indução da resposta imune inata pela Nattectina;

- Verificação da influência de citocinas Th1/Th2 na ativação polarizada de macrófagos induzida pela Nattectina. 


\section{MATERIAIS E MÉTODOS}

\subsection{Animais}

Para a obtenção da medula óssea femoral, foram utilizados camundongos BALB/c fêmeas e C57BL/6 machos fornecidos pelo Biotério Central do Instituto Butantan, e camundongos machos C57BL/6 deficientes nos genes das citocinas IL-4, IL-12 ou IFN- $\gamma$ provenientes do Biotério Central do Instituto de Ciências Biomédicas da Universidade de São Paulo (ICB-USP), todos pesando entre 18 - 22 g. Antes da realização dos experimentos, os animais foram mantidos em estantes ventiladas sob condições controladas de temperatura, umidade e iluminação (ciclo claro/escuro de 12 horas), com água e ração ad libitum. Os experimentos foram realizados conforme as leis da Comissão Brasileira de Experimento Animal (COBEA) e aprovados pelo Comitê de Ética Animal do Instituto Butantan (634/09) e pela Comissão de Ética no Uso de Animais (CEUA) do Instituto de Ciências Biomédicas (ICB-USP) registrado sob $\mathrm{n}^{\mathrm{o}} 106$ nas fls. 91 do livro 02 para uso de animais de experimentação.

\subsection{Isolamento da Nattectina do Veneno de T. nattereri}

A Nattectina foi isolada utilizando-se um sistema de cromatografia de fase-reversa HPLC (Äkta, Amersham Biosciences, Suécia) e protocolo padronizado por nosso laboratório. Para este ensaio foi utilizado um pool de veneno coletado em diferentes meses do ano. Imediatamente antes da cromatografia, $10 \mathrm{mg}$ de veneno foram diluídos em $800 \mu \mathrm{l}$ de tampão A $\left(\mathrm{H}_{2} \mathrm{O}\right.$ 0,1\% TFA - ácido trifluoroacético) e centrifugado a 14.000 g por $5 \mathrm{~min}$. Esta solução foi aplicada a um sistema de cromatografia líquida de proteína (HPLC - Amershan Biosciences, Suécia) em uma coluna de extração de fase sólida $\mathrm{C}_{18}$ (Shim-pack PREP-ODS Shimadzu) semi-preparativa equilibrada com tampão A. As proteínas retidas na coluna foram eluídas com um gradiente linear de tampão B (90\% ACN $10 \% \mathrm{H}_{2} \mathrm{O}$ 0,1\% TFA) de $10 \%$ a $80 \%$ em $60 \mathrm{~min}$ sob fluxo constante de $5,0 \mathrm{ml} / \mathrm{min}$. O pico obtido na $\mathrm{C}_{18}$ correspondente a Nattectina foi recromatografado em uma coluna $C_{8}$ (Beta Basic- 8 - Thermo). O gradiente inicial utilizado foi de $15 \%$ a $70 \%$ de solvente B por $50 \mathrm{~min}$, sob fluxo constante de 1,0 $\mathrm{ml} / \mathrm{min}$. Os perfis das eluições foram determinados pela medida de absorbância a $220 \mathrm{~nm}$ e apresentados em um cromatograma. A pureza do material foi determinada por espectrometria 
de massa tipo MALDI-TOF em um sistema Ettan MALDI-TOF/Pro (Amersham Biosciences, Suécia), usando $\alpha$-CHCA como matriz e por coloração de prata de gel SDS-PAGE a $15 \%$ como descrito por Laemmli (1970). O material foi liofilizado, ressuspenso em água e estocado a $-20{ }^{\circ} \mathrm{C}$ até o momento do uso. Além disso, as amostras foram levadas a Seção de Controle Biológico do Instituto Butantan e apresentaram resultado negativo quanto a contaminação com LPS $(<0.8 \mathrm{pg})$.

\subsection{Obtenção de Macrófagos Derivados da Medula Óssea (BMMo)}

A cultura primária de macrófagos foi obtida da medula óssea femoral de camundongos BALB/c fêmeas e C57BL/6 machos normais (WT) ou deficientes nos genes das citocinas IL4, IL-12 ou IFN- $\gamma$, como descrito por Falk et al. (1995) e Muller (2003). Células dos fêmures foram isoladas por perfusão e cultivadas na concentração de 2 × $10^{6}$ células/ml em DMEM (Sigma-Aldrich) suplementado com soro de cavalo a $2 \%$ adicionado de $1 \%$ vitaminas, $1 \%$ piruvato de sódio, $1 \%$ aminoácidos não-essenciais, $1 \%$ L-glutamina e $1 \%$ penicilina/estreptomicina mais 30\% de sobrenadante da cultura de células L929 transfectadas com o gene murino de M-CSF. O meio foi trocado nos dias 2 e 4, e no sétimo dia a população homogênea de macrófagos ( $>95 \%$ BMMo $\left.=\mathrm{CD} 11 b^{\mathrm{pos}} \mathrm{F} 4 / 80^{\mathrm{pos}}\right)$ foi determinada por citometria de fluxo. Primeiramente, as células foram mantidas a $4{ }^{\circ} \mathrm{C}$ por $20 \mathrm{~min} \operatorname{com} 2 \mu \mathrm{l}$ de soro normal de camundongo e então $100 \mu \mathrm{l}$ de células foram incubadas por 30 min a $4{ }^{\circ} \mathrm{C}$ no escuro com anticorpos específicos marcados com distintos fluorocromos: FITC anti-mouse CD11c, FITC anti-mouse CD14, FITC anti-mouse Ly-6C, PE anti-mouse CD11b. Foram também utilizados os anticorpos de rato não marcados anti-mouse F4/80 like R seguido da incubação com segundo anticorpo FITC anti-rat IgG. Após nova lavagem e centrifugação, as células foram ressuspensas em $1 \mathrm{ml}$ de formaldeído $3 \%$ e mantidas a $4{ }^{\circ} \mathrm{C}$ até o momento da aquisição dos dados (10.000 eventos) no citômetro de fluxo FACSCalibur de três cores (BDPharmingen, San Diego, CA, USA). Os dados foram analisados usando o programa Cellquest (BD-Pharmingen, San Diego, CA, USA). As células foram analisadas inicialmente quanto ao tamanho (FSC) e a granulosidade (SSC) e os resultados expressos como a média de intensidade de fluorescência (MIF). 


\subsection{Estimulação de BMMo com a Nattectina}

BMMo foram distribuídos em placas de cultura na concentração de $2 \times 10^{6}$ células $/ \mathrm{ml}$ e estimulados $24 \mathrm{~h}$ com Nattectina na concentração de $10 \mu \mathrm{g} / \mathrm{ml}$. Após a estimulação, o sobrenadante celular foi coletado e estocado a $-20{ }^{\circ} \mathrm{C}$ para dosagens de MMPs, e as células foram processadas para análise por citometria de fluxo. Para avaliarmos se a função da Nattectina está relacionada à sua capacidade de ligação ao carboidrato, a Nattectina foi previamente incubada por $1 \mathrm{~h}$ na presença de D-galactose a $10 \mathrm{nM}$.

Após o cultivo, as células foram lavadas, desaderidas com $4 \mathrm{~mL}$ de Accutase (MP Biomedicals, LLC) durante 30 a 50 min a $37{ }^{\circ} \mathrm{C}$ e processadas para marcação com anticorpos conjugados a fluorocromos para análise por citometria de fluxo. Primeiramente, as células foram mantidas a $4{ }^{\circ} \mathrm{C}$ por $20 \mathrm{~min}$ com $2 \mu \mathrm{l}$ de soro normal de camundongo e então $100 \mu \mathrm{l}$ de células foram incubadas por 30 min a $4{ }^{\circ} \mathrm{C}$ no escuro com anticorpos específicos marcados com distintos fluorocromos: PE ou PE-Cy5 anti-mouse CD11b, anticorpo de rato não marcado anti-mouse F4/80 like R seguido da incubação com segundo anticorpo FITC anti-rat IgG, PE anti-mouse CD40, PE anti-mouse CD80, PE anti-mouse CD86, PE anti-mouse MHC de classe II, PE-Cy5 anti-mouse CCR7, anticorpos de rato não marcado anti-mouse TLR2 e anti-mouse CD16 (FcyRIII), anti-mouse CD44 biotinilado seguido da incubação com streptavidin-PE. Após nova lavagem e centrifugação, as células foram ressuspensas em $1 \mathrm{ml}$ de formaldeído $3 \%$ e mantidas a $4^{\circ} \mathrm{C}$ até o momento da aquisição dos dados (10.000 eventos) no citômetro de fluxo FACSCalibur de três cores (BD-Pharmingen, San Diego, CA, USA). Os dados foram analisados usando o programa Cellquest (BD-Pharmingen, San Diego, CA, USA). As células foram analisadas inicialmente quanto ao tamanho (FSC) e a granulosidade (SSC) e os resultados expressos como MIF.

4.5 Avaliação da Ativação de Vias de Sinalização em BMMo Estimulados com Nattectina in vitro

BMMo foram distribuídos em placas de cultura na concentração de 2 × $10^{6}$ células $/ \mathrm{ml}$ e tratados por $1 \mathrm{~h}$ a $37{ }^{\circ} \mathrm{C}$ com $1 \mu \mathrm{l}$ de DMSO, PD 98059 a $2 \mu \mathrm{M}$ que previne a ativação de ERK1/2, SB 203580 a 0,05 $\mu \mathrm{M}$ que inibe a ativação de MAPK p38 ou Wortmannin a 0,005 $\mu \mathrm{M}$, um inibidor de PI3K. Após incubação por $1 \mathrm{~h}$, os macrófagos foram lavados e incubados por mais $24 \mathrm{~h}$ com $10 \mu \mathrm{g} / \mathrm{ml}$ de Nattectina. Após a estimulação, os sobrenadantes foram 
coletados e estocados a $-20{ }^{\circ} \mathrm{C}$ para dosagens e as células processadas para marcação com anticorpos específicos conjugados com distintos fluorocromos e análise por citometria de fluxo.

\subsection{Efeito da Nattectina na Capacidade Endocítica de BMMo in vitro}

BMMo previamente tratados ou não com inibidores de vias de sinalização (PD 98059 a $2 \mu \mathrm{M}$, SB 203580 a $0,05 \mu \mathrm{M}$ ou Wortmannin a $0,005 \mu \mathrm{M}$ ) foram estimulados com $10 \mu \mathrm{g} / \mathrm{ml}$ de Nattectina previamente incubada ou não com D-galactose a $10 \mathrm{nM}$ por $24 \mathrm{~h}$, e em seguida, incubados com $0,1 \mathrm{mg} / \mathrm{ml}$ de partículas sólidas de $0,431-\mu \mathrm{m}$ de dextran acoplado com FITC (Sigma-Aldrich, St Louis, MO, USA) a $37{ }^{\circ} \mathrm{C}$ por $30 \mathrm{~min}$ (fagocitose dependente de energia) em placas de cultura celular. Após a incubação, as placas foram lavadas 3 vezes com PBS gelado contendo $1 \%$ FCS e $0,01 \% \mathrm{NaN}_{3}$ para a remoção das partículas livres. Em seguida, as suspensões celulares foram centrifugadas a 544 g por $10 \mathrm{~min}$, fixadas com formaldeído a $3 \%$ e analisadas por citometria de fluxo quanto a expressão de moléculas de dextran-FITC (FACSCalibur de 3 cores, BD-Pharmingen, San Diego, CA, USA). Os dados foram analisados usando o programa Cellquest (BD-Pharmingen, San Diego, CA, USA).

\subsection{Efeito da Nattectina na Expressão de Integrinas em BMMo in vitro}

Para avaliar a expressão de integrinas em cultura de BMMo, células cultivadas na presença de $10 \mu \mathrm{g} / \mathrm{ml}$ de Nattectina por $24 \mathrm{~h}$ foram incubadas por $30 \mathrm{~min}$ a $4{ }^{\circ} \mathrm{C}$ no escuro com anticorpos específicos marcados com distintos fluorocromos (PE, FITC, PECy5): anti- $\beta 1$ (CD29), anti- $\beta 2$ (CD18), anti- $\alpha 1$ (CD49a), anti- $\alpha 2$ (CD49b), anti- $\alpha 5$ (CD49e) (Invitrogen Co., CA, USA). Após nova lavagem e centrifugação, as células foram ressuspensas em formaldeído $3 \%$ e mantidas a $4{ }^{\circ} \mathrm{C}$ até o momento da aquisição dos dados (10.000 eventos) no citômetro de fluxo FACSCalibur de três cores cores (BD-Pharmingen, San Diego, CA, USA).

4.8 Avaliação do Papel da Nattectina na Indução da Resposta Imune Inata

Para avaliar o papel da Nattectina na indução da resposta imune inata, foi utilizado o protocolo descrito por Lima et al. (2003), no qual camundongos foram injetados por via 
intraperitoneal com $500 \mu \mathrm{l}$ de salina $0,9 \%$ estéril ou $500 \mu \mathrm{l}$ de Nattectina a $20 \mu \mathrm{g} / \mathrm{ml}$ diluída em salina. Em diferentes períodos de tempo (6 e 24 h) após a administração da toxina, os animais foram mortos e a cavidade peritoneal lavada com $5 \mathrm{ml}$ de tampão PBS + EDTA 10 mM para obtenção da suspensão celular. Em seguida, o material coletado foi centrifugado a $378 \mathrm{~g}$ a $4{ }^{\circ} \mathrm{C}$ por $10 \mathrm{~min}$, o sobrenadante separado e congelado a $-20{ }^{\circ} \mathrm{C}$ para a dosagem de citocinas, enquanto o botão celular foi ressuspenso em PBS 0,1\% BSA para análise celular. A contagem de leucócitos totais foi efetuada em câmara de Neubauer na diluição de 1:10 em solução Turk ( $0,2 \%$ azul de cristal de violeta em $30 \%$ de ácido acético). Para a contagem diferencial, alíquotas contendo $100 \mu \mathrm{l}$ das suspensões celulares foram aplicadas em lâminas de vidro, submetidas a centrifugação em centrífuga Cytospin e coradas com Hema-3 para a contagem de neutrófilos e macrófagos em microscópio óptico Nikon ECLIPSE E200 com objetiva de 40x, de acordo com os aspectos morfológicos como descrito em Cook et al. (2003). As micrografias representativas de cada grupo foram obtidas por meio do microscópio óptico Carl Zeiss Axio Imager A1 acoplado a máquina fotográfica Zeiss AxioCam IcC1 em objetiva de 40x.

\subsection{Determinação dos Níveis de Citocinas e MMPs por ELISA}

Para a dosagem de citocinas e MMPs, placas de 96 poços (Costar) foram sensibilizadas durante $1 \mathrm{~h}$ a $37{ }^{\circ} \mathrm{C}$ com $100 \mu \mathrm{l}$ de anticorpos monoclonais específicos para cada citocina e MMP: anti-IL-1 $\beta$, anti-IL-6, anti-MMP-2 e anti-MMP-9 diluídos em tampão carbonato 0,1 M pH 9,6; e anti-IL-10, anti-IL-12p70 e anti-TNF- $\alpha$ diluídos em tampão fosfato 0,2 M pH 6,5. Em seguida, as placas foram lavadas com PBS $+0,05 \%$ Tween e incubadas com $200 \mu \mathrm{l}$ de PBS Tween $+10 \%$ BSA em cada poço durante $18 \mathrm{~h}$ a $37^{\circ} \mathrm{C}$. Após novo ciclo de lavagens, $100 \mu \mathrm{l}$ das amostras e dos padrões das citocinas e das MMPs recombinantes foram adicionados e as placas foram incubados durante $3 \mathrm{~h} \mathrm{a} 4{ }^{\circ} \mathrm{C}$. Posteriormente, as placas foram novamente lavadas e, a seguir, foram acrescentados $100 \mu \mathrm{l}$ de anticorpos de detecção biotinilados específicos para cada citocina e MMPs (IL-1 $\beta$, IL-6, IL-10, IL-12p70, TNF- $\alpha$, MMP-2 e MMP-9). Após serem mantidos por $1 \mathrm{~h}$ em temperatura ambiente e em seguida lavadas, as placas receberam $100 \mu \mathrm{l}$ de estreptoavidina-peroxidase em cada poço. Finalmente, após $1 \mathrm{~h}$ em temperatura ambiente, as reações foram reveladas pela adição de $100 \mu \mathrm{l}$ de tetrametilbenzidina (TMB) e interrompidas pela adição de $50 \mu \mathrm{l}$ de ácido cítrico $0,2 \mathrm{M}$ em cada um dos poços. A leitura da reação foi realizada a $450 \mathrm{~nm}$ em espectrofotômetro Victor 3 
(Multilabel Counter, PerkinElmer). As concentrações das amostras foram calculadas a partir das curvas-padrão obtidas com as citocinas e MMPs recombinantes. O limite de detecção foi de 15,6 pg/ml para IL-1 $\beta$, IL-10 e IL-12p70; de 7,8 pg/ml para IL-6 e TNF- $\alpha$; de 1,5 ng/ml para MMP-2; e de 1,25 ng/ml para MMP-9.

\subsection{Avaliação da Atividade das MMPs por Zimografia}

A atividade proteolítica de MMP-2 e MMP-9 no sobrenadante da cultura de BMMo foi analisada por zimografia utilizando gelatina como substrato. Para isso, alíquotas de $10 \mu \mathrm{l}$ do sobrenadante de BMMo estimulados ou não com Nattectina foram diluídas em um mesmo volume de tampão de amostra e, em seguida, as amostras não-fervidas foram submetidas a eletroforese $(180 \mathrm{~V}, 20 \mathrm{~mA})$ em gel de poliacrilamida $12 \%$ contendo SDS e $5 \mathrm{mg} / \mathrm{ml}$ de gelatina durante $1 \mathrm{~h}$ e $30 \mathrm{~min}$. Em seguida, o gel foi incubado por $30 \mathrm{~min}$ a $37^{\circ} \mathrm{C} \mathrm{em} 100 \mathrm{ml}$ de Triton X-100 2,5\% e, após lavagem com água destilada, foi acrescentado $100 \mathrm{ml}$ de tampão de incubação para zimografia. Após $18 \mathrm{~h}$ de incubação a $37{ }^{\circ} \mathrm{C}$, o gel foi corado com Coomassie Blue e as MMPs foram detectadas como bandas claras visualizadas no gel corado e comparadas com as bandas geradas pelas MMPs recombinantes (apresentando-se com 80 a $105 \mathrm{kDa}$, sob condições não-redutoras).

\subsection{Análise Estatística}

Todos os resultados foram apresentados como a média aritmética acrescida do desvio padrão. As diferenças estatísticas entre os grupos experimentais foram detectadas após análise de variância (One-Way ANOVA) seguida do teste paramétrico Bonferroni. Valores de $p<$ 0,05 foram considerados significativos. O programa SPSS (Release 8.0, Standard Version, 1997) foi empregado. 


\section{RESULTADOS}

5.1 Obtenção da toxina Nattectina do veneno de T. nattereri

Para obtenção da Nattectina, inicialmente amostras contendo $10 \mathrm{mg}$ de veneno de $T$. nattereri foram aplicadas em coluna semi-preparativa $\mathrm{C}_{18}$ fase reversa equilibrada em tampão $\mathrm{H}_{2} \mathrm{O}$ 0,1\% TFA (tampão A) e eluídas com gradiente de 10 a $80 \%$ de ACN sob fluxo constante de $5 \mathrm{ml} / \mathrm{min}$ de acordo com metodologia padronizada por nosso laboratório. O resultado do fracionamento encontra-se na Figura $\mathbf{2 A}$ : foram identificadas 3 frações, denominadas de 1 a 3 , que foram submetidas ao sistema MALDI-TOF para análise das massas moleculares e determinação de pureza. Com base no trabalho de Magalhães et al. (2006) que mostra que a Nattectina apresenta uma massa molecular de $15 \mathrm{kDa}$ e ponto isoelétrico em torno de 9,73, determinamos que a toxina estava contida na fração 1.

Para isolar a Nattectina, a fração 1 foi aplicada em coluna analítica $\mathrm{C}_{8}$ fase reversa equilibrada no mesmo tampão A. O material retido na coluna foi eluído com um gradiente de 15 a 70\% de ACN sob fluxo constante de $1 \mathrm{ml} / \mathrm{min}$ e a fração de interesse foi quantificada pela medida da absorbância a $280 \mathrm{~nm}$. Posteriormente, a pureza da fração obtida após as duas cromatografias seqüenciais foi confirmada pelo aparecimento de uma banda única em torno de $15 \mathrm{kDa}$ em gel de poliacrilamida a 15\% na presença de SDS (SDS-PAGE, Figura $2 \boldsymbol{B}$ ) corado com nitrato de prata, e irrefutavelmente, pela determinação da massa de $15.064,472$ Da no espectrômetro de massa (Figura $2 C$ ). 

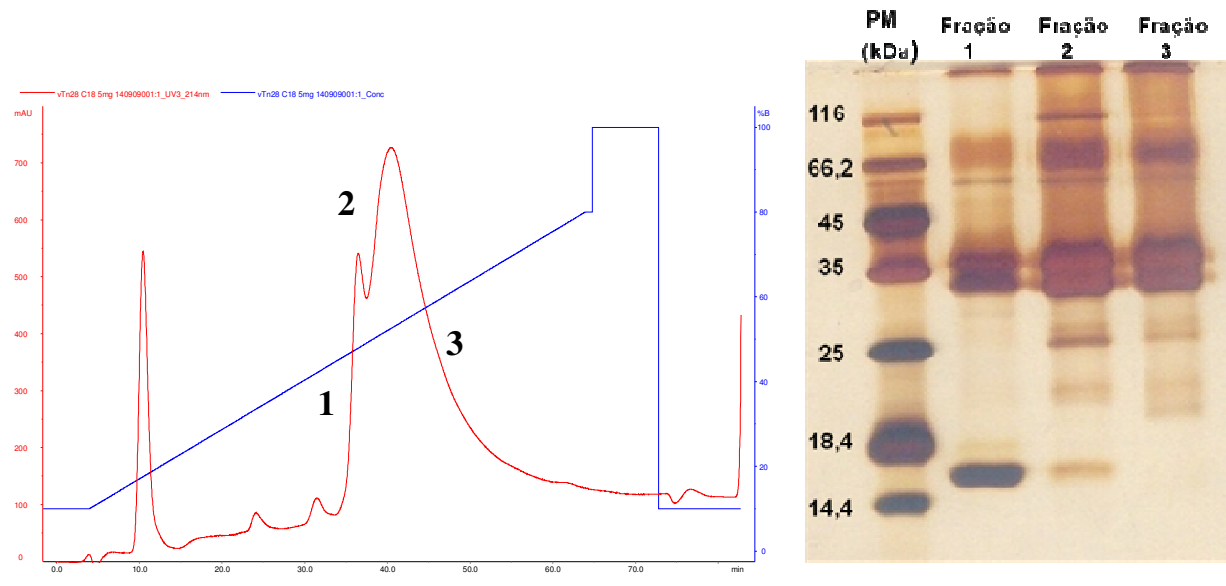

(A)
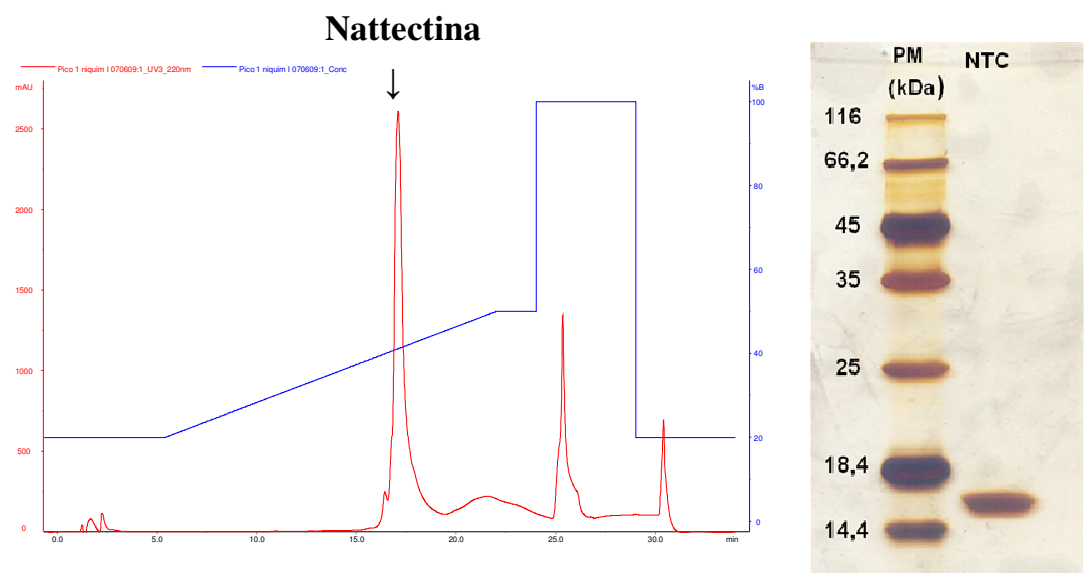

(B)

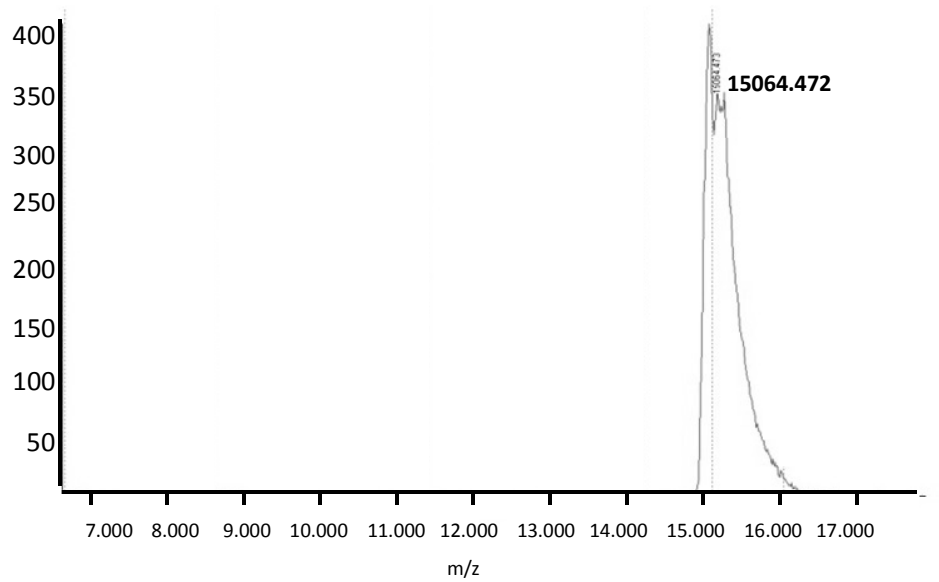

(C)

Figura 2- Obtenção da Nattectina do veneno de T. nattereri. Amostras de $10 \mathrm{mg}$ do veneno de T. nattereri diluída em tampão A $\left(\mathrm{H}_{2} \mathrm{O} 0,1 \%\right.$ TFA) foram aplicadas em coluna semi-preparativa $\mathrm{C}_{18}$ fase reversa e eluídas com gradiente de tampão B (90\% ACN $10 \% \mathrm{H}_{2} \mathrm{O} 0,1 \%$ TFA) de 10 a $80 \%$ sob fluxo constante de $5,0 \mathrm{ml} / \mathrm{min}(\boldsymbol{A})$. A fração 1 foi recromatografada em uma coluna analítica $\mathrm{C}_{8}$ de fase reversa e as proteínas foram eluídas em gradiente de tampão B de 15 a $70 \%$ sob fluxo constante de $1,0 \mathrm{ml} / \mathrm{min}(\boldsymbol{B})$. A fração obtida na segunda cromatografia correspondente a Nattectina foi avaliada por espectrometria de massa revelando uma massa de 15.064, 472 Da $(\boldsymbol{C})$. 
5.2 Caracterização Fenotípica de Macrófagos Derivados de Medula Óssea

A descoberta do fator de crescimento específico para a diferenciação de macrófagos M-CSF, também conhecido como CSF-1, associada as técnicas de transfecção de genes em tipos imortalizados de células vem possibilitando a geração fácil de produtos destinados a diferenciação de células de medula óssea, sem a necessidade de uso de moléculas recombinantes caras ou de células teciduais como as da cavidade peritoneal ou de outros órgãos. Com isto, tendo acesso às células L929 produtoras de M-CSF cedidas pelo Dr. Bernard Ryffel do Instituto Transgenose (Orleans, França) foi possível no laboratório a produção de sobrenadantes ricos em fatores de crescimento para macrófagos. Macrófagos são identificados pela expressão concomitante das moléculas CD11b e F4/80 e a diferenciação entre subtipos individuais é ainda possível pela identificação conjunta de outros marcadores da linhagem monocítica como Ly6C e CD14. Os resultados apresentados na Figura 3 mostram que após 7 dias de cultura na presença do sobrenadante contendo M-CSF, as células de medula óssea diferenciaram-se em uma população positiva para CD11b com expressão intermediária e alta de F4/80 (Fig. 3A), alta expressão de CD14 (Fig. 3B) e baixa expressão de Ly6C (Fig. 3C).

Recentes estudos têm demonstrado que macrófagos murinos com o fenótipo $\mathrm{CD} 11 \mathrm{~b}^{\text {pos }} \mathrm{F} 4 / 80^{\text {pos }} \mathrm{Ly}^{\mathrm{h}} \mathrm{C}^{\text {high }}$ e que expressam dectina-1 e o receptor de manose usam arginase-1 e/ou iNOS para regular a função de linfócitos T, induzindo morte ou inibindo a proliferação, apresentando, portanto, um papel supressor (HUANG et al., 2006; MARHABA et al., 2007; MAKARENKOVA et al., 2006). Dessa forma, a utilização do sobrenadante de células L929 mostrou-se adequado para a diferenciação de macrófagos com fenótipo ativador, caracterizado como CD $11 b^{\text {pos }} \mathrm{F} 4 / 80^{\text {high/int }} \mathrm{CD} 14^{\text {high }} \mathrm{Ly} 6 \mathrm{C}^{\text {low }}$. 

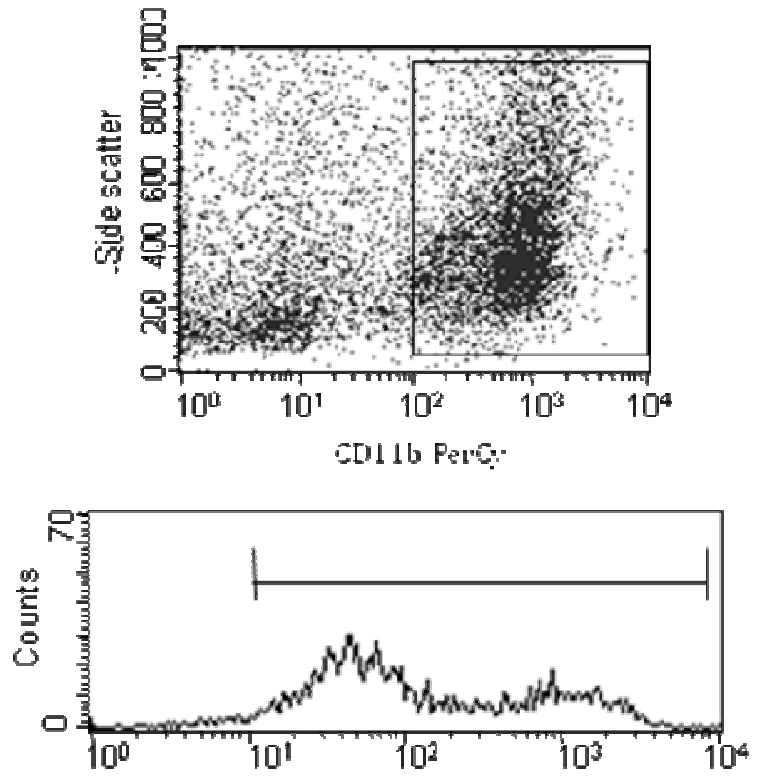

(A)

FA Ging FE

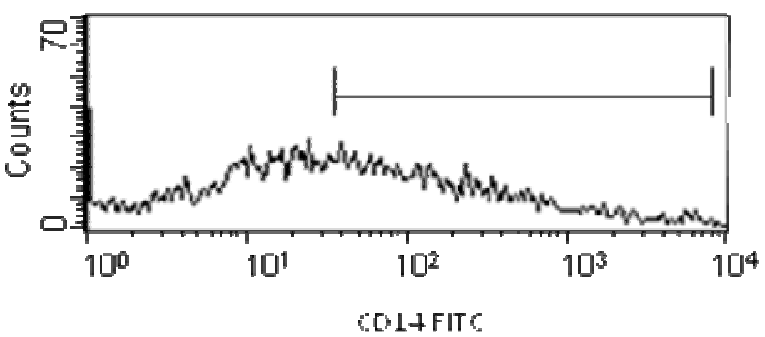

(B)

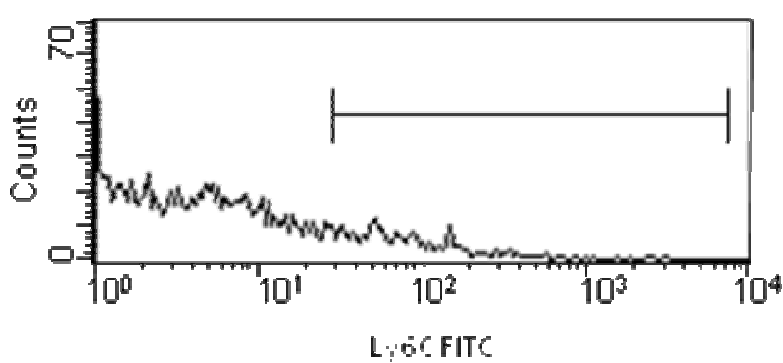

(C)

Figura 3- Obtenção de macrófagos de medula óssea femoral pelo uso de sobrenadante de células L929 produtoras de M-CSF. Células da medula óssea femoral de camundongos BALB/c fêmeas foram cultivadas por 7 dias na presença do sobrenadante de cultura de células L929 transfectadas com o gene de M-CSF. Após o cultivo, as células $\mathrm{CD}_{11} \mathrm{~b}^{\mathrm{pos}}$ foram marcadas com distintos anticorpos conjugados com fluorocromos FITC, PE ou PE-Cy5 e analisadas quanto a expressão de F4/80 (A), CD14 $(\boldsymbol{B})$ e Ly6C $(\boldsymbol{C})$ em FACSCalibur de três cores (BD-Pharmingen, San Diego, CA, USA). 
5.3 Avaliação da Ação da Nattectina e a Influência da Ligação a Açúcares na Ativação de Macrófagos

Inicialmente, avaliamos em células da cultura de medula óssea obtido com o sobrenadante das células L929 produtoras de M-CSF, a capacidade da Nattectina de ativar a população de macrófagos $\mathrm{CD} 11 \mathrm{~b}^{\mathrm{pos}} \mathrm{F} 4 / 80^{\mathrm{pos}} \mathrm{CD} 14^{\mathrm{pos}} \mathrm{Ly} 6 \mathrm{C}^{\text {low }}$. Avaliamos a expressão de moléculas co-estimuladoras e moléculas envolvidas na fagocitose, tais como FcyRIII e TLR2. Em seguida, avaliamos a dependência da ligação da Nattectina ao carboidrato na indução da expressão destas moléculas em macrófagos, uma vez que é conhecida a afinidade da Nattectina por estruturas terminadas em galactose ou glicanas terminadas em $\mathrm{N}$ acetilgalactosamina (GalNAc).

Para isto, macrófagos $\mathrm{CD} 11 \mathrm{~b}^{\mathrm{pos}} \mathrm{F} 4 / 80^{\mathrm{pos}} \mathrm{CD} 14^{\mathrm{pos}} \mathrm{Ly} 6 \mathrm{C}^{\text {low }}$ foram estimulados por $24 \mathrm{~h}$ com $10 \mu \mathrm{g} / \mathrm{ml}$ de Nattectina previamente tratada ou não com D-galactose por $1 \mathrm{~h}$ a $37{ }^{\circ} \mathrm{C}$. De acordo com a Figura $\mathbf{4 A}$, podemos observar que a Nattectina foi capaz de induzir aumento na expressão das moléculas co-estimuladoras (CD40, CD80 e CD86) e de MHC de classe II nos macrófagos em comparação ao grupo controle, porém, o bloqueio do seu domínio CRD pela ligação prévia ao carboidrato não alterou a sua capacidade de induzir a expressão das moléculas CD80 ou CD86. De forma interessante, a Nattectina na presença de D-galactose acentuou a expressão de CD40, e ao contrário, induziu diminuição na expressão do MHC de classe II. Estes resultados indicam uma dependência positiva da ligação da Nattectina a estruturas glicosiladas expressas em macrófagos para a indução da expressão de MHC de classe II e negativa para CD40.

Receptores do tipo Toll-like (TLRs) e a formação de imuno-complexos e a subseqüente ligação aos receptores Fc $\gamma$ em macrófagos representam mediadores centrais da eliminação de patógenos. Quanto às moléculas FçRIII (CD16) e TLR2, podemos observar que a Nattectina tratada ou não com D-galactose não alterou a expressão desses receptores na superfície de macrófagos (Fig. 4B). Ademais, na Figura 5 observamos que a Nattectina induziu um aumento na expressão de CD44 (receptor de hialuronan) e este efeito não foi alterado pela incubação prévia com D-galactose, indicando que a expressão dessa molécula nos macrófagos $\mathrm{CD} 11 \mathrm{~b}^{\mathrm{pos}} \mathrm{F} 4 / 80^{\mathrm{pos}} \mathrm{CD} 14^{\mathrm{pos}} \mathrm{Ly} 6 \mathrm{C}^{\text {low }}$ é independente da ligação da Nattectina a estruturas glicosiladas expressas nestas células. 
(A)
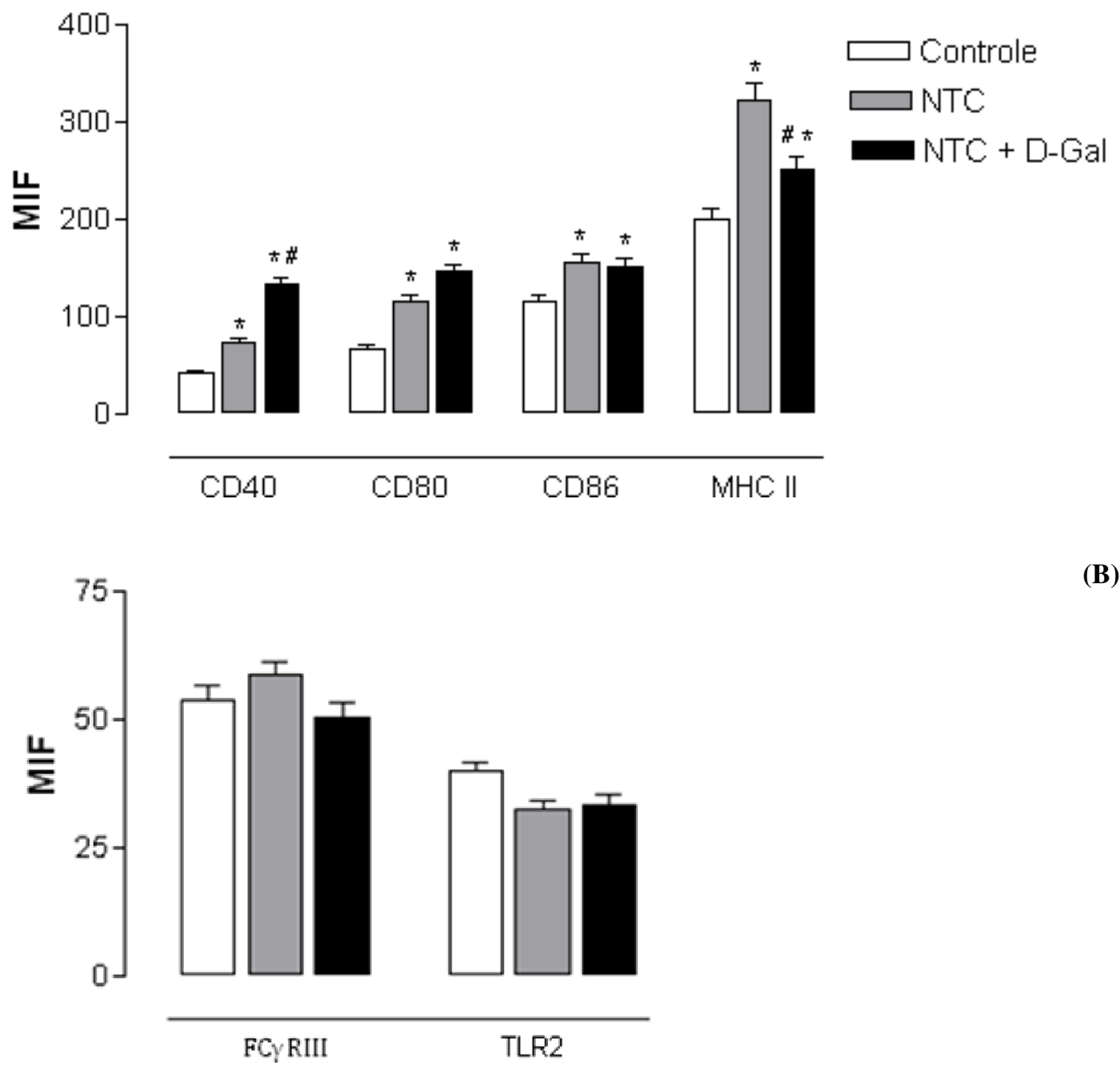

(B)

Figura 4- Influência da ligação da Nattectina a açúcares na ativação de BMMo. Macrófagos $\mathrm{F} 4 / 80^{\text {pos }} \mathrm{CD} 11 \mathrm{~b}^{\text {pos }}$ foram estimulados por $24 \mathrm{~h}$ com $10 \mu \mathrm{g} / \mathrm{ml}$ de Nattectina previamente incubada ou não com D-galactose a $10 \mathrm{nM}$. Em seguida, as células foram marcadas com os anticorpos monoclonais anti-CD40 PE, anti-CD80 PE, anti-CD86 PE, anti-MHC de classe II PE e analisados por citometria de fluxo. As barras representam a expressão de moléculas co-estimuladoras $(\boldsymbol{A})$ e de FcyRIII e TLR2 (B) nos macrófagos duplo-positivos $\left(\mathrm{F} 4 / 80^{\text {pos }} \mathrm{CD} 11 \mathrm{~b}^{\text {pos }}\right)$ em termos de MIF acrescida do desvio-padrão. ${ }^{*} p<0,05$ em relação ao controle e \# $p<0,05$ em relação a Nattectina. 


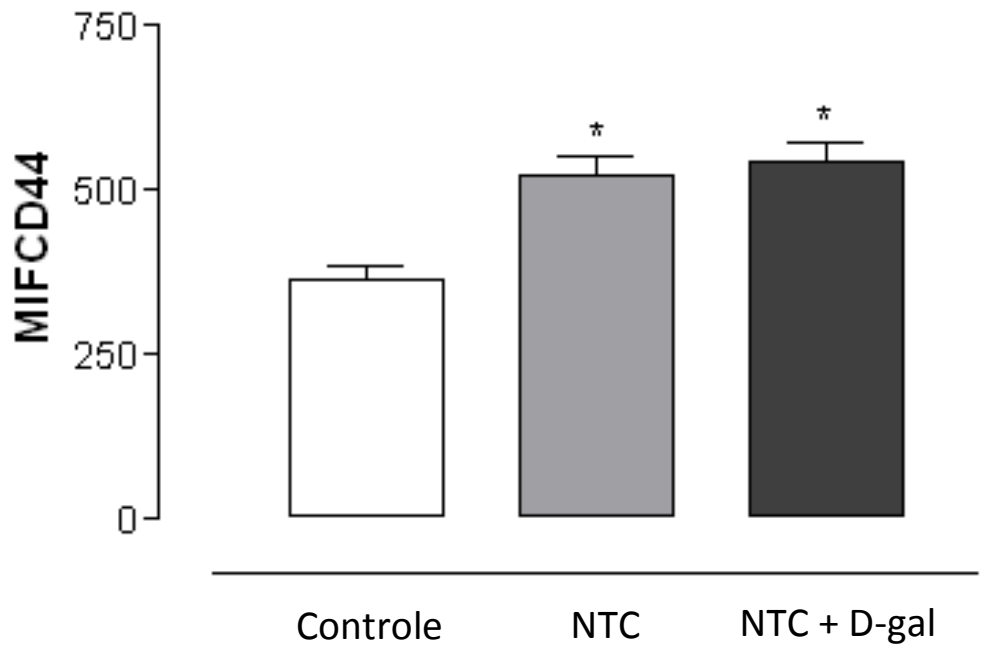

Figura 5- A ligação da Nattectina a açúcares não altera a expressão de CD44 em BMMo. Macrófagos $\mathrm{F} 4 / 80^{\text {pos }} \mathrm{CD} 11 \mathrm{~b}^{\text {pos }}$ foram estimulados por $24 \mathrm{~h}$ com $10 \mu \mathrm{g} / \mathrm{ml}$ de Nattectina previamente incubada ou não com D-galactose a $10 \mathrm{nM}$. Em seguida, as células foram marcadas com o anticorpo monoclonal anti-CD44. As barras representam a expressão de CD44 nos macrófagos duplo-positivos $\left(\mathrm{F} 4 / 80^{\mathrm{pos}} \mathrm{CD} 11 \mathrm{~b}^{\mathrm{pos}}\right)$ em termos de MIF acrescida do desvio-padrão. ${ }^{*} p<0,05$ em relação ao controle. 
5.4 Nattectina Induz Aumento na Expressão de Integrinas em Macrófagos

Integrinas são glicoproteínas transmembranosas que funcionam como receptores de adesão em interações célula-matriz extracelular, ligando proteínas da matriz ao citoesqueleto celular, regulando a migração celular (GU e TANIGUCHI, 2004).

Na Figura 6A, podemos observar que a Nattectina induziu aumento na expressão das integrinas CD49e e principalmente de CD49a, sendo esta última parcialmente modulada após a estimulação dos macrófagos $\mathrm{CD} 11 \mathrm{~b}^{\text {pos }} \mathrm{F} 4 / 80^{\text {pos }} \mathrm{CD} 14^{\text {pos }}$ Ly6C ${ }^{\text {low }}$ com a Nattectina previamente tratada com D-galactose a $10 \mathrm{nM}$. Por outro lado, o tratamento prévio da Nattectina com o seu ligante específico levou ao aumento na expressão das integrina CD29 e CD49b, o que não foi verificado na cultura de macrófagos estimulados apenas com a Nattectina. Em relação à integrina CD18, não houve diferença estatística em relação ao controle na cultura de macrófagos estimulada com a Nattectina tratada ou não com a galactose. Estes resultados sugerem que a ligação da Nattectina a estruturas glicosiladas expressas em macrófagos induz sua ativação, favorecendo aumento na expressão de moléculas de aderência como as integrinas CD49e $(\alpha 5)$ e principalmente de CD49a $(\alpha 1)$.

Considerando que os macrófagos são células capazes de migrar para sítios de infecção ou lesão e que tal capacidade é dependente não só de integrinas, mas também da ação de MMPs, avaliamos a capacidade da Nattecina de induzir a produção de MMP-2 e MMP-9 pelos macrófagos. Nas Figuras $\mathbf{6} \boldsymbol{B}$ e $\boldsymbol{6} \boldsymbol{C}$ podemos verificar a presença de MMP-2 e MMP-9 no sobrenadante da cultura dos macrófagos $\mathrm{CD} 11 \mathrm{~b}^{\text {pos }} \mathrm{F} 4 / 80^{\mathrm{pos}} \mathrm{CD} 14^{\text {pos }} \mathrm{Ly} 6 \mathrm{C}^{\text {low }}$ após 2 h de cultivo com a Nattectina. Verificou-se ainda uma dependência positiva da ligação da Nattectina ao seu açúcar específico na produção de MMP-9, porém este efeito não foi observado em relação a MMP-2. 
(A)
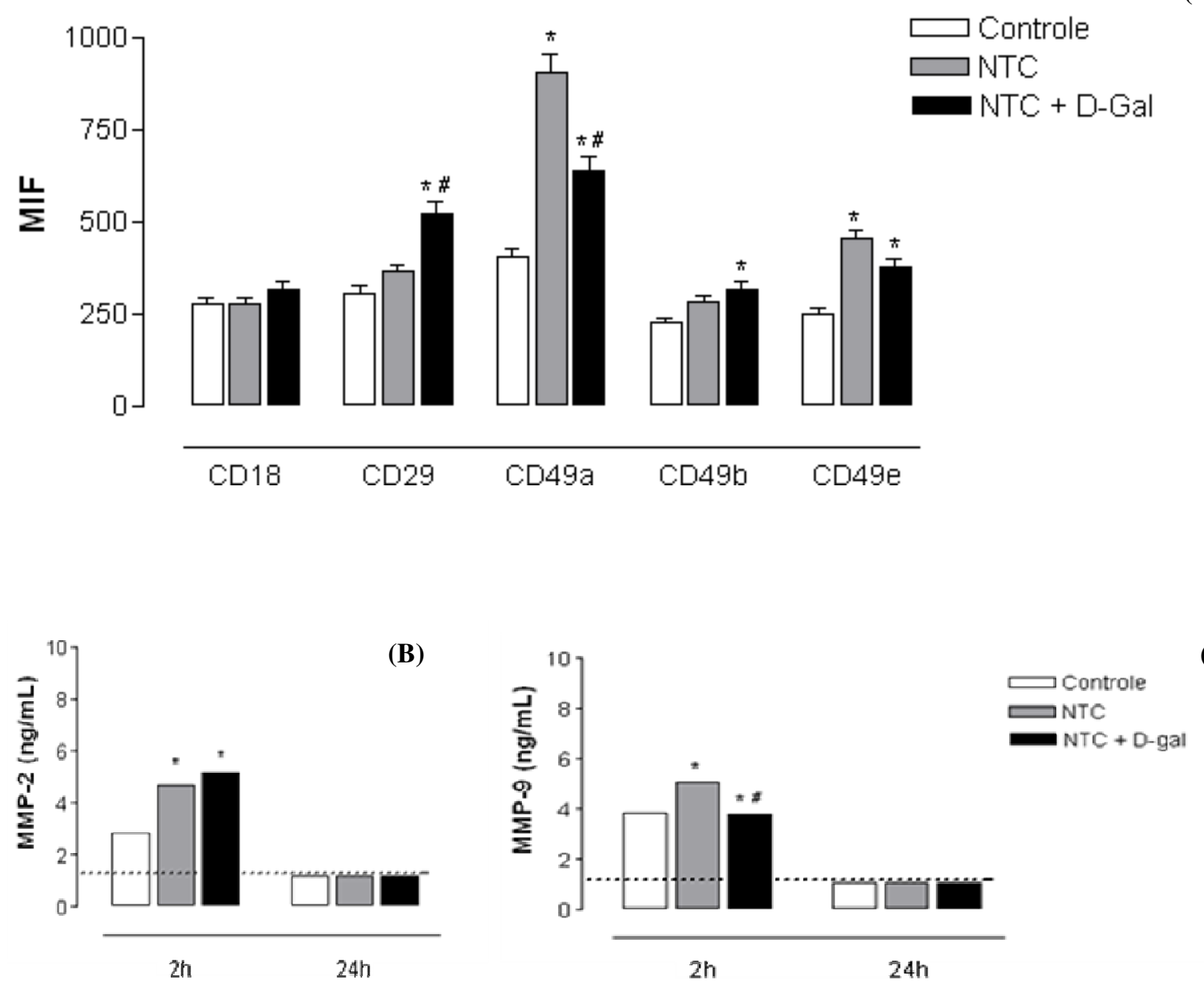

(C)

Figura 6- Nattectina induz a expressão de integrinas e a produção de MMPs pelas BMMo. Macrófagos $\mathrm{F} 4 / 80^{\text {pos }} \mathrm{CD} 11 \mathrm{~b}^{\text {pos }}$ foram estimulados por $24 \mathrm{~h}$ com $10 \mu \mathrm{g} / \mathrm{ml}$ de Nattectina previamente incubado ou não com D-galactose a $10 \mathrm{nM}$. As células foram marcadas com os anticorpos monoclonais anti-CD18 PE, anti-CD29 PE, anti-CD49a FITC, anti-CD49b FITC, anti-CD49e e analisadas por citometria de fluxo. As barras representam a expressão de integrinas $(\boldsymbol{A})$ em BMMo $\left(\mathrm{F} 4 / 80^{\mathrm{pos}} \mathrm{CD} 11 \mathrm{~b}^{\mathrm{pos}}\right)$ em termos de MIF acrescida do desvio-padrão. O sobrenadante da cultura foi analisado por ELISA quanto a presença de MMP-2 $(\boldsymbol{B})$ e MMP-9 $(\boldsymbol{C})$. A linha tracejada representa o limite de detecção do método para MMP-2 $(1,5 \mathrm{ng} / \mathrm{ml})$ e MMP-9 $(1,25 \mathrm{ng} / \mathrm{ml}) .{ }^{*} p<0,05$ em relação ao controle e \# $p<0,05 \mathrm{em}$ relação a Nattectina. 
5.5 A Ativação de Macrófagos Induzida pela Nattectina é Mediada por MAPK p38 e PI3K

Em monócitos e macrófagos, vários estímulos inflamatórios podem desencadear a fosforilação de MAP quinases (RAO, 2001), as quais exercem importante papel na regulação da função efetora dessas células inflamatórias. Nosso próximo passo foi investigar o envolvimento de diferentes vias de transdução de sinal dependentes de MAPK na modulação da ativação de macrófagos $\mathrm{CD} 11 \mathrm{~b}^{\mathrm{pos}} \mathrm{F} 4 / 80^{\mathrm{pos}} \mathrm{CD} 14^{\text {pos }} \mathrm{Ly} 6 \mathrm{C}^{\text {low }}$ induzida pela Nattectina.

Os resultados na Figura 7 mostram que a estimulação com a Nattectina foi capaz de induzir um grande aumento na expressão das moléculas co-estimuladoras, as quais não foram alteradas pelo tratamento com um inibidor das quinases MEK1 e MEK2 responsáveis pela fosforilação de ERK1/2 (PD98059 a $2 \mu \mathrm{M}$ ). Já o tratamento com o inibidor farmacológico da MAPK p38 (SB203580 a 0,05 $\mu \mathrm{M}$ ) conseguiu inibir a indução da expressão de CD40 em aproximadamente $23 \%$, de CD80 em 19\%, e de CD86 em $21 \%$.

Outra via de transdução de sinal analisada foi a dependente de PI3 quinase (PI3K), e neste caso também verificamos que o tratamento com o inibidor Wortmannin a 0,005 $\mu \mathrm{M}$ conseguiu inibir em torno de $36 \%$ a indução da expressão de CD40, de $31 \%$ a expressão de CD80 e 26\% a expressão de CD86. Estes resultados mostram que a regulação da expressão de moléculas co-estimuladoras pela Nattectina é mediada positivamente pelas vias de sinalização MAPK p38 e PI3K. 

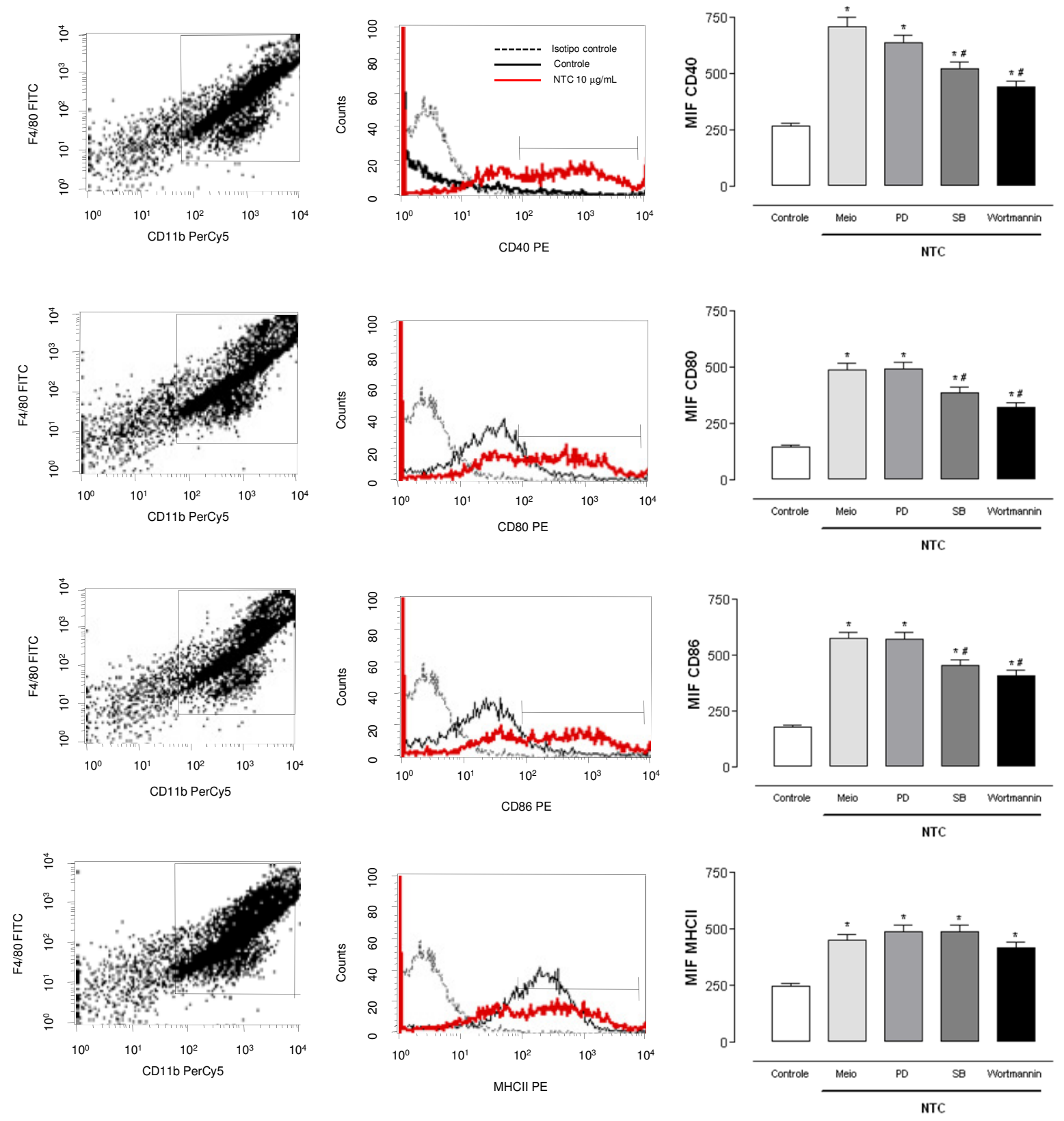

Figura 7- Avaliação do papel da ativação de MAPKs na modulação de BMMo induzida pela Nattectina. BMMo foram previamente incubados com inibidores farmacológicos específicos como PD98059 a 2 $\mu \mathrm{M}$, que previne a ativação de ERK1/2; SB203580 a $0,05 \mu \mathrm{M}$ que inibe a ativação de MAPK ou Wortmannin a $0,005 \mu \mathrm{M}$, inibidor de PI3K por $1 \mathrm{~h}$ a $37^{\circ} \mathrm{C}$ e, em seguida, estimulados com $10 \mu \mathrm{g} / \mathrm{ml}$ de Nattectina por $24 \mathrm{~h}$. Em seguida as células foram marcadas com os anticorpos monoclonais antiCD40 PE, anti-CD80 PE, anti-CD86 PE e anti-MHC de classe II PE e analisados por citometria de fluxo. As barras representam a expressão de moléculas co-estimuladoras em BMMo $\left(\mathrm{F} 4 / 80^{\mathrm{pos}} \mathrm{CD} 11 \mathrm{~b}^{\mathrm{pos}}\right)$ em termos de MIF acrescida do desvio-padrão. ${ }^{*} p<0,05$ em relação ao controle e $\# p<0,05$ em relação a Nattectina. 
5.6 Nattectina Induz Síntese de Metaloproteinases Dependente de ERK1/2

Para a progressão celular pela matriz extracelular intersticial, é necessária uma série coordenada de etapas que incluem a adesão/liberação e a degradação focal da matriz. MMP-2 e MMP-9 são consideradas responsáveis pela degradação de laminina e colágeno tipo IV, este último o maior constituinte da membrana basal endotelial (PARKS; WILSON; LÓPEZBOADO, 2004). A expressão de MMPs pode ser analisada através de uma técnica denominada zimografia, que identifica a atividade proteolítica das MMPs por meio da degradação do substrato de sua preferência. Vários substratos, tais como gelatina, caseína e colágeno podem ser utilizados para detectar a atividade proteolítica das MMPs, e com esta técnica é possível determinar se estas se encontram sob a forma latente ou ativa (SNOEKVAN BEURDEN e VON DEN HOFF, 2005).

A zimografia em gelatina é utilizada principalmente para a detecção de gelatinases, tais como MMP-2 e MMP-9. Na Figura 8, podemos observar a presença de atividade gelatinolítica das formas latente e ativa da MMP-9 proveniente do sobrenadante de macrófagos estimulados com Nattectina por 24 h (linha 3), o que indica que a lectina induz a produção de ambas as formas de MMP-9 pelos macrófagos. Quando os macrófagos foram tratados com os diferentes inibidores de vias de sinalização e posteriormente estimulados com a Nattectina, observou-se uma diminuição da atividade proteolítica de ambas as formas de MMP-9 pelo inibidor PD98059 (linha 4). Por outro lado, este efeito não foi verificado após o tratamento dos macrófagos com SB203580 ou Wortmannin (dados não-mostrados), sugerindo que a produção de MMP-9 induzida pela Nattectina é dependente da via de sinalização mediada por ERK1/2. 


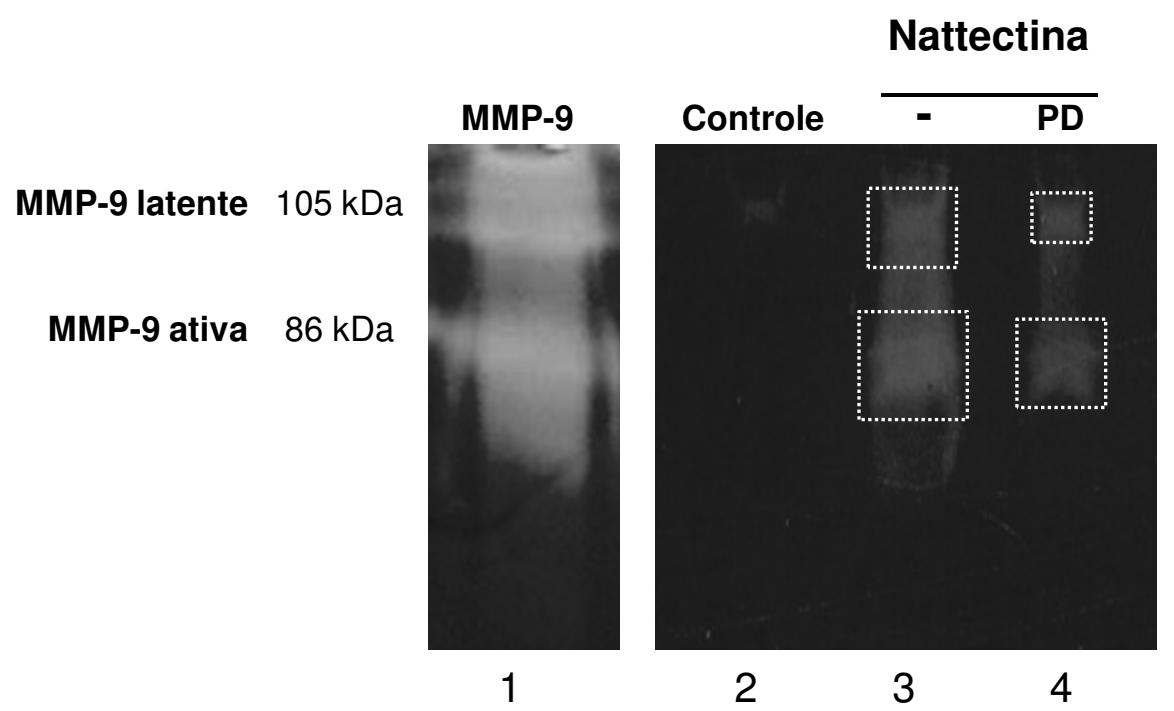

Figura 8- Avaliação da atividade das MMPs no sobrenadante de BMMo tratados com inibidores de vias de sinalização. BMMo foram previamente incubados com o inibidor PD98059 a $2 \mu \mathrm{M}$, que previne a ativação de ERK1/2, por $1 \mathrm{~h}$ a $37{ }^{\circ} \mathrm{C}$ e, em seguida, estimulados ou não com $10 \mu \mathrm{g} / \mathrm{ml}$ de Nattectina. Após $24 \mathrm{~h}$, os sobrenadantes foram coletados e alíquotas de $10 \mu \mathrm{l}$ foram submetidos a zimografia em gel de poliacrilamida $12 \%$ contendo gelatina. Em seguida, após incubação em Triton-X 100 a 2,5\% por $30 \mathrm{~min}$, o gel foi incubado por $18 \mathrm{~h}$ em tampão de desenvolvimento. Por fim, após a coloração com Azul de Coomassie, as bandas gelatinolíticas foram comparadas com MMP-9 murina recombinante. 
5.7 Influência da Ligação da Nattectina a Açúcares e de Vias de Sinalização na Capacidade Endocítica de Macrófagos

Dextran é um antígeno representativo de endocitose e, em menor escala, de pinocitose por células apresentadoras de antígenos primariamente via o receptor de manose (SALLUSTO et al., 1995). Cultura de macrófagos estimuladas com $10 \mu \mathrm{g} / \mathrm{ml}$ de Nattectina tratada previamente por $1 \mathrm{~h}$ a $37{ }^{\circ} \mathrm{C}$ com D-galactose a $10 \mathrm{nM}$ foram avaliadas quanto a capacidade endocítica. De acordo com a Figura $\mathbf{9 A}$, observa-se que a Nattectina induziu aumento na capacidade endocítica de partículas de dextran pelos macrófagos, e esse efeito foi revertido após o cultivo dos macrófagos estimulados com a Nattectina previamente tratada com a D-galactose, ou seja, os macrófagos ficam mais ávidos para endocitar partículas de dextran quando a Nattectina se liga a açúcares na sua superfície.

Em relação às vias de sinalização envolvidas na capacidade endocítica dos macrófagos, verifica-se que o tratamento prévio das células com o inibidor das quinases MEK1 e MEK2 responsáveis pela fosforilação de ERK1/2 (PD98059 a $2 \mu \mathrm{M}$ ) levou a uma diminuição da capacidade endocítica de macrófagos estimulados com a Nattectina (Fig. 9B), o que indica o envolvimento da sinalização mediada por ERK1/2 na endocitose de partículas de dextran pelos macrófagos ativados pela Nattectina. 


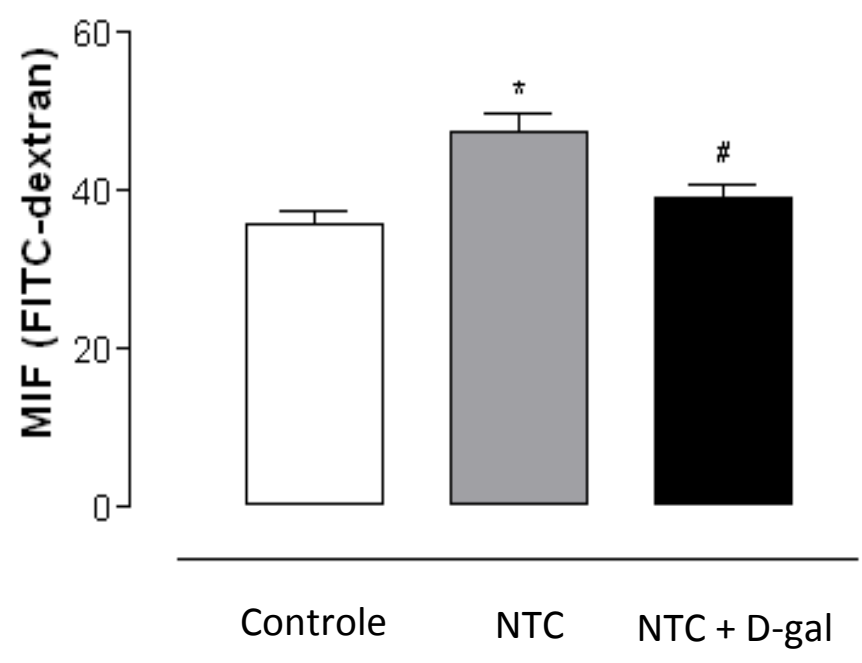

(A)

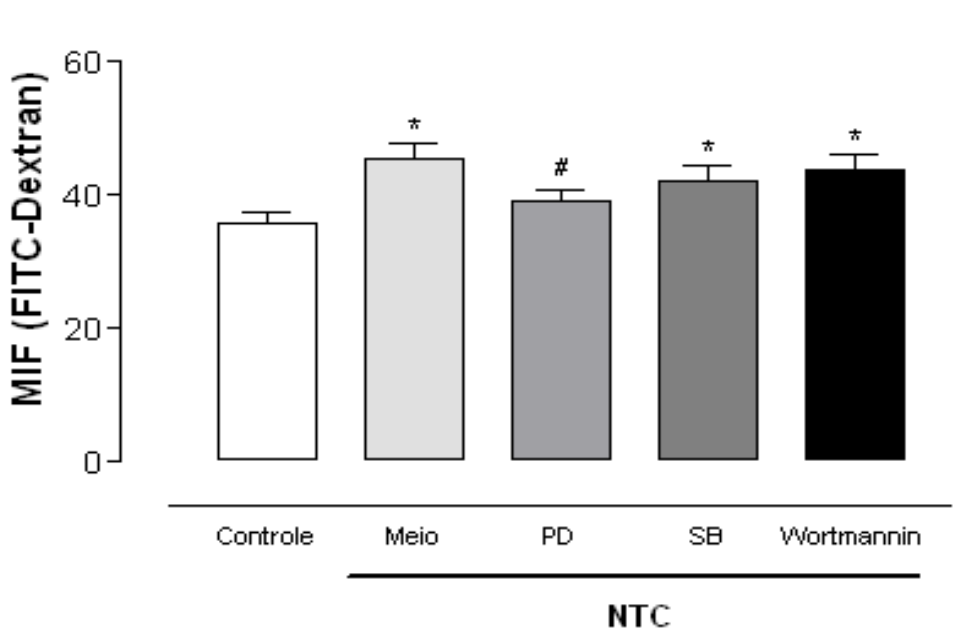

(B)

Figura 9- Influência da ligação da Nattectina a açúcares e da sinalização de MAPKs na capacidade endocítica de BMMo. Macrófagos F4/80 ${ }^{\mathrm{pos}} \mathrm{CD} 11 \mathrm{~b}^{\mathrm{pos}}$ foram estimulados por $24 \mathrm{~h}$ com $10 \mu \mathrm{g} / \mathrm{ml} \mathrm{de}$ Nattectina tratados previamente com D-galactose a $10 \mathrm{nM}(\boldsymbol{A})$ ou com os inibidores PD98059, SB203580 e Wortmannin por $1 \mathrm{~h}$ a $37{ }^{\circ} \mathrm{C}(\boldsymbol{B})$. Em seguida, as células foram lavadas e incubadas com partículas de FITC-dextran a $37{ }^{\circ} \mathrm{C}$ e, depois de $30 \mathrm{~min}$, a captura de dextran fluorescente foi determinada por citometria de fluxo. BMMo incubados apenas com FITC-dextran a $37{ }^{\circ} \mathrm{C}$ foram consideradas controles positivo. $\mathrm{O}$ resultado representa a média acrescida de desvio-padrão de dois experimentos independentes e estão expressos como MIF. ${ }^{*} p<0,05$ em relação ao controle e \# $p<$ 0,05 em relação a Nattectina. 
5.8 Indução da Resposta Imune Inata pela Nattectina

O perfil da resposta inflamatória induzida pela Nattectina foi avaliado através da indução de peritonite em camundongos. Para tanto, camundongos C57BL/6 WT, IL-4 KO ou IFN- $\gamma K O$ foram injetados por via intraperitoneal com $500 \mu \mathrm{l}$ de Nattectina a $20 \mu \mathrm{g} / \mathrm{ml}$ diluída em salina $0,9 \%$ estéril. Após diferentes períodos de tempo (6 e 24 h), os animais foram mortos para obtenção do lavado peritoneal. Foi realizada a análise do influxo leucocitário para a cavidade peritoneal e a determinação dos níveis de citocinas (IL-1 $\beta$, IL-6, IL-10 e IL-12p70) no sobrenadante da suspensão celular.

\subsubsection{Peritonite Induzida pela Nattectina}

Nossos resultados na Figura $\mathbf{1 0 A}$ indicam que a Nattectina foi capaz de induzir um intenso influxo leucocitário para a cavidade peritoneal dos camundongos C57BL/6 WT, se comparado ao grupo controle, caracterizado principalmente pelo recrutamento de neutrófilos em $6 \mathrm{~h}$, que foi substituído por macrófagos no período de $24 \mathrm{~h}$. O recrutamento de neutrófilos induzido pela Nattectina nos animais C57BL/6 WT foi completamente abolido nos animais deficientes nos genes de IL-4 ou de IFN- $\gamma$. Já o recrutamento de macrófagos em ambos os grupos de animais IL-4 $K O$ ou IFN- $\gamma K O$ foi positivo em relação aos controles, porém parcialmente diminuído em relação aos animais C57BL/6 WT, indicando uma regulação positiva de ambas as citocinas no recrutamento tanto de neutrófilos quanto de macrófagos induzido pela Nattectina.

De acordo com Ghosn et al. (2010), existem dois subtipos de macrófagos derivados da cavidade peritoneal de camundongos, denominados de SPMs (Small Peritoneal Macrophages) e LPMs (Large Peritoneal Macrophages). Dessa forma, levando-se em consideração a diferença de tamanho a partir da medida do diâmetro das células estabelecidas por imagem de microscopia, podemos observar na Figura $10 B$ a presença de LPMs com baixa relação núcleo/citoplasma e diâmetro médio de $20 \mu \mathrm{m}$ nos animais controle injetados somente com salina, ao passo que no período de $6 \mathrm{~h}$ após a injeção dos animais com a Nattectina, observa-se um aumentado número de neutrófilos e SMPs com alta relação núcleo/citoplasma e diâmetro médio de $12 \mu \mathrm{m}$, os quais foram posteriormente substituídos pelos LPMs em $24 \mathrm{~h}$. Nos animais IL-4 $K O$ e IFN- $\gamma$ KO, podemos observar um influxo predominante de LPMs no lugar dos SPMs em $6 \mathrm{~h}$, indicando, portanto, que IL-4 e IFN- $\gamma$ regulam positivamente o 
influxo recente dos SPMs induzido pela Nattectina. Ademais, foi observada também uma substituição dos neutrófilos por eosinófilos nos animais IFN- $\gamma$ KO. O influxo de LPMs no período de 24 h não foi alterado pela ausência funcional de ambas as citocinas.

\subsubsection{Síntese de Mediadores Inflamatórios Induzidos pela Nattectina}

A peritonite é uma reação inflamatória aguda caracterizada por um influxo leucocitário acompanhado da produção e liberação de diversos mediadores inflamatórios. $\mathrm{Na}$ Figura 11, podemos observar que, 1 h após a injeção da Nattectina, houve a liberação somente de IL-6 na cavidade peritoneal de camundongos C57BL/6 WT em relação aos animais controle. Já os animais deficientes em IL-4 apresentaram uma produção maior de IL-6, o que indica que a liberação desta citocina induzida pela Nattectina na cavidade peritoneal é negativamente regulada pela IL-4. Nos animais IFN- $\gamma K O$, por sua vez, a ausência da produção de IL-6 induzida pela Nattectina indica uma regulação positiva desta citocina. 
(A)
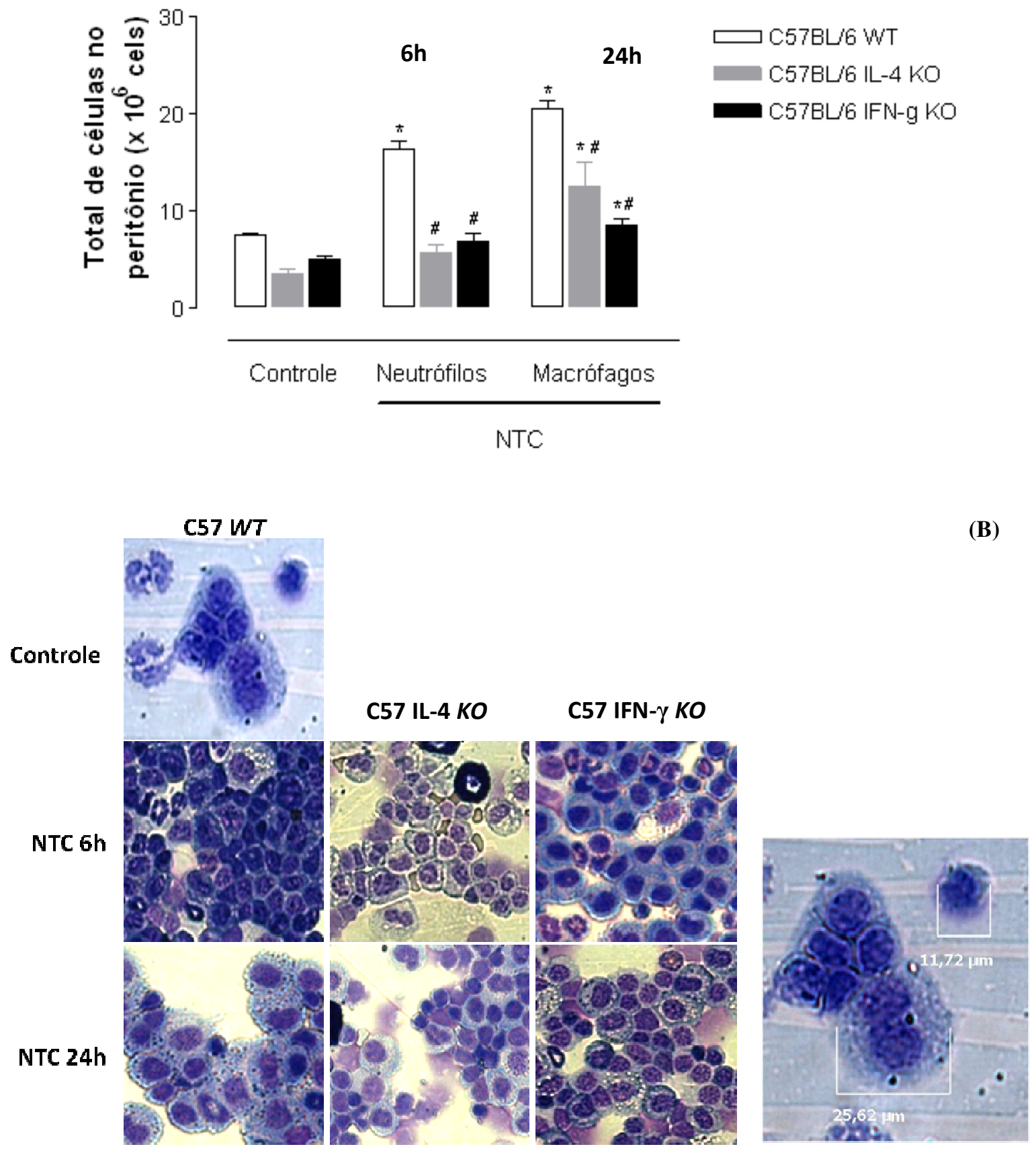

Figura 10- Neutrofilia induzida pela Nattectina é dependente de IL-4 e IFN- $\gamma$ e o subtipo de macrófagos por IFN- $\gamma$. Camundongos C57BL/6 WT, IL-4 KO ou IFN- $\gamma$ KO machos foram injetados com $500 \mu \mathrm{l}$ de Nattectina a $20 \mu \mathrm{g} / \mathrm{ml}$ por via intraperitoneal. Os animais mortos após 6 e $24 \mathrm{~h}$ da injeção tiveram a cavidade peritoneal lavada com salina $0,9 \%$ EDTA $10 \mathrm{mM}$ para a coleta da suspensão celular e contagem de neutrófilos em 6 h e macrófagos em 24 h $(\boldsymbol{A})$. Imagem das lâminas das suspensões celulares obtidas da cavidade peritoneal dos animais injetados com a Nattectina e do diâmetro dos subtipos de macrófagos $(\boldsymbol{B})$. * $p<0,05$ em relação aos controles. \# $p<0,05$ em relação aos animais C57BL/6 WT injetados com a Nattectina. 


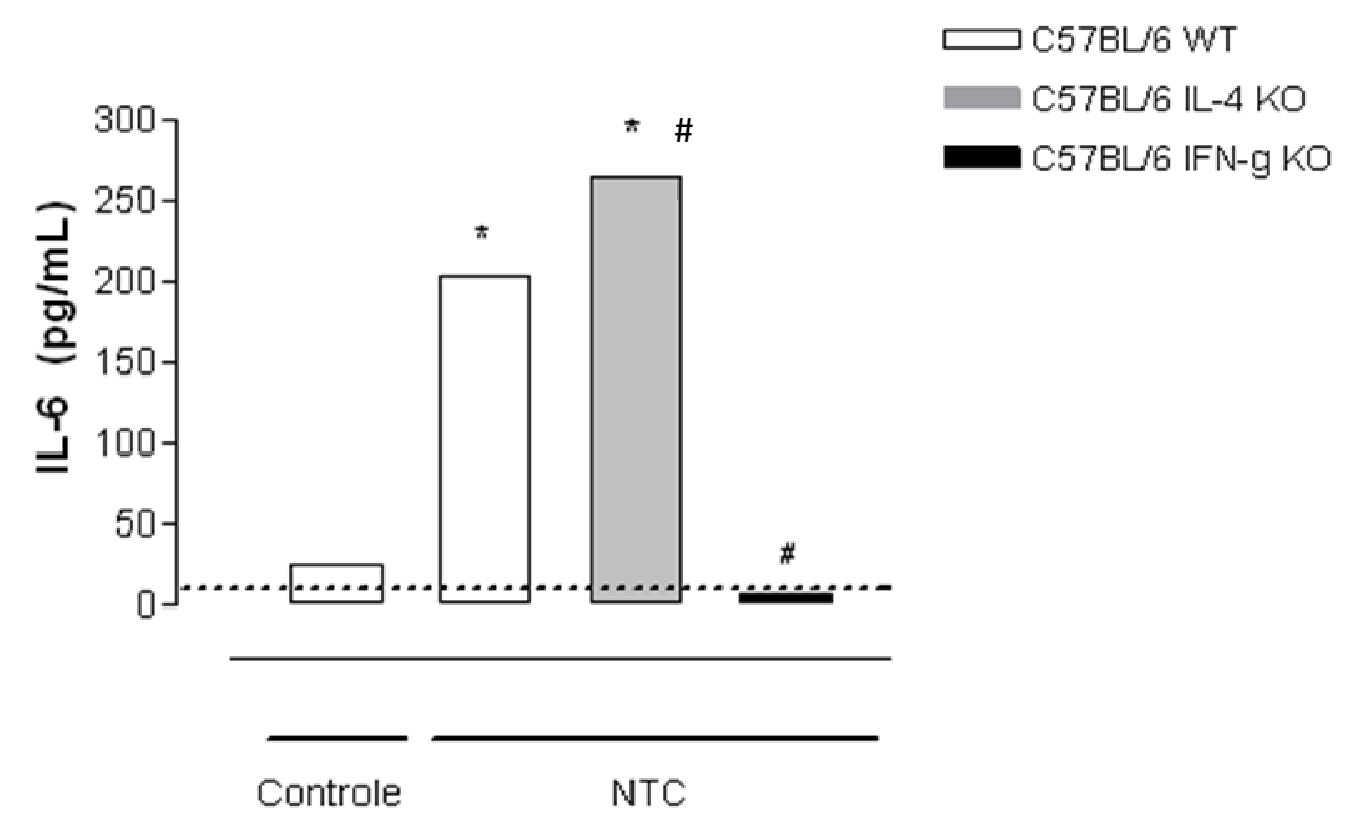

Figura 11- A produção de IL-6 induzida pela Nattectina é dependente de IFN- $\boldsymbol{\gamma}$. Camundongos C57BL/6 $W T$, IL-4 KO ou IFN- $\gamma$ KO machos foram injetados com $500 \mu \mathrm{l}$ de Nattectina a $20 \mu \mathrm{g} / \mathrm{ml}$ por via intraperitoneal. Os animais mortos após $1 \mathrm{~h}$ da aplicação tiveram a cavidade peritoneal lavada com salina $0,9 \%$ EDTA $10 \mathrm{mM}$ para a coleta da suspensão celular, que foi analisada para a presença de IL-6 por ELISA. A linha tracejada representa o limite de detecção para IL-6 de 7,8 pg/ml. * $p<0,05$ em relação aos controles e \# $p<0,05$ em relação aos animais WT injetados com a Nattectina. 
5.9 Influência de Citocinas Th1/Th2 na Ativação Polarizada de Macrófagos Induzida pela Nattectina

As atividades pró-inflamatória e citotóxica de macrófagos classicamente ativados (M1) são aumentadas na presença de agentes microbianos e/ou de citocinas Th1 como IFN- $\gamma$ ou IL-12, enquanto a ativação alternativa de macrófagos (M2) acontece na presença de citocinas Th2 como IL-4 ou IL-13 (GORDON, 2003; MOSSER e EDWARDS, 2008; MARTINEZ; HELMING; GORDON, 2009). Para avaliar a influência destas citocinas na ativação e expressão de moléculas co-estimuladoras induzida pela Nattectina, foram realizados experimentos utilizando macrófagos $\mathrm{CD}_{11} \mathrm{~b}^{\mathrm{pos}} \mathrm{F} 4 / 80^{\mathrm{pos}} \mathrm{CD} 14^{\mathrm{pos}} \mathrm{Ly} 6 \mathrm{C}^{\text {low }} \mathrm{de}$ camundongos C57BL/6 WT, IL-4 KO, IL-12 KO ou IFN- $\gamma$ KO.

Na Figura 12 podemos observar que a Nattectina induziu um aumento na expressão de CD40 (ativação), MHC classe II (apresentação) e CCR7 (migração) nos macrófagos obtidos de animais $W T$, porém na ausência de IL-4, os macrófagos estimulados com a Nattectina apresentaram um maior aumento na expressão de CD40 e diminuída expressão de MHC classe II e CCR7 em relação aos animais WT. Isto indica uma regulação negativa de IL-4 na expressão de CD40 e positiva na expressão de MHC de classe II e CCR7. Macrófagos proveniente de animais IL-12 $\mathrm{KO}$ ou de IFN- $\gamma \mathrm{KO}$ apresentaram após a estimulação com a Nattectina diminuída expressão de CD40, MHC de classe II e CCR7, indicando que a expressão dessas moléculas é fortemente regulada positivamente por citocinas do tipo Th1.

Para confirmar o papel de citocinas Th1 na ativação polarizada dos macrófagos (M1) induzida pela Nattectina, adicionamos citocinas recombinantes ao sistema in vitro de cultura de macrófagos derivados de animais deficientes de IL-12, IFN- $\gamma$ ou IL-4.

Os resultados mostrados na Figura 13A e 13B indicam que em macrófagos de animais $W T$, o tratamento das células com IL-10 ou IL-13 induziu uma grande diminuição na expressão de CD40 e MHC de classe II a níveis semelhantes ao observado em células de animais $W T$ não estimuladas, enquanto nas células obtidas dos animais IL-12 KO e IFN- $\gamma \mathrm{KO}$ tanto IL-10 quanto IL-13 não alteraram a baixa expressão destas moléculas após a estimulação com a Nattectina. Diferentemente do que ocorre com as moléculas CD40 e MHC de classe II, o tratamento das células de animais WT com IL-10 não alterou a expressão de CCR7, sendo diminuída somente por IL-13. Porém, na ausência de IFN- $\gamma$ ou de IL-12, as citocinas IL-10 ou IL-13 induziram a expressão de CCR7, respectivamente. Estes resultados confirmam a regulação positiva de IL-12 e IFN- $\gamma$ na polarização M1 dos macrófagos ativados 
pela Nattectina e revelam um controle negativo das citocinas IL-10 ou IL-13 na polarização M1 (Fig. 13C). 


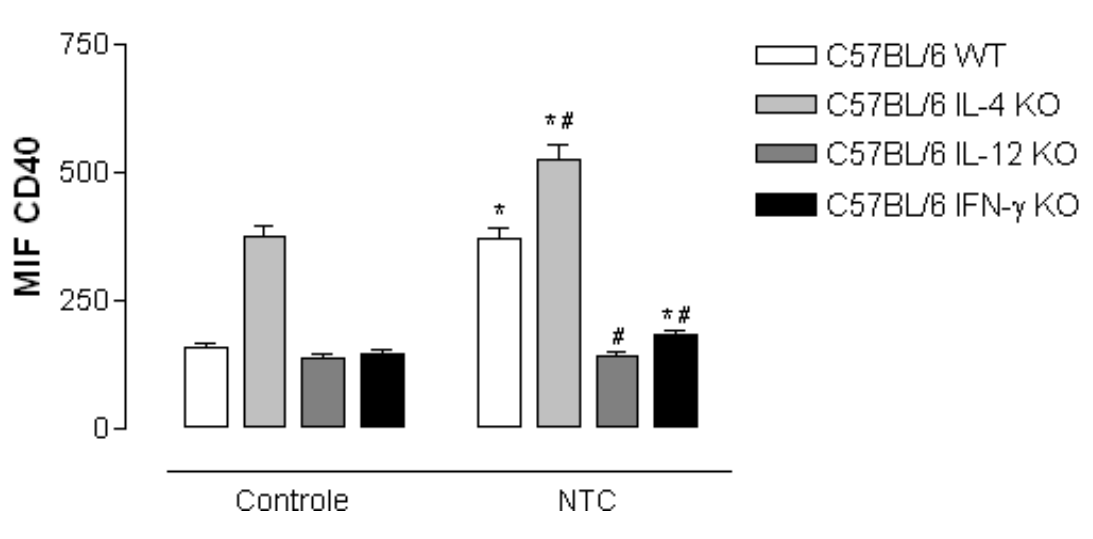

(A)

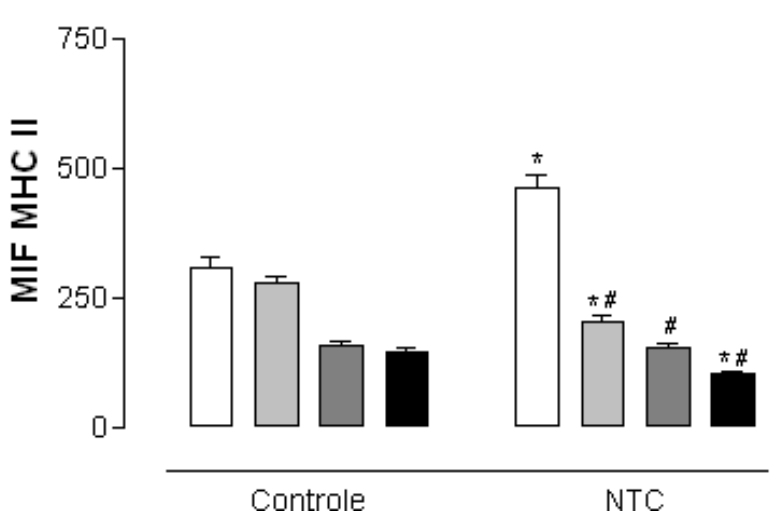

(B)

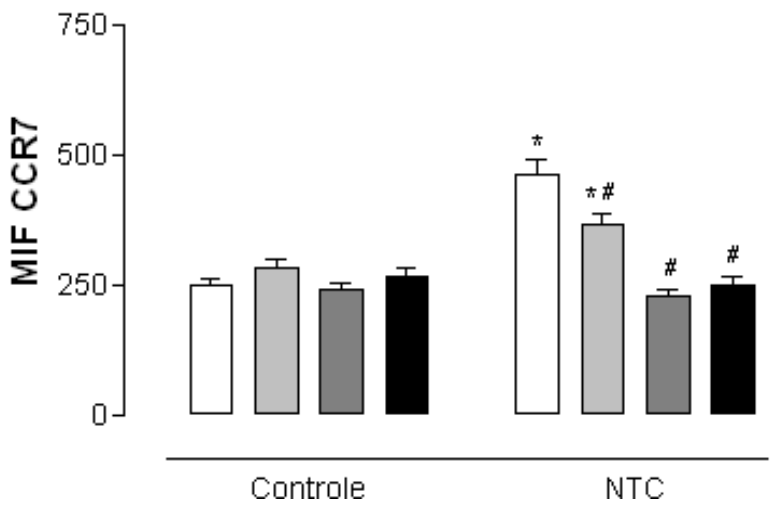

(C)

Figura 12- Modulação por citocinas da expressão de CD40, MHC de classe II e CCR7 em BMMo ativados pela Nattectina. Macrófagos $\mathrm{F} 4 / 80^{\mathrm{pos}} \mathrm{CD} 11 \mathrm{~b}^{\mathrm{pos}}$ derivados da medula óssea de camundongos C57BL/6 WT, IL-4 KO, IL-12 KO ou IFN- $\gamma$ KO machos foram estimulados com Nattectina a $10 \mu \mathrm{g} / \mathrm{ml}$ por $24 \mathrm{~h}$ a $37{ }^{\circ} \mathrm{C}$. Após o estimulo, as células foram processadas e marcadas com os anticorpos monoclonais anti-CD40 PE, anti-MHC de classe II PE, anti-CCR7 PE-Cy5 e analisados por citometria de fluxo. As barras representam a expressão de CD40 (A), MHC de classe II $(\boldsymbol{B})$ e CCR7 $(\boldsymbol{C})$ nos macrófagos em termos de MIF acrescida do desvio-padrão. ${ }^{*} p<0,05$ em relação aos controles e \# $p<0,05$ em relação aos animais C57BL/6 WT injetados com a Nattectina. 


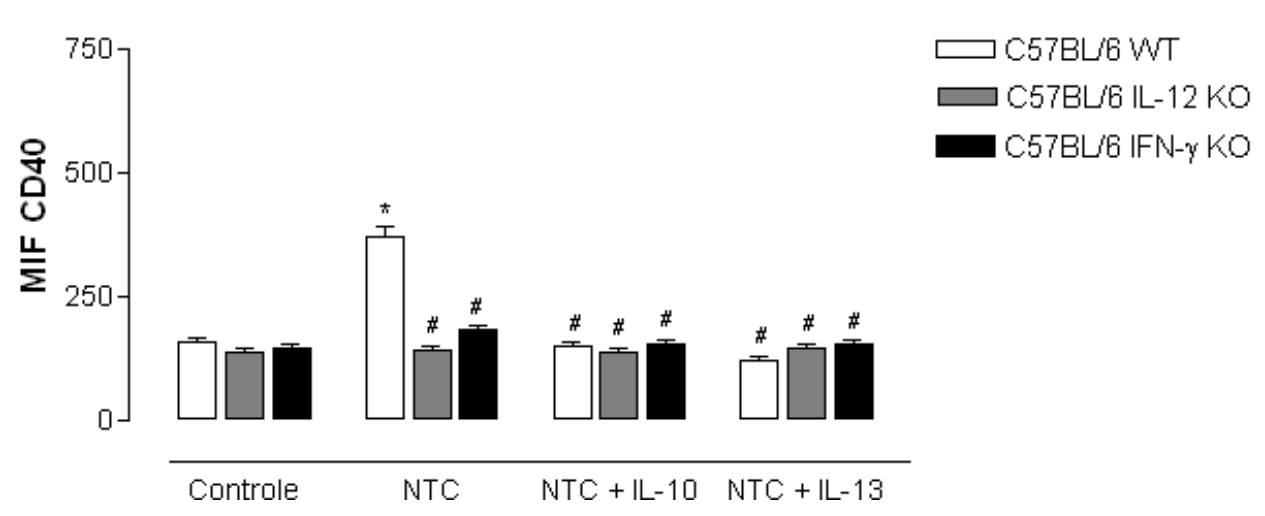

(A)

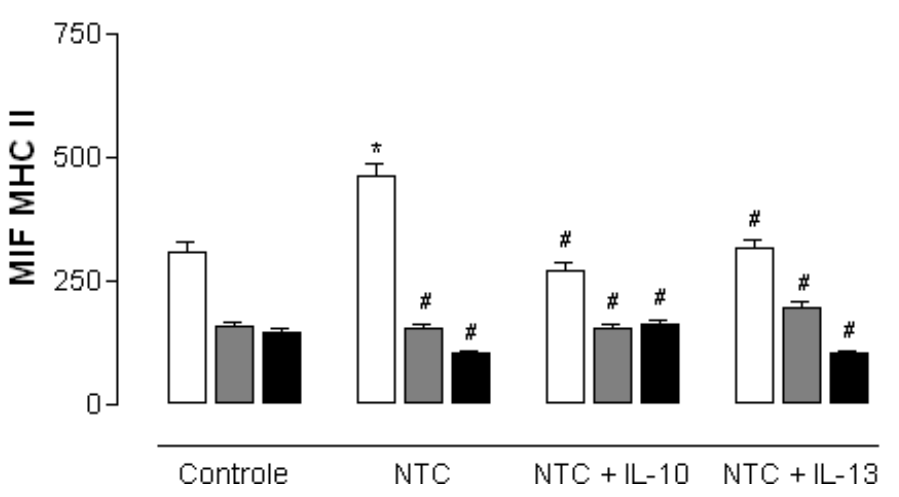

(B)

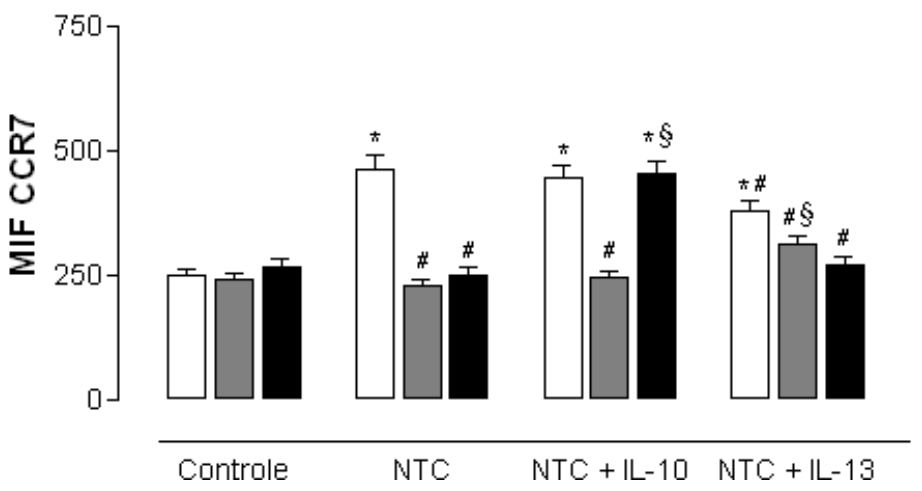

(C)

Figura 13- Modulação por IL-10 e IL-13 da expressão de moléculas induzida pela Nattectina em BMMo. Macrófagos $\mathrm{F} 4 / 80^{\mathrm{pos}} \mathrm{CD} 11 \mathrm{~b}^{\mathrm{pos}}$ de camundongos C57BL/6 WT, IL-12 KO ou IFN- $\gamma$ KO machos foram estimulados com $10 \mu \mathrm{g} / \mathrm{ml}$ de Nattectina por $24 \mathrm{~h}$ na ausência ou presença das citocinas recombinantes IL-10 e IL-13, ambas a $5 \mathrm{ng} / \mathrm{ml}$. Em seguida, as células foram marcadas com os anticorpos monoclonais anti-CD40 PE, anti-MHC de classe II PE, anti-CCR7 PE-Cy5 e analisados por citometria de fluxo. As barras representam a expressão de CD40 (A), MHC de classe II $(\boldsymbol{B})$ e CCR7 $(\boldsymbol{C})$ em BMMo em termos de MIF acrescida do desvio-padrão. ${ }^{*} p<0,05$ em relação ao controle, \# $p<0,05$ em relação aos animais C57BL/6 WT injetados com a Nattectina e $\$ p<0,05$ em relação aos animais $K O$ injetados com Nattectina. 


\section{DISCUSSÃO}

Os sinais oriundos da resposta inata ou adaptativa podem influenciar a fisiologia de macrófagos, e estas alterações permitem que eles participem em processos homeostáticos, tais como remodelamento tecidual e fechamento de feridas como também na defesa do hospedeiro contra patógenos. A resposta dos macrófagos aos sinais de perigo endógenos é somente um exemplo de quantos estímulos diferentes podem provocar a ativação de macrófagos nos tecidos. Neste sentido, diversas pesquisas vêm sendo realizadas na busca de drogas ou componentes que de alguma maneira consigam modular as funções de macrófagos.

$\mathrm{O}$ veneno de $T$. nattereri e suas toxinas vêm sendo amplamente estudados quanto a diferentes aspectos e recentemente foi caracterizada uma toxina monomérica de $15 \mathrm{kDa}$ da família das lectinas tipo C, denominada Nattectina, que apresenta afinidade por estruturas terminadas em galactose ou glicanas terminadas em $N$-acetilgalactosamina (GalNAc). Neste trabalho, nosso objetivo foi avaliar a capacidade desta lectina de ativar as funções de macrófagos como fagocitose, produção de mediadores inflamatórios, expressão de moléculas co-estimuladoras e integrinas, e verificar a influência de citocinas Th1/Th2 na ativação polarizada dos macrófagos induzida pela Nattectina.

Macrófagos são tipicamente caracterizadas como células grandes que expressam a glicoproteína de superfície F4/80 e CD11b, uma das cadeias da integrina Mac-1 (GORDON e TAYLOR, 2005). Além destes, outro marcador de diferenciação para os macrófagos é o CD14, uma glicoproteína associada a membrana que inicialmente foi descrita por apresentar LPS ao ligante TLR4 (ULEVITCH e TOBIAS, 1999). Dados recentes mostram que CD14 também apresenta vários ligantes para outros receptores tipo Toll, incluindo ácido lipoteicóico, ceramida e Poly(I:C)/dupla fita de RNA (SCHMITZ e ORSÓ, 2002; LEE et al., 2006; AKASHI-TAKAMURA e MIYAKE, 2008). Além disso, CD14 tem sido proposto mediar a endocitose de Poly(I:C) nos endossomos contendo TLR3, promovendo assim a ativação de TLR3 (LEE et al., 2006). Recentemente, Baumann et al. (2010) demonstraram em diferentes tipos celulares, incluindo macrófagos e DCs obtidos de medula óssea, macrófagos RAW264.7, células Hek293, Vero e HeLaS3, que CD14 promove a endocitose seletiva de ácidos nucléicos virais e age como um co-receptor da ativação endossomal de TLR7 e TLR9. Em nossos estudos, a utilização do sobrenadante de L929 contendo M-CSF foi capaz de gerar células caracterizadas pela expressão intermediária ou alta de F4/80, alta expressão de CD11b e CD14, e baixa expressão de Ly6C. 
Recentemente, Arikawa et al. (2010) utilizaram em seus estudos macrófagos murinos provenientes do lavado broncoalveolar com o fenótipo $\mathrm{CD} 11 \mathrm{~b}^{\mathrm{pos}} \mathrm{F} 4 / 80^{\mathrm{pos}} \mathrm{Ly} 6 \mathrm{C}^{\text {high }}$, capazes de suprimir a proliferação e ativação de células T. Em nossos estudos, porém, foram utilizados macrófagos $\mathrm{CD} 11 \mathrm{~b}^{\text {pos }} \mathrm{F} 4 / 80^{\text {pos }} \mathrm{CD} 14^{\text {pos }}$ Ly $6 \mathrm{C}^{\text {low }}$ com fenótipo ativador. Nossos resultados mostram que nesta sub-população, a Nattectina foi capaz de induzir aumento na expressão de MHC de classe II e das moléculas co-estimuladoras como CD40, CD80 e CD86, indicando ativação celular. O aumento na capacidade de apresentação antigênica (MHC de classe II) com aumentada expressão da integrina CD49a, produção de MMP-9 e capacidade endocítica são dependentes da função lectina da Nattectina. O efeito da Nattectina na maturação dos macrófagos (CD40, CD80 e CD86) é dependente das vias de sinalizações mediadas por PI3K e MAPK p38, as quais não interferem na expressão de MHC de classe II.

Durante o desenvolvimento da resposta imune adaptativa, a eficiente ativação de linfócitos T necessita de um conjunto de sinais como (1) a ligação do receptor do antígeno (TCR) do linfócito às moléculas de MHC complexadas ao antígeno na APC, (2) a interação das moléculas CD80 e CD86 ou CD40 expressas na APC com as moléculas CD28 ou CD40L expressas nos linfócitos T, respectivamente, e (3) a ação de citocinas como IL-12 produzidas pelas APCs que podem promover a diferenciação para resposta Th1 ou de receptores Notch para Th2. O que podemos dizer de nossos resultados é que a Nattectina foi capaz de induzir a maturação dos macrófagos, fazendo-os expressarem mais moléculas de co-estimulação.

Galectinas são lectinas tipo C com afinidade para galactose e são encontradas nas formas solúveis ou expressas em membranas e desenvolvem importante papel na imunidade inata por modificar a função de células efetoras. Por exemplo, a galectina-3 exibe atividade quimiotática para macrófagos (SANO et al., 2000) e a galectina-9 para eosinófilos (MATSUMOTO et al., 1998). O efeito da galectina-9 em eosinófilos é dependente de sua atividade lectina (MATSUSHITA et al., 2000) e em contraste, a habilidade da galectina-9 em induzir maturação de DCs independe desta propriedade. Ainda, Dai et al. (2005) demonstraram que a galectina-9 induz maturação de DCs com baixa produção de TNF- $\alpha$, o que vem sendo aceito como um fator característico de células supressoras derivadas de precursores mielóides (MDSC) ou de DCs reguladoras (DCreg) (HUANG et al., 2006; MARHABA et al., 2007; YOUN et al., 2008).

No nosso estudo, a Nattectina, que possui homologia com lectinas tipo $\mathrm{C}$ e apresenta afinidade por estruturas terminadas em galactose ou glicanas terminadas em $N$ acetilgalactosamina (GalNAc) semelhante às galectinas, foi capaz de induzir macrófagos a 
produzirem mediadores inflamatórios tais como a MMP-2 e MMP-9, sem contudo induzir a síntese das citocinas TNF- $\alpha$, IL-6 ou IL-12p70 (dados não-mostrados). Citocinas controlam a produção de MMP através de elementos reguladores negativos ou positivos a nível genético (WOESSNER, 1991), assim como influenciam também a produção de enzimas proteolíticas que ativam ou inibem as MMPs (GALBOIZ et al., 2002; RIES e PETRIDES, 1995). Embora citocinas inflamatórias não tenham sido detectadas no sobrenadante das culturas de macrófagos estimulados com a Nattectina podemos inferir que esta lectina gerou um microambiente favorável à produção de MMPs com atividade pelos macrófagos.

Adesão e migração são funções celulares integradas essenciais de vários processos como organogênese, tumorigênese e inflamação. Em células em migração, integrinas são os receptores transmembrânicos principais que providenciam interações dinâmicas entre o citoesqueleto de actina e ligantes na matriz extracelular. Além de integrinas, outros receptores medeiam este processo, incluindo receptores multifuncionais como sindecans e CD44. Este último é uma glicoproteína transmembrana ligante do ácido hialurônico, um polissacarídeo encontrado na matriz extracelular de mamíferos (ICZKOWSKI, 2010; GOODISON; URQUIDI; TARIN, 1999; RANGASWAMI; BULBULE; KUNDU, 2006). Sua expressão membranosa é aumentada com a polimerização da actina que se dá após a ativação do leucócito, que também promove uma alteração espacial da molécula, promovendo maior acessibilidade à ação da pró-MMP-9 e a sua conseqüente ativação e secreção (SAMANNA et al., 2007; REDONDO-MUÑOZ et al., 2008). Nossos resultados que mostram a Nattectina gerando aumento na expressão das integrinas $\alpha 1$ e $\alpha 5$, CD44 e MMP-9 suportam a idéia de que ocorreu polarização das integrinas na membrana, alteração de citoesqueleto de actina, maior acessibilidade de CD44, formação do complexo CD44/integrinas, liberação de MMP-9 ativa e degradação da matriz extracelular pela MMP-9. Assim, macrófagos ativados pela Nattectina adquirem um competente complexo molecular de migração que os habilita a ter acesso aos tecidos.

Ademais, a presença das formas latente e ativa da MMP-9 no sobrenadante da cultura de macrófagos estimulados com a Nattectina é depende da via de sinalização mediada por ERK1/2, semelhante aos estudos realizados por Lai et al. (2003), que demonstraram a dependência desta via na produção de MMP-9 por monócitos estimulados com LPS.

Macrófagos são conhecidos por expressarem vários receptores que reconhecem componentes antigênicos ou ligam opsoninas aderidas a eles (UNDERHILL e OZINSKY, 2002). Entre estes, os receptores FcyR e de complemento servem como receptores de 
opsoninas para IgG e C3b, respectivamente (GARCIA-GARCIA e ROSALES, 2002;

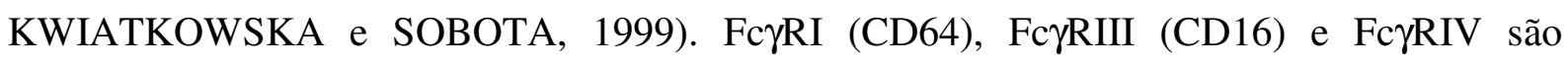

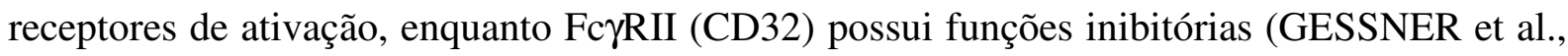
1998). Nossos resultados mostram claramente que a Nattectina induziu aumento na capacidade endocítica dos macrófagos sem, contudo, aumentar a expressão de receptores FçRIII ou TLR2 (implicado na ligação de componentes de bactérias gram-positivas), sugerindo que a endocitose é promovida por outros tipos de receptores.

Estudos realizados por Coltri et al. (2008) mostraram que a lectina $\mathrm{KM}(+)$ isolada da planta Artocarpus integrifolia e com capacidade de ligação a manose, pode-se ligar diretamente aos resíduos de N-glicana em TLR2, levando a produção de IL-12. Por sua vez, Kammanadiminti et al. (2004), estudando o mecanismo de regulação de TLRs pela lectina de superfície amebiana Gal/GalNAc, descobriram que esta lectina é capaz de induzir uma grande expressão de TLR2 em macrófagos murinos. Embora em nosso estudo a Nattectina não tenha levado a um aumento na expressão de TLR2 nos macrófagos, não podemos descartar a possibilidade de que a ativação seja dependente da ligação da Nattectina aos resíduos de galactose presentes em receptores do tipo Toll, uma vez que eles expressam 15 potenciais sítios de glicosilação localizados na superfície côncava do domínio extracelular rico em leucina (BELL et al., 2003).

Ainda, nossos estudos demonstraram que o aumento da capacidade endocítica dos macrófagos promovido pela Nattectina é dependente da sua ligação a estruturas glicosiladas expressas nestas células e também depende do envolvimento da sinalização mediada por MEK1/2 - ERK1/2.

PI3K/AKT envolvem uma família conservada de enzimas transdutoras de sinais que estão implicadas na regulação de uma variedade de processos celulares, incluindo sobrevivência, proliferação e ativação (CANTLEY, 2002). Dados mostram também que esta sinalização participa de maneira importante na regulação negativa de respostas imunes excessivas mediadas por TLR (KIM et al., 2005). PI3K é um heterodímero que consiste de uma subunidade catalítica (p110) associada ao polipeptídeo regulador p85. Produtos lipídicos gerados pela atividade de PI3K podem mediar efeitos acima ou abaixo da molécula small GTPase Racl (CARPENTER e CANTLEY, 1996). PI3K catalisa a fosforilação de várias espécies de fosfatidilinositol que são importantes no recrutamento de moléculas sinalizadoras como Akt/PKB para regiões específicas na membrana. Isto está envolvido na extensão da membrana, fusão das vesículas fagocíticas e endossomais e inserção de nova membrana ao 
sitio de internalização da partícula (UNDERHILL e OZINSKY, 2002). As diferentes classes de $\operatorname{PI3K}(\gamma, \beta, \alpha, \delta)$ são reguladas positivamente em células imunes após a ativação de receptores acoplados a proteína $\mathrm{G}$, como receptores de quimiocinas (ROMMEL; CAMPS; JI, 2007).

Em conjunto, nossos resultados mostram que a ativação de macrófagos com indução de moléculas co-estimuladoras é dependente não só da sinalização PI3K, mas também da via mediada por MAPK p38, a qual é fortemente ativada pelo estresse do ambiente e por citocinas inflamatórias. Várias evidências indicam que a atividade p38 é crítica para respostas imunes normais e inflamatórias. A isoforma p38 é ativada em macrófagos, neutrófilos e células T por vários mediadores da inflamação como citocinas, quimiocinas e LPS, participando da quimiotaxia, exocitose de grânulos, aderência e apoptose, além de mediar a diferenciação de células T através da regulação da produção de IFN- $\gamma$ (ROUX e BLENIS, 2004).

Citocinas recombinantes (IL-4, IL-13 ou IFN- $\gamma$ ) ou produtos microbianos desencadeiam a diferenciação in vitro de precursores de macrófagos em dois tipos polarizados, um com características reparativas (chamado ativação alternativa ou M2) e outro com características inflamatórias, M1, especializado na defesa contra patógenos intracelulares. Porém, os sinais que dirigem a diferenciação de precursores no tecido em condições de infecção, injúria estéril ou transformação neoplásica são ainda mais complexos e vem sendo alvo de intensa investigação. Neste contexto, a próxima etapa de nosso estudo consistiu na avaliação em modelo in vivo e in vitro do papel de citocinas Th1 ou Th2 na ativação polarizada de macrófagos induzida pela Nattectina.

A peritonite é uma reação inflamatória aguda do peritônio, a membrana serosa que reveste parte da cavidade abdominal e vísceras. Já a cavidade peritoneal é um compartimento único que seletivamente atrai e mantém células especializadas do sistema imune, incluindo os macrófagos, que são facilmente isolados por lavagem peritoneal (GHOSN et al., 2010; LIU et al., 2006). Estudos realizados por Saraiva et al. (2011) demonstraram que a Nattectina é capaz de induzir uma resposta inflamatória aguda na cavidade peritoneal murina com grande influxo leucocitário, caracterizado pelo influxo de neutrófilos nos períodos mais recentes (até 6 horas após a injeção) e de macrófagos mais tardiamente em 24 horas. Nossos estudos corroboram esses resultados, porém revelam que o influxo de neutrófilos e macrófagos induzido pela Nattectina é totalmente dependente de IL-4 e IFN- $\gamma$ e que a indução da liberação de IL-6 é regulada parcial e negativamente por IL-4 e positiva e totalmente por IFN- $\gamma$. Estes resultados 
demonstram que a lectina Nattectina é capaz de induzir o recrutamento de macrófagos dependente de um microambiente misto, contendo as citocinas IL-4 e IFN- $\gamma$ e ativá-los mediante a ação exclusiva de IFN- $\gamma$, demonstrando uma ativação clássica M1.

Recentemente, duas sub-populações de macrófagos peritoneais denominados SPMs (Small Peritoneal Macrophages) e LPMs (Large Peritoneal Macrophages) foram identificadas. Essas duas sub-populações diferem quanto ao tamanho e também do ponto de vista fenotípico e do desenvolvimento, além de apresentarem diferenças em relação à resposta in vivo e in vitro a estímulo inflamatório (GHOSN et al., 2010). Em nossos estudos, foi possível identificar após a injeção com a Nattectina ambos os subtipos de macrófagos baseado na diferença de tamanho, e identificar que IL-4 e IFN- $\gamma$ regulam positivamente o influxo recente dos SPMs e não exercem efeito modulador sobre o influxo de LPMs no período tardio. Porém, avaliações fenotípicas destas sub-populações de macrófagos no nosso modelo são ainda necessárias, por exemplo, determinar os níveis de MHC de classe II (SPM) e Gr1 (LPM) nas sub-populações isoladas.

Para confirmar o papel de citocinas Th1 na ativação polarizada dos macrófagos (M1) induzida pela Nattectina, adicionamos citocinas recombinantes ao sistema in vitro da cultura de macrófagos derivados da medula óssea de animais deficientes de IL-12, IFN- $\gamma$ ou IL-4. Nossos resultados confirmam a regulação positiva de IL-12 e IFN- $\gamma$ na polarização M1 dos macrófagos ativados pela Nattectina e revelam um controle negativo das citocinas IL-10 ou IL-13.

Entretanto, um aspecto interessante observado em nosso estudo é o papel duplo da citocina IL-4 na polarização de macrófagos M1 após o estímulo com a Nattectina. Observamos uma atuação coadjuvante de IL-4 com IFN- $\gamma$ no i) recrutamento dos SPMs no período mais recente, uma vez que animais deficientes no gene da IL-4 apresentaram macrófagos LPM, e também ii) na indução da expressão de MHC de classe II e CCR7 em macrófagos $\mathrm{CD} 11 \mathrm{~b}^{\mathrm{pos}} \mathrm{F} 4 / 80^{\text {pos }} \mathrm{CD} 14^{\text {pos }} \mathrm{Ly} 6 \mathrm{C}^{\text {low }}$. Entretanto, um papel regulador negativo de IL-4 foi observado em algumas situações, como na expressão de CD40 (in vitro) e na síntese de IL-6 (in vivo).

Estudos demonstram que citocinas podem alterar as respostas de macrófagos, tendo em vista que atividades inflamatórias e citotóxicas dessas células apresentam-se qualitativamente e quantitativamente acentuadas na presença de IFN- $\gamma$, ao passo que o tratamento dos macrófagos com IL-4 induz um fenótipo caracterizado por elevada expressão 
de receptores de manose e um padrão único de funções que estão em nítido contraste com aqueles induzidos por macrófagos tratados com IFN- $\gamma$ (STOUT et al., 2005). Neste trabalho, porém, conseguimos ampliar a visão dicotômica M1 versus M2 fortemente influenciada pela ação de citocinas mutuamente inibitórias, uma vez que demonstramos que a lectina tipo C Nattectina gera um microambiente onde a participação conjunta de IL-4 e IFN- $\gamma$ será decisiva para o recrutamento de macrófagos SPM que serão classicamente ativados.

Em conjunto, podemos dizer que a Nattectina é capaz de induzir a ativação de macrófagos mediante o aumento na expressão de moléculas coestimuladoras dependente das vias de sinalização PI3K e MAPK p38 e independente da ligação da toxina a resíduos de galactose, e ainda um aumento na capacidade endocítica e apresentação antigênica influenciada pela sinalização ERK1/2 e pela ligação da Nattectina a resíduos de galactose na superfície dos macrófagos. Ademais, a Nattectina induz a formação de um complexo de migração que permite ao macrófago se deslocar através da matriz extracelular (Figura 14).

Portanto, o conjunto de resultados obtidos neste trabalho nos permitiu uma ampliação dos conhecimentos sobre a regulação da ativação de diferentes subtipos de macrófagos, assim como permitiu confirmar a capacidade da Nattectina, membro da família das lectinas tipo C, como um importante agente imunomodulador, abrindo desta forma a possibilidade de uso de agentes sintéticos derivados de secreções de animais marinhos como candidatos antigênicos imunomoduladores, úteis no desenvolvimento de vacinas e com aplicações terapêuticas. 

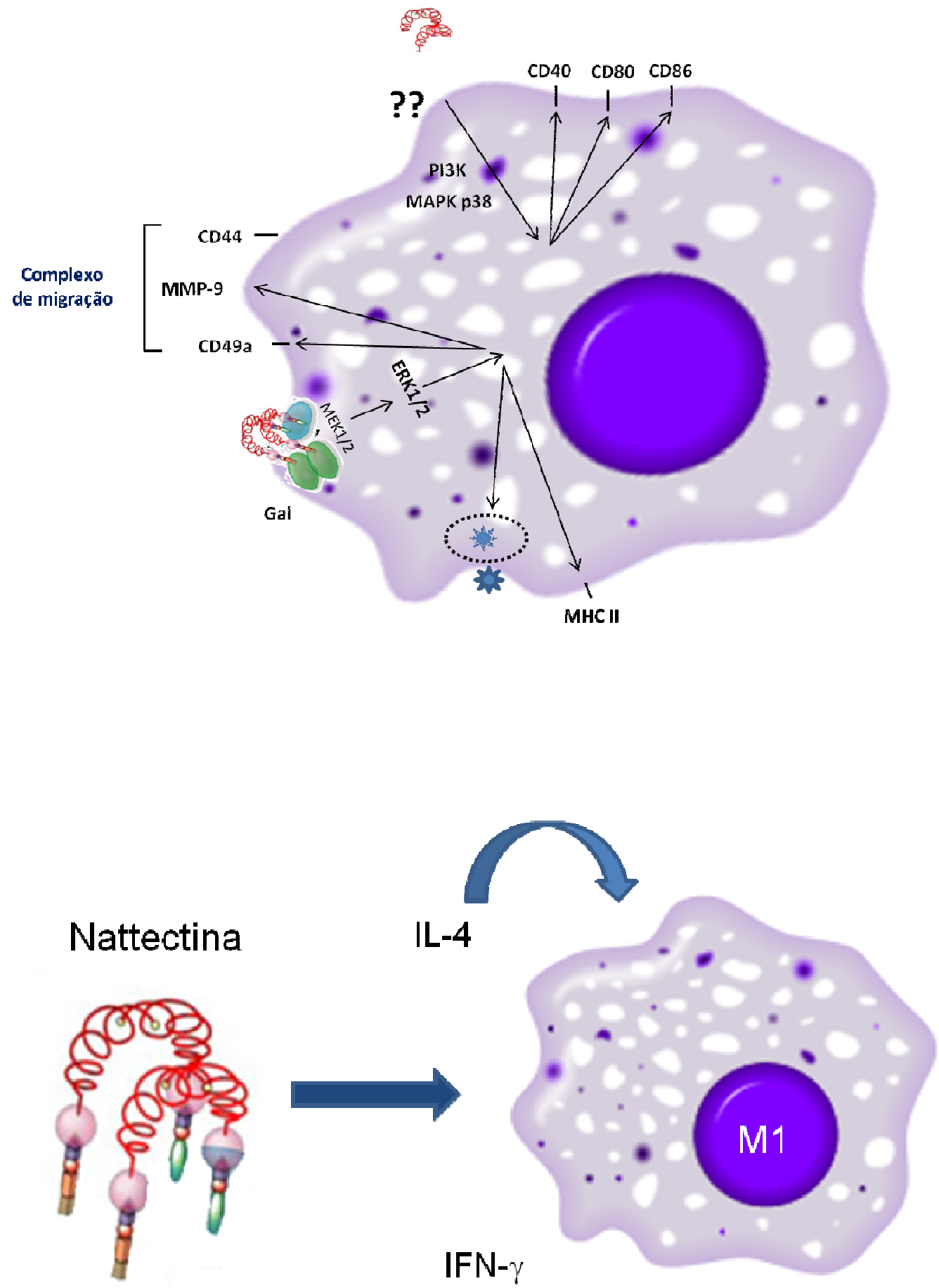

IL-12

Figura 14- Esquema da ativação de macrófago induzida pela Nattectina. 


\section{CONCLUSÕES}

Este estudo nos permitiu concluir que a Nattectina, uma lectina tipo $\mathrm{C}$ do veneno de Thalassophryne nattereri é capaz de induzir maturação de macrófagos obtidos de medula óssea que apresentam aumentada expressão de moléculas co-estimuladoras e de MHC de classe II, aumentada capacidade endocítica e maior capacidade de migração pela matriz extracelular (ECM). Verificamos ainda que a capacidade aumentada de expressão de moléculas co-estimuladoras dos macrófagos ativados pela Nattectina é dependente da sinalização PI3K e MAPK p38. Ademais, as alterações fenotípicas nos macrófagos peritoneais e obtidos de medula óssea induzida pela Nattectina são consistentes com a ativação clássica M1, dependente das citocinas Th1, IL-12 e IFN- $\gamma$, e regulada negativamente por IL-4, IL-10 e IL-13. Ainda, também demonstramos uma ação coadjuvante de IL-4 na ação de IFN- $\gamma$ na mobilização do subtipo SPM na cavidade peritoneal e na ativação (expressão de MHC de classe II e CCR7) de macrófagos derivados de medula óssea. 


\section{REFERÊNCIAS $^{1}$}

AGREN, M. S. Gelatinase activity during wound healing. Br. J. Dermatol., v. 131, p. 634640, 1994.

AKASHI-TAKAMURA, S.; MIYAKE, K. TLR accessory molecules. Curr. Opin. Immunol., v. 20, p. 420-425, 2008.

ALMEIDA, V. G.; ROCHA, C. M. Registros de acidentes com peixes peçonhentos e/ou venenosos. Rev. Soc. Bras. Toxicol., v. 2, p. 49-51, 1989.

ARIKAWA, T.; SAITA, N.; OOMIZU, S.; UENO, M.; MATSUKAWA, A.; KATOH, S.; KOJIMA, K.; NAGAHARA, K.; MIYAKE, M.; YAMAUCHI, A.; KOHROGI, H.; HIRASHIMA, M. Galectin-9 expands immunosuppressive macrophages to ameliorate T-cellmediated lung inflammation. Eur. J. Immunol., v. 40, p. 548-558, 2010.

AUTO, H. F. Acidentes por peixes peçonhentos Thalassophryne (Niquim), considerações em torno de 32 casos. Rev. Esc. Ciênc. Méd. Alagoas., v. 5, p. 35-36, 1992.

BASBAUM, C. B.; WERB, Z. Focalized proteolysis: spatial and temporal regulation of extracellular matrix degradation at the cell surface. Curr. Opin. Cell Biol., v. 8, p. 731-738, 1996.

BAUMANN, C. L.; ASPALTER, I. M.; SHARIF, O.; PICHLMAIR, A.; BLÜML, S.; GREBIEN, F.; BRUCKNER, M.; PASIERBEK, P.; AUMAYR, K.; PLANYAVSKY, M.; BENNETT, K. L.; COLINGE, J.; KNAPP, S.; SUPERTI-FURGA, G. CD14 is a coreceptor of Toll-like receptors 7 and 9. J. Exp. Med., v. 207, p. 2689-2701, 2010.

BELL, J. K.; MULLEN, G. E.; LEIFER, C. A.; MAZZONI, A.; DAVIES, D. R.; SEGAL, D. M. Leucine-rich repeats and pathogen recognition in Toll-like receptors. Trends Immunol., v. 24, p. 528-533, 2003.

\footnotetext{
${ }^{1}$ De acordo com: ASSOCIAÇÃO BRASILEIRA DE NORMAS TÉCNICAS. NBR 6023: informação e documentação: referências: elaboração. Rio de Janeiro, 2002.
} 
BIANCHI, E.; BENDER, J. R.; BLASI, F.; PARDI, R. Through and beyond the wall: late steps in leukocyte transendothelial migration. Immunol. Today., v. 18, p. 586-591, 1997.

BIRKEDAL-HANSEN, H. Proteolytic remodeling of extracellular matrix. Curr. Opin. Cell Biol., v. 7, p. 728-735, 1995.

BRANDT, E.; WOERLY, G.; YOUNES, A. B.; LOISEAU, S.; CAPRON, M. IL-4 production by human polymorphonuclear neutrophils. J. Leukoc. Biol., v. 68, p. 125-130, 2000 .

CAMPBELL, J. J.; BUTCHER, E. C. Chemokines in tissue-specific and microenvironmentspecific lymphocyte homing. Curr. Opin. Immunol., v. 12, p. 336-341, 2000.

CANTLEY, L. C. The phosphoinositide 3-kinase pathway. Science, v. 296, p. 1655-1657, 2002.

CARPENTER, C. L.; CANTLEY, L. C. Phosphoinositide kinases. Curr. Opin. Cell Biol., v. 8, p. 153-158, 1996.

CHEN, C. J.; KONO, H.; GOLENBOCK, D.; REED, G.; AKIRA, S.; ROCK, K. L. Identification of a key pathway required for the sterile inflammatory response triggered by dying cells. Nat. Med., v. 7, p. 851-856, 2007.

COLTRI, K. C.; OLIVEIRA, L. L.; PINZAN, C. F.; VENDRUSCOLO, P. E.; MARTINEZ, R.; GOLDMAN, M. H.; PANUNTO-CASTELO, A.; ROQUE-BARREIRA, M. C. Therapeutic administration of KM+ lectin protects mice against Paracoccidioides brasiliensis infection via Interleukin-12 production in a Toll-like receptor 2-dependent mechanisms. Am. J. Pathol., v. 173, p. 423-432, 2008.

COMINETTI, M. R.; MARQUES, M. R.; LORENZINI, D. M.; LÖFGREN, S. E.; DAFFRE, S.; BARRACCO, M. A. Characterization and partial purification of a lectin from the hemolymph of the white shrimp Litopenaeus schmitti. Dev. Comp. Immunol., v. 26, p. 715$721,2002$. 
COOK, A. D.; BRAINE, E. L.; HAMILTON, J. A. The phenotype of inflammatory macrophages is stimulus dependent: implications for the nature of the inflammatory response. J. Immunol., v. 171, p. 4816-4823, 2003.

DAI, S. Y.; NAKAGAWA, R.; ITOH, A.; MURAKAMI, H.; KASHIO, Y.; ABE, H.; KATOH, S.; KONTANI, K.; KIHARA, M.; ZHANG, S. L.; HATA, T.; NAKAMURA, T.; YAMAUCHI, A.; HIRASHIMA, M. Galectin-9 induces maturation of human monocytederived dendritic cells. J. Immunol., v. 175, p. 2974-2981, 2005.

DAY, A. J. The C-type carbohydrate recognition domain (CDR) superfamily. Biochem. Soc. Trans., v. 22, p. 83-88, 1994.

DENIS, M.; PALATTY, P. D.; BAI, N. R.; SURIYA, S. J. Purification and characterization of a sialic acid specific lectin from the hemolymph of the freshwater crab Paratelphusa jacquemontii. Eur. J. Biochem., v. 270, p. 4348-4355, 2003.

DIAKONOVA, M.; BOKOCH, G.; SWANSON, J. A. Dynamics of cytoskeletal proteins during Fcgamma receptor-mediated phagocytosis in macrophages. Mol. Biol. Cell., v. 13, p. 402-411, 2002.

EDWARDS, J. P.; ZHANG, X.; FRAUWIRTH, K. A.; MOSSER, D. M. Biochemical and functional characterization of three activated macrophage populations. J. Leukoc. Biol., v. 80, p. 1298-1307, 2006.

FACÓ, P. E.; HAVT, A.; BARBOSA, P. S.; NOBRE, A. C.; BEZERRA, G. P.; MENEZES, D. B.; FONTELES, M. C.; LOPES-FERREIRA, M.; MONTEIRO, H. S. Effects of Thalassophryne nattereri fish venom in isolated perfused rat kidney. Toxicon, v. 42, p. 509514, 2003.

FACÓ, P. E.; BEZERRA, G. P.; BARBOSA, P. S. F.; MARTINS, A. M. C.; GUIMARÃES, J. A.; LOPES-FERREIRA, M.; MONTEIRO, H. S. A. Epidemiology of the injuries caused by Thalassophryne nattereri (niquim) in Ceara State (1992-2002). Rev. Soc. Bras. Med. Trop., v. 38, p. 479-482, 2005.

FALK, L. A.; FORTIER, A. H. Isolation of murine macrophages. In: COICO, R. Current Protocols in Immunology. New York: John Wiley \& Sons, 1995, v. 3, p. 14-1.1 
FONSECA, L. A.; LOPES-FERREIRA, M. Clinical and experimental studies regarding poisoning caused by a fish Thalassophryne nattereri (niquim). An. Bras. Dermatol., v. 75, p. 435-443, 2000.

FRÓES, H. P. Peixes toxíforos do Brasil. Bahia Médica, v. 4, p. 69-75, 1933 a.

FRÓES, H. P. Studies on venomous fishes of tropical countries. J. Trop. Med. Hyg., v. 36, p. 134-135, $1933 b$.

FRÓES, H. P. Estudo experimental sobre o veneno dos niquins (Thalassophrynidae). Bahia Médica, v. 4, p. 225-227, 1933c.

FUJIWARA, N.; KOBAYASHI, K. Macrophages in inflammation. Curr. Drug Targets Inflamm. Allergy, v. 4, p. 281-286, 2005.

GALBOIZ, Y.; SHAPIRO, S.; LAHAT, N.; MILLER, A. Modulation of monocytes matrix metalloproteinase-2, MT1-MMP and TIMP-2 by interferon-gamma and -beta: implications to multiple sclerosis. J. Neuroimmunol., v. 131, p. 191-200, 2002.

GARCÍA-GARCÍA, E.; ROSALES, C. Signal transduction during Fc receptor-mediated phagocytosis. J. Leukoc. Biol., v. 72, p. 1092-1108, 2002.

GEISSMANN, F.; JUNG, S.; LITTMAN, D. R. Blood monocytes consist of two principal subsets with distinct migratory properties. Immunity, v. 19, p. 71-82, 2003.

GEISSMANN, F.; MANZ, M. G.; JUNG, S.; SIEWEKE, M. H.; MERAD, M.; LEY, K. Development of monocytes, macrophages and dendritic cells. Science, v. 327, p. 656-661, 2010.

GESSNER, J. E.; HEIKEN, H.; TAMM, A.; SCHMIDT, R. E. The IgG Fc receptor family. Ann. Hematol., v. 76, p. 231-248, 1998. 
GHOSN, E. E. B.; CASSADO, A. A.; GOVONI, G. R.; FUKUHARA, T.; YANG, Y.; MONACK, D. M.; BORTOLUCI, K. R.; ALMEIDA, S. R.; HERZENBERG L. A.; HERZENBERG, L. A. Two physically, functionally, and developmentally distinct peritoneal macrophage subsets. PNAS, v. 107, p. 2568-2573, 2010.

GOETZL, E. J.; BANDA, M. J.; LEPPERT, D. Matrix metalloproteinases in immunity. J. Immunol., v. 156, p. 1-4, 1996.

GOODISON, S.; URQUIDI, V.; TARIN, D. CD44 cell adhesion molecules. Mol. Pathol., v. 52, p. 189-196, 1999.

GORDON, S. Alternative activation of macrophages. Nat. Rev. Immunol., v. 3, p. 23-35, 2003.

GORDON, S.; TAYLOR, P. R. Monocyte and macrophage heterogeneity. Nat. Rev Immunol., v. 5, p. 953-964, 2005.

GRUND, L. Z.; SOUZA, V. M.; FAQUIM-MAURO, E. L.; LIMA, C.; LOPES-FERREIRA, M. Experimental immunization with Thalassophryne nattereri fish venom: striking IL-5 production and impaired of B220+ cells. Toxicon, v. 48, p. 499-508, 2006.

GU, J.; TANIGUCHI, N. Regulation of integrin functions by N-glycans. Glycocon J., v. 21, p. 9-15, 2004.

HADDAD JUNIOR, V.; PARDAL, P. P. O.; CARDOSO, J. L. C.; MARTINS, I. A. The venomous toadfish Thalassophryne nattereri (niquim or miquim): report of 43 injuries provoked in fishermen of Salinópolis (Pará State) and Aracaju (Sergipe State), Brazil. Rev. Inst. Med. Trop. S. Paulo, v. 45, p. 221-223, 2003.

HANADA, T.; YOSHIMURA, A. Regulation of cytokine signaling and inflammation. Cytokine Growth Factor Rev., v. 13, p. 413-421, 2002.

HUANG, B.; PAN, P. Y.; LI, Q.; SATO, A. I.; LEVY, D. E.; BROMBERG, J.; DIVINO, C. M.; CHEN, S.H. Gr-1+CD115+ immature myeloid suppressor cells mediate the development 
of tumor-induced T regulatory cells and T-cell anergy in tumor bearing host. Cancer Res., v. 66, p. 1123-1131, 2006.

ICZKOWSKI, K. A. Cell adhesion molecule CD44: its functional roles in prostate cancer. Am. J. Transl. Res., v. 3, p. 1-7, 2010.

IMHOF, B. A.; AURRAND-LIONS, M. Adhesion mechanisms regulating the migration of monocytes. Nat. Rev. Immunol., v. 4, p. 432-444, 2004.

KAMMANADIMINTI, S.; MANN, B. J.; DUTIL, L.; CHADEE, K. Regulation of Toll-like receptor-2 expression by the Gal-lectin of Entamoeba histolytica. FASEB J., v. 18, p. 155157, 2004.

KIM, Y. H.; CHOI, K. H.; PARK, J. W.; KWON, T. K. LY294002 inhibits LPS-induced NO production through a inhibition of NF-kappaB activation: independent mechanism of phosphatidylinositol 3-kinase. Immunol. Lett., v. 99, p. 45-50, 2005.

KONO, H.; ROCK, K. L. How dying cells alert the immune system to danger. Nat. Rev. Immunol., v. 8, p. 279-289, 2008.

KREIDER, T.; ANTHONY, R. M.; URBAN JR, J. F.; GAUSE, W. C. Alternatively activated macrophages in helminth infections. Curr. Opin. Immunol., v. 19, p. 448-453, 2007.

KWIATKOWSKA, K.; SOBOTA, A. Signaling pathways in phagocytosis. Bioessays, v. 21, p. 422-431, 1999.

LAEMMLI, U. K. Cleavage of structural proteins during the assembly of the head of bacteriophage T4. Nature, v. 227, p. 680-685, 1970.

LAI, W. C.; ZHOU, M.; SHANKAVARAM, U.; PENG, G.; WAHL, L. M. Differential regulation of lipopolysaccharide-induced monocyte matrix metalloproteinase (MMP)-1 and MMP-9 by p38 and extracellular signal-regulated kinase $1 / 2$ mitogen-activated protein kinases. J. Immunol., v. 170, p. 6244-6249, 2003. 
LARSON, R. S.; SPRINGER, T. A. Structure and function of leukocyte integrins. Immunol. Rev., v. 114, p. 181-217, 1990.

LAUFFENBURGER, D. A.; HORWITZ, A. F. Cell migration: a physically integrated molecular process. Cell, v. 84, p. 359-369, 1996.

LEE, H. K.; DUNZENDORFER, S.; SOLDAU, K.; TOBIAS, P. S. Double-stranded RNAmediated TLR3 activation is enhanced by CD14. Immunity, v. 24, p. 153-163, 2006.

LIMA, C.; BIANCA CLISSA, P.; PIRAN-SOARES, A. A.; TANJONI, I.; MOURA-DASILVA, A. M.; LOPES-FERREIRA, M. Characterisation of local inflammatory response induced by Thalassophryne nattereri fish venom in a mouse model of tissue injury. Toxicon, v. 42, p. 499-507, 2003.

LIU, G.; XIA, X.; GONG, S.; ZHAO, Y. The macrophage heterogeneity: difference between mouse peritoneal exudate and splenic F4/80+ macrophage. J. Cell Physiol., v. 209, p. 341$352,2006$.

LOKE, P.; GALLAGHER, I.; NAIR, M. G.; ZANG, X.; BROMBACHER, F.; MOHRS, M.; ALLISON, J. P.; ALLEN, J E. Alternative activation is an innate response to injury that requires CD4+ T cells to be sustained during chronic infection. J. Immunol., v. 179, p. 39263936, 2007.

LOPES-FERREIRA, M.; BARBARO, K. C.; CARDOSO, D. F.; MOURA-DA-SILVA, A. M.; MOTA, I. Thalassophryne nattereri fish venom: biological and biochemical characterization and serum neutralization of its toxic activities. Toxicon, v. 36, p. 405-410, 1998.

LOPES-FERREIRA, M.; EMIM, J. A.; OLIVEIRA, V.; PUZER, L.; CEZARI, M. H.; ARAÚJO MDA, S.; JULIANO, L.; LAPA, A. J.; SOUCCAR, C.; MOURA-DA-SILVA, A. M. Kininogenase activity of Thalassophryne nattereri fish venom. Biochem. Pharmacol., v. 68, p. 2151-2157, 2004.

LOPES-FERREIRA, M.; MAGALHÃES, G. S.; FERNANDEZ, J. H.; JUNQUEIRA-DEAZEVEDO I. L.; HO P. L.; LIMA C.; VALENTE R.H.; MOURA-DA-SILVA A. M. 
Structural and biological characterization of Nattectin, a new C-type lectin from the venomous fish Thalassophryne nattereri. Biochimie, v.93, p. 971-980, 2011.

LOPES-FERREIRA, M.; MOURA-DA-SILVA, A. M.; MOTA, I.; TAKEHARA, H. A. Neutralization of Thalassophryne nattereri (niquim) fish venom by an experimental antivenom. Toxicon, v. 38, p. 1149-1156, 2000.

LOPES-FERREIRA, M.; MOURA-DA-SILVA, A. M.; PIRAN-SOARES, A A.; ANGULO, Y.; LOMONTE, B.; GUTIÉRREZ, J. M.; FARSKY, S. H. Hemostatic effects induced by Thalassophryne nattereri fish venom: a model of endothelium-mediated blood flow impairment. Toxicon, v. 40, p. 1141-1147, 2002.

LOPES-FERREIRA, M.; NUÑEZ, J.; RUCAVADO, A.; FARSKY, S. H.; LOMONTE, B.; ANGULO, Y.; MOURA-DA-SILVA, A. M.; GUTIÉRREZ, J. M. Skeletal muscle necrosis and regeneration after injection of Thalassophryne nattereri (niquim) fish venom in mice. Int. J. Exp. Pathol., v. 82, p. 55-64, 2001.

LUCAS, M.; ZHANG, X.; PRASANNA, V.; MOSSER, D. M. ERK activation following macrophage FcgammaR ligation leads to chromatin modifications at the IL-10 locus. J. Immunol., v. 175, p. 469-477, 2005.

LUO, T.; YANG, H.; LI, F.; ZHANG, X.; XU, X. Purification, characterization and cDNA cloning of a novel lipopolysaccharide-binding lectin from the shrimp Penaeus monodon. Dev. Comp. Immunol., v. 30, p. 607-617, 2006.

MACKANESS, G. B. Cellular immunity and the parasite. Adv. Exp. Med. Biol., v. 93, p. 6573, 1977.

MAGALHÃES， G. S.; JUNQUEIRA-DE-AZEVEDO, I. L.; LOPES-FERREIRA， M.; LORENZINI, D. M.; HO, P. L.; MOURA-DA-SILVA, A. M. Transcriptome analysis of expressed sequence tags from the venom glands of the fish Thalassophryne nattereri. Biochimie, v. 88, p. 693-699, 2006.

MAGALHÃES, G. S.; LOPES-FERREIRA, M.; JUNQUEIRA-DE-AZEVEDO, I. L.; SPENCER, P. J.; ARAÚJO, M. S.; PORTARO, F. C.; MA, L.; VALENTE, R. H.; JULIANO, L.; FOX, J. W.; HO, P. L.; MOURA-DA-SILVA, A. M. Natterins, a new class of proteins 
with kininogenase activity characterized from Thalassophryne nattereri fish venom. Biochimie, v. 87, p. 687-699, 2005.

MAKARENKOVA, V. P.; BANSAL, V.; MATTA, B. M.; PEREZ, L. A.; OCHOA, J.B. CD11b+/Ly-6G+ myeloid suppressor cells cause T cell dysfunction after traumatic stress. J. Immunol., v. 176, p. 2085-2094, 2006.

MARHABA, R.; VITACOLONNA, M.; HILDEBRAND, D.; BANIYASH, M.; FREYSCHMIDT-PAUL, P.; ZÖLLER, M. The importance of myeloid suppressor cells in the regulation of autoimmune effector cells by a chronic contact eczema. J. Immunol., v. 179, p. 5071- 5081, 2007.

MARTINEZ, F. O.; HELMING, L.; GORDON, S. Alternative activation of macrophages: an immunologic functional perspective. Annu. Rev. Immunol., v. 27, p. 451-483, 2009.

MATSUMOTO, R.; MATSUMOTO, H.; SEKI, M.; HATA, M.; ASANO, Y.; KANEGASAKI, S.; STEVENS, R. L.; HIRASHIMA, M. Human ecalectin, a variant of human galectin-9, is a novel eosinophil chemoattractant produced by T lymphocytes. J. Biol. Chem., v. 273, p. 16976-16984, 1998.

MATSUSHITA, N.; NISHI, N.; SEKI, M.; MATSUMOTO, R.; KUWABARA, I.; LIU, F. T.; HATA, Y.; NAKAMURA, T.; HIRASHIMA, M. Requirement of divalent galactosidebinding activity of ecalectin/galectin-9 for eosinophil chemoattraction. J. Biol. Chem., v. 275, p. 8355-8360, 2000.

MEREDITH JR, J. E.; FAZELI, B.; SCHWARTZ, M. A. The extracellular matrix as a cell survival factor. Mol. Biol. Cell., v. 4, p. 953-961, 1993.

METLAY, J. P.; WITMER-PACK, M. D.; AGGER, R.; CROWLEY, M. T.; LAWLESS, D.; STEINMAN, R. M. The distinct leukocyte integrins of mouse spleen dendritic cells as identified with new hamster monoclonal antibodies. J. Exp. Med., v. 171, p. 1753-1771, 1990.

MOSSER, D. M. The many faces of macrophage activation. J. Leukoc. Biol., v. 73, p. 209$212,2003$. 
MOSSER. D. M.; EDWARDS, J. P. Exploring the full spectrum of macrophage activation. Nat. Rev. Immunol., v. 8, p. 958-969, 2008.

MOSTAFAVI-POUR, Z.; ASKARI, J. A.; PARKINSON, S. J.; PARKER, P. J.; NG, T. T.; HUMPHRIES, M. J. Integrin-specific signaling pathways controlling focal adhesion formation and cell migration. J. Cell Biol., v. 161, p. 155-167, 2003.

MULLER, W. A. Leukocyte - endothelial cell interactions in leukocyte transmigration and the inflammatory response. Trends in Immunology, v. 24, p. 326-333, 2003.

NAGANUMA, T.; OGAWA, T.; HIRABAYASHI, J.; KASAI, K.; KAMIYA, H.; MURAMOTO, K. Isolation, characterization and molecular evolution of a novel pearl shell lectin from a marine bivalve, Pteria penguin. Mol. Divers., v. 10, p. 607-618, 2006.

NATHAN, C. Metchnikoff’s legacy in 2008. Nat. Immunol., v. 9, p. 695-698, 2008.

O'SHEA, J. J.; MURRAY, P. J. Cytokine signaling modules in inflammatory responses. Immunity, v. 28, p. 477-487, 2008.

ORLANDO, R. A.; CHERESH, D. A. Arginine-glycine-aspartic acid binding leading to molecular stabilization between integrin alpha v beta 3 and its ligand. J. Biol. Chem., v. 266, p. 19543-19550, 1991.

PARK, J. S.; SVETKAUSKAITE, D.; HE, Q.; KIM, J. S.; STRASSHEIM, D.; ISHIZAKA, A.; ABRAHAM, E. Involvement of Toll-like receptors 2 and 4 in cellular activation by high mobility group box 1 protein. J. Biol. Chem., v. 279, p. 7370-7377, 2004.

PARKS, W. C.; WILSON, C. L.; LÓPEZ-BOADO, Y. S. Matrix metalloproteinases as modulators of inflammation and innate immunity. Nat. Rev. Immunol., v. 4, p. 617-629, 2004.

PASSLICK, B.; FLIEGER, D.; ZIEGLER-HEITBROCK, H. W. Identification anda characterization of a novel monocyte subpopulation in human peripheral blood. Blood, v. 74, p. 2527-2534, 1989. 
PIRAN-SOARES, A. A.; KOMEGAE, E. N.; SOUZA, V. M. O.; FONSECA, L. A.; LIMA, C.; LOPES-FERREIRA, M. Neutralizing antibodies obtained in a persistent immune response are effective against deleterious effects induced by the Thalassophryne nattereri fish venom. Toxicon., v. 49, p. 920-930, 2007.

RANGASWAMI, H.; BULBULE, A.; KUNDU, G. C. Osteopontin: role in cell signaling and cancer progression. Trends Cell Biol., v. 16, p. 79-87, 2006.

RAO, K. M. MAP kinase activation in macrophages. J. Leukoc. Biol., v. 69, p. 3-10, 2001.

RAVANTI, L.; KAHARI, V. M. Matrix metalloproteinases in wound repair. Int. J. Mol. Med., v. 6, p. 391-407, 2000.

REDONDO-MUÑOZ, J.; UGARTE-BERZAL, E.; GARCÍA-MARCO, J. A.; DEL CERRO, M. H.; VAN DEN STEEN, P. E.; OPDENAKKER, G.; TEROL, M. J.; GARCÍA-PARDO, A. Alpha4beta1 integrin and 190-kDa CD44v constitute a cell surface docking complex for gelatinase B/MMP-9 in chronic leukemic but not in normal B cells. Blood, v. 112, p. 169$178,2008$.

RIES, C.; PETRIDES, P. E. Cytokine regulation of matrix metalloproteinase activity and its regulatory dysfunction in disease. Biol. Chem. Hoppe. Seyler., v. 376, p. 345-355, 1995.

ROMMEL, C.; CAMPS, M.; JI, H. PI3K delta and PI3K gamma: partners in crime in inflammation in rheumatoid arthritis and beyond? Nat. Rev. Immunol., v. 7, p. 191-201, 2007.

ROUX, P.P.; BLENIS, J. ERK and p38 MAPK-activated protein kinases: a family of protein kinases with diverse biological functions. Microbiol. Mol. Biol. Rev., v. 68, p. 320-344, 2004.

SAlluSTO, F.; CELlA, M.; DANIELI, C.; LANZAVECCHIA, A. Dendritic cells use macropinocytosis and the mannose receptor to concentrate macromolecules in the major histocompatibility complex class II compartment: downregulation by cytokines and bacterial products. J. Exp. Med., v. 182, p. 389-400, 1995. 
SAMANNA, V.; MA, T.; MAK, T. W.; ROGERS, M.; CHELLAIAH, M. A. Actin polymerization modulates CD44 surface expression, MMP-9 activation, and osteoclast function. J. Cell Physiol., v. 213, p. 710-720, 2007.

SANO, H.; HSU, D. K.; YU, L.; APGAR, J. R.; KUWABARA, I.; YAMANAKA, T.; HIRASHIMA, M.; LIU, F. T. Human galectin-3 is a novel chemoattractant for monocytes and macrophages. J. Immunol., v. 165, p. 2156-2164, 2000.

SARAIVA, T. C.; GRUND, L. Z.; KOMEGAE, E. N.; RAMOS, A. D.; CONCEIÇÃO, C.; ORII, N. M.; LOPES-FERREIRA, M.; LIMA, C. Nattectin a fish C-type lectin drives Th1 responses in vivo: license macrophages to differentiate into cells exhibiting typical DC function. Toxicon., 2011. Submitted.

SATO, H.; TAKINO, T.; OKADA, Y.; CAO, J.; SHINAGAWA, A.; YAMAMOTO, E.; SEIKI, M. A matrix metalloproteinase expressed on the surface of invasive tumour cells. Nature, v. 370, p. 61-65, 1994.

SCHMITZ, G.; ORSÓ, E. CD14 signaling in lipid rafts: new ligands and co-receptors. Curr. Opin. Lipidol., v. 13, p. 513-521, 2002.

SCHWARTZ, M. A.; GINSBERG, M. H. Networks and crosstalk: integrin signalling spreads. Nat. Cell Biol., v. 4, p. E65-E68, 2002.

SHIMIZU, Y.; SHAW, S. Lymphocyte interactions with extracellular matrix. FASEB J., v. 5, p. 2292-2299, 1991.

SIMON, S. I.; GREEN, C. E. Molecular mechanics and dynamics of leukocyte recruitment during inflammation. Annu. Rev. Biomed. Eng., v. 7, p. 151-185, 2005.

SNOEK-VAN BEURDEN, P. A.; VON DEN HOFF, J. W. Zymographic techniques for the analysis of matrix metalloproteinases and their inhibitors. Biotechniques, v. 38, p. 73-83, 2005. 
SOSA-ROSALES, J. I.; D’SUZE, G.; SALAZAR, V.; FOX, J.; SEVCIK, C. Purification of a myotoxin from the toadfish Thalassophryne maculosa (Günter) venom. Toxicon., v. 45, p. 147-153, 2005.

SPRINGER, T.; GALFRÉ, G.; SECHER, D. S.; MILSTEIN, C. Mac-1: a macrophage differentiation antigen identified by monoclonal antibody. Eur. J. Immunol., v. 9, p. 301306, 1979.

STERNBERG, E. M. Neural regulation of innate immunity: a coordinated nonspecific host response to pathogens. Nat. Rev. Immunol., v. 6, p. 318-328, 2006.

STERNLICHT, M.; COUSSENS, L. M.; VU, T. H.; WERB, Z. Biology and regulation of the matrix metalloproteinases. In: CLENDENINNN, N. J.; APPELT, K. Cancer drug discovery and development: Matrix metalloproteinase inhibitors in cancer therapy. New Jersey: Humana Press Totowa Inc., 2000. p. 1-37.

STOUT, R. D.; JIANG, C.; MATTA B.; TIETZEL, I.; WATKINS, S. K.; SUTTLES, J. Macrophages sequentially change their functional phenotype in response to changes in microenvironmental influences. J. Immunol., v. 175, p. 342-349, 2005.

STRICKLIN, G. P.; LI, L.; NANNEY, L. B. Localization of mRNAs representing interstitial collagenase, 72-kda gelatinase, and TIMP in healing porcine burn wounds. J. Invest. Dermatol., v. 103, p. 352-358, 1994.

ULEVITCH, R. J.; TOBIAS, P. S. Recognition of gram-negative bacteria and endotoxin by the innate immune system. Curr. Opin. Immunol., v. 1, p. 19-22, 1999.

UNDERHILL, D. M.; OZINSKY, A. Phagocytosis of microbes: complexity in action. Annu. Rev. Immunol., v. 20, p. 825-852, 2002.

UTARABHAND, P.; RITTIDACH, W.; PAIJIT, N. Bacterial agglutination by sialic acidspecific lectin in the hemolymph of the banana shrimp, Penaeus (Fenneropenaeus) merguiensis. Sci. Asia., v. 33, p. 41-46, 2007. 
VASTA, G. R.; AHMED, H.; DU, S.; HENRIKSON, D. Galectins in teleost fish: Zebrafish (Danio rerio) as a model species to address their biological roles in development and innate immunity. Glycoconj. J., v. 21, p. 503-521, 2004.

VICENTE-MANZANARES, M.; SÁNCHEZ-MADRID, F. Role of the cytoskeleton during leukocyte responses. Nat. Rev. Immunol., v. 4, p. 110-122, 2004.

VU, T. H.; WERB, Z. Gelatinase B: structure, regulation, and function. In: PARKS, W. C.; MECHAM, R. P. Biology of extracellular matrix-matrix metalloproteinases. San Diego: Academic Press, 1998. p. 115-148.

VU, T. H.; WERB, Z. Matrix metalloproteinases: effectors of development and normal physiology. Genes Dev., v. 14, p. 2123-2133, 2000.

ZIEGLER-HEITBROCK, H. W.; FINGERLE, G.; STROBEL, M.; SCHRAUT, W.; STELTER, F.; SCHÜTT, C.; PASSLICK, B.; PFORTE, A. The novel subset of CD14+/CD16+ blood monocytes exhibits features of tissue macrophages. Eur. J. Immunol., v. 23, p. 2053-2058, 1993.

YOUN, J. I.; NAGARAJ, S.; COLLAZO, M.; GABRILOVICH, D. I. Subsets of myeloidderived suppressor cells in tumor-bearing mice. J. Immunol., v. 181, p. 5791-5802, 2008.

WANG, H.; SONG, L.; LI, C.; ZHAO, J.; ZHANG, H.; NI, D.; XU, W. Cloning and characterization of a novel C-type lectin from Zhikong scallop Chlamys farreri. Mol. Immunol., v. 44, p. 722-731, 2007.

WILSON, R.; CHEN, C.; RATCLIFFE, N. A. Innate immunity in insects: the role of multiple, endogenous serum lectins in the recognition of foreign invaders in the cockroach, Blaberus discoidalis. J. Immunol., v. 162, p. 1590-1596, 1999.

WOESSNER JR, J. F. Matrix metalloproteinases and their inhibitors in connective tissue remodeling. FASEB J., v. 5, p. 2145-2154, 1991. 